DIEC DEFENSE TECHNICAL INFORMATION CENTER Inforintion for the Defouse Cownerity

DTIC ${ }^{\circledR}$ has determined on $03 / 12 / 2015$ that this Technical Document has the Distribution Statement checked below. The current distribution for this document can be found in the DTIC ${ }^{\otimes}$ Technical Report Database.

$\checkmark$ Distribution STATEMENT A. Approved for public release; distribution is unlimited. () COPYRIGHTED. U.S. Government or Federal Rights License. All other rights and uses except those permitted by copyright law are reserved by the copyright owner.

DISTRIBUTION STATEMENT B. Distribution authorized to U.S. Government agencies only (fill in reason) (date of determination). Other requests for this document shall be referred to (insert controlling DoD office).

DISTRIBUTION STATEMENT C. Distribution authorized to U.S. Government Agencies and their contractors (fill in reason) (date determination). Other requests for this document shall be referred to (insert controlling DoD office).

DISTRIBUTION STATEMENT D. Distribution authorized to the Department of Defense and U.S. DoD contractors only (fill in reason) (date of determination). Other requests shall be referred to (insert controlling DoD office).

DISTRIBUTION STATEMENT E. Distribution authorized to DoD Components only (fill in reason) (date of determination). Other requests shall be referred to (insert controlling DoD office).

DISTRIBUTION STATEMENT F. Further dissemination only as directed by (insert controlling DoD office) (date of determination) or higher DoD authority.

Distribution Statement $F$ is also used when a document does not contain a distribution statement and no distribution statement can be determined.

DISTRIBUTION STATEMENT X. Distribution authorized to U.S. Government Agencies and private individuals or enterprises eligible to obtain export-controlled technical data in accordance with DoDD 5230.25; (date of determination). DoD Controlling Office is (insert controlling DoD office). 


\title{
HIGH-PERFORMANCE NANOSTRUCTURED SUPERCAPACITOR ON AN ENGINEERED NONWOVEN
}

\section{Natick Soldier Research Development and Engineering Center Final Scientific Report Contract Number: W911QY-13-C-0008}

\author{
Sponsor Point of Contact: \\ David Ziegler, Research Chemical Engineer \\ david.p.ziegler.civ@mail.mil
}

Tel: 508-233-6484

\section{NCSU Research Staff:}

Dr. Behnam Pourdeyhimi, Director, The Nonwovens Institute Dr. Benoît Mazé, Research Assistant Professor, The Nonwovens Institute

Dr. Eric Fox, Post-Doctoral Scholar, The Nonwovens Institute Jennifer Leary, PhD Student, The Nonwovens Institute

NCSU Contract Award Notification Date: 2/25/13

Project Start Date: $3 / 1 / 13$

Project End Date: 6/30/14

Report Submission Date: 7/1/14 


\section{TABLE OF CONTENTS}

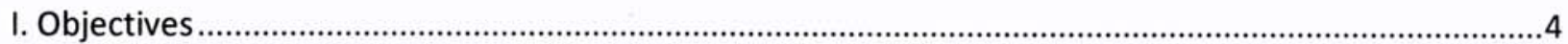

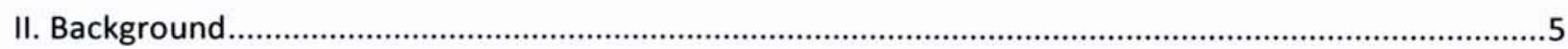

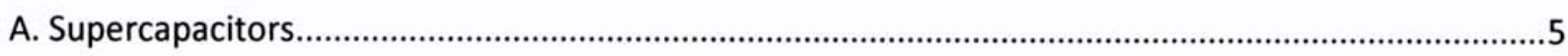

Supercapacitor Charge Storage Mechanism ...........................................................................................

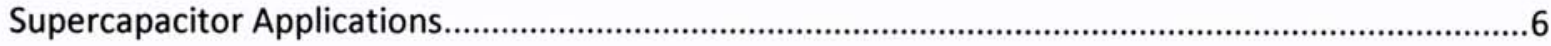

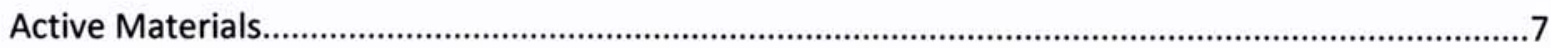

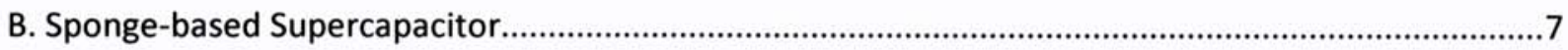

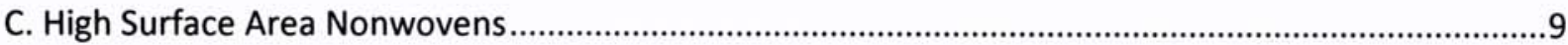

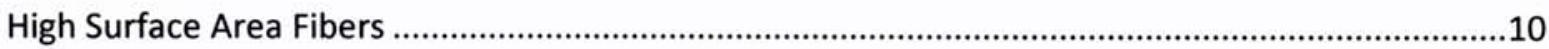

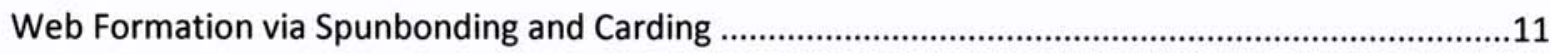

Web Consolidation via Hydroentangling and Needlepunching ......................................................13

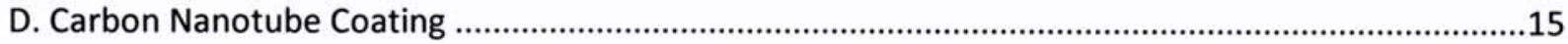

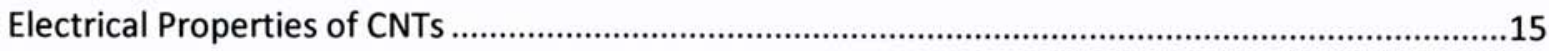

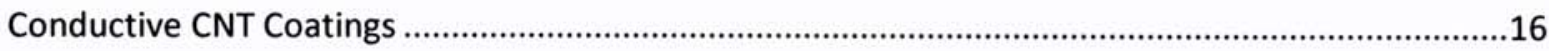

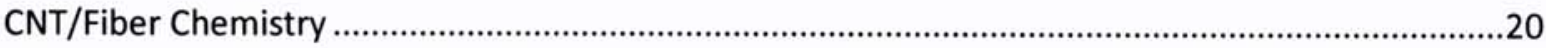

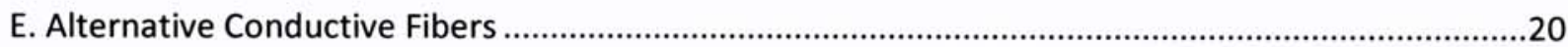

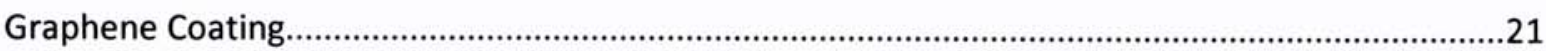

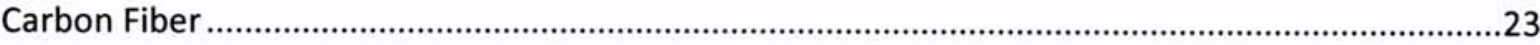

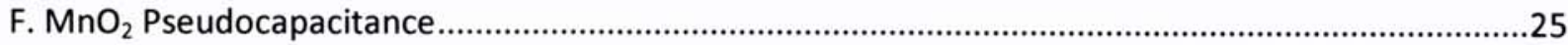

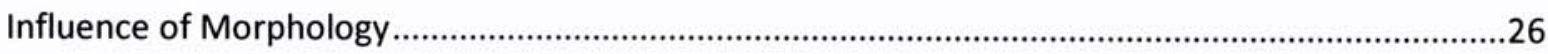

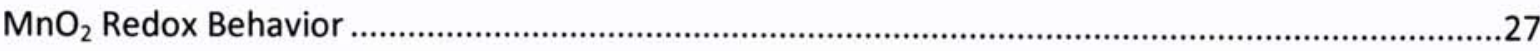

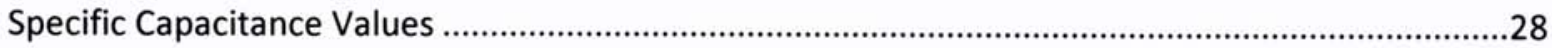

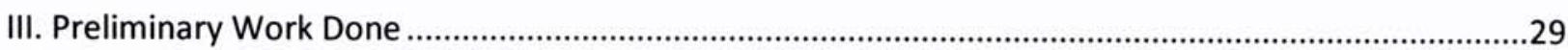

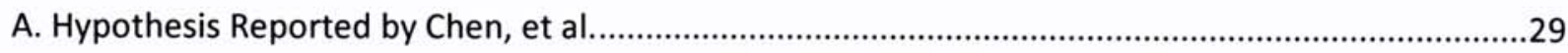

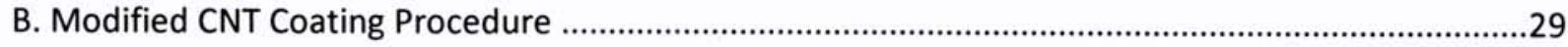

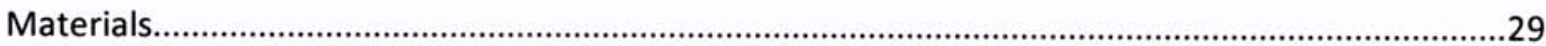

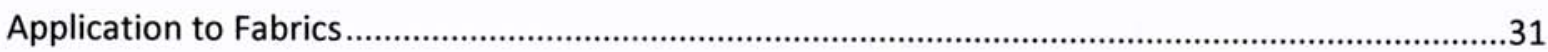

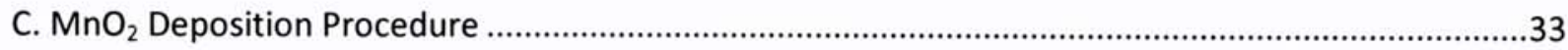




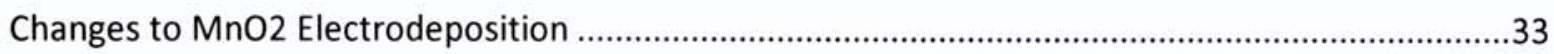

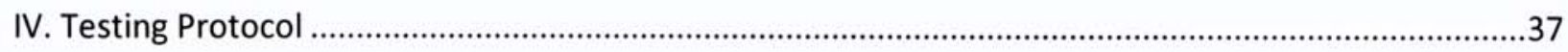

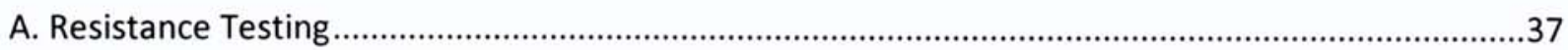

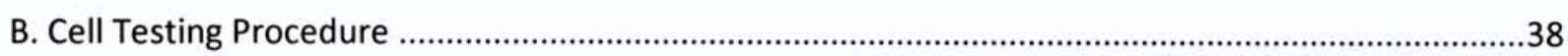

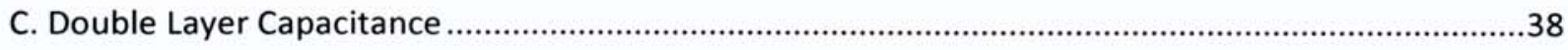

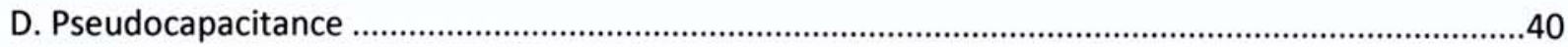

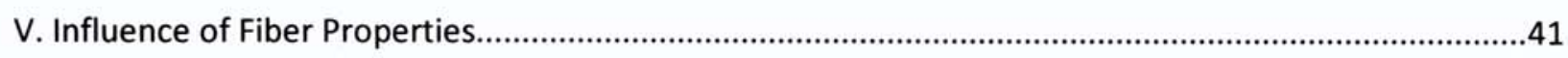

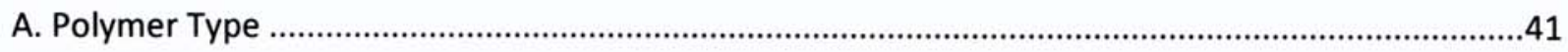

B. Fiber Shape

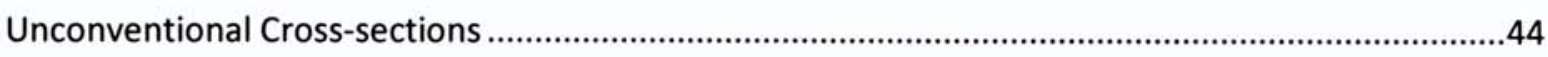

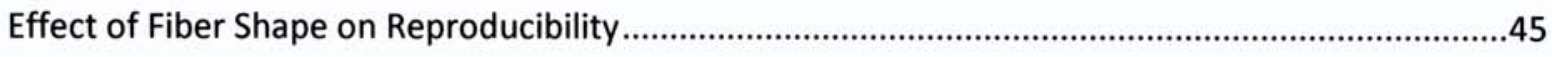

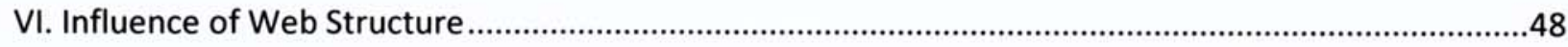

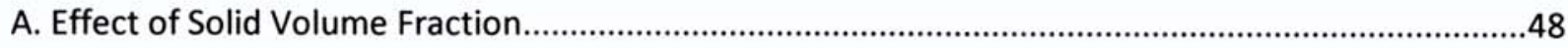

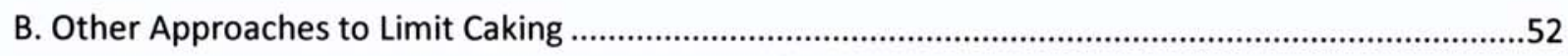

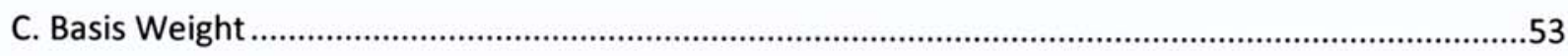

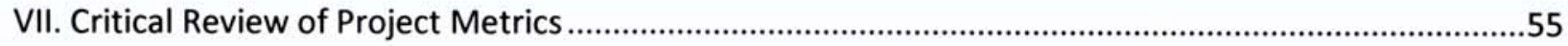

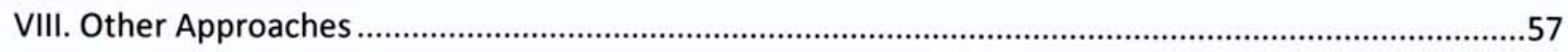

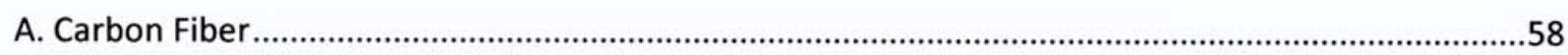

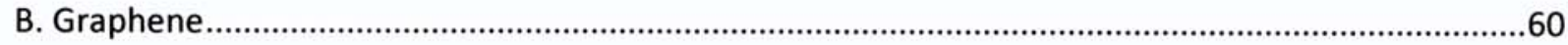

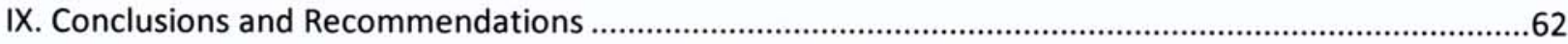

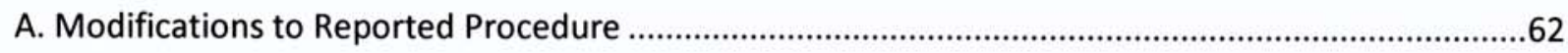

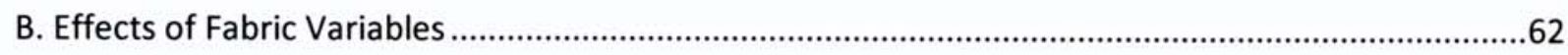

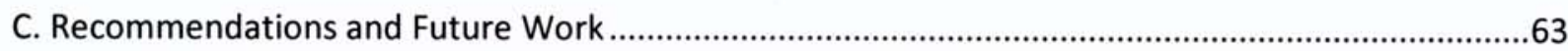

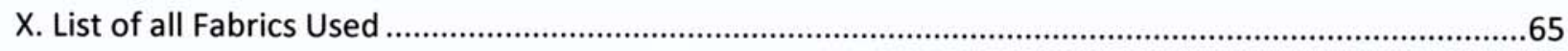

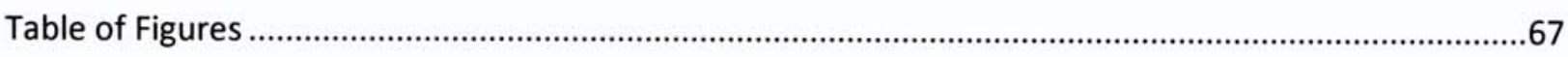

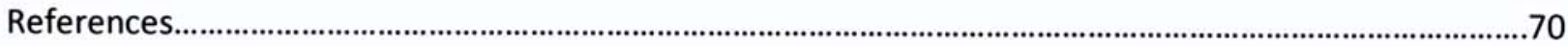




\section{OBJECTIVES}

In recent years, efforts to improve energy storage technologies have focused attention on electrochemical systems. The family of electrochemical energy storage devices is comprised of batteries, supercapacitors, and fuel cells - all three of which rely on charge separation at the electrode-electrolyte interface to store and subsequently release energy [1], [2]. Within this group, supercapacitors employ the simplest chemical reactions, in many cases relying only on physical charge separation (double-layer capacitance). Another attractive feature is their high power density.

Improving the energy density of supercapacitors has become an increasingly widespread topic of research over the past decade. In 2013, over 3,000 studies related to energy density in supercapacitors were published, compared to just under 300 ten years prior [3]. Energy density $\left(\mathrm{Wh} \mathrm{kg}^{-1}\right.$ ) relies on many parameters, a key one being accessible surface area at which electrochemical reactions or charge separation may occur [4]. The quest for optimization has thus sought out three-dimensional electrodes with high specific surface area (SSA) and controllable porosity [5], [6]. Among these, flexible sheet materials such as paper, fabric, and foam are being studied as electrode scaffolds for lightweight, low-cost, easily portable cells.

The goal of this research was to investigate the feasibility of engineered nonwovens for forming supercapacitor electrode scaffolds. A further objective was to develop and demonstrate a scalable method for coating a nonwoven with conductive carbon nanotubes (CNT) and an active redox species such as $\mathrm{MnO}_{2}$. CNT provide the low electrical resistivity required of an electrode conductive pathway, as well as increased surface roughness. Surface-adsorbed $\mathrm{MnO}_{2}$ contributes to energy storage when it undergoes reversible reduction from Mn(IV) to Mn(III). Based on recently reported studies of $\mathrm{CNT} / \mathrm{MnO}_{2}$ electrodes, a specific pseudocapacitance greater than $1,000 \mathrm{~F} \mathrm{~g}^{-1}$ (based on the mass of $\mathrm{MnO}_{2}$ ) was sought [7]. 


\section{BACKGROUND}

\section{A. SUPERCAPACITORS}

Alternative sources of energy, such as solar radiation and wind, require devices that can convert and harness the energy via electrolytic reactions. Device options can be mapped on a Ragone plot to show their relative specific power and energy capabilities (Figure 1). Supercapacitors have a wider power range than batteries and fuel cells, and a higher energy range than conventional capacitors. This class relies on two distinct mechanisms: Faradaic redox reactions and non-Faradaic charge separation, respectively termed pseudocapacitance and double-layer capacitance.

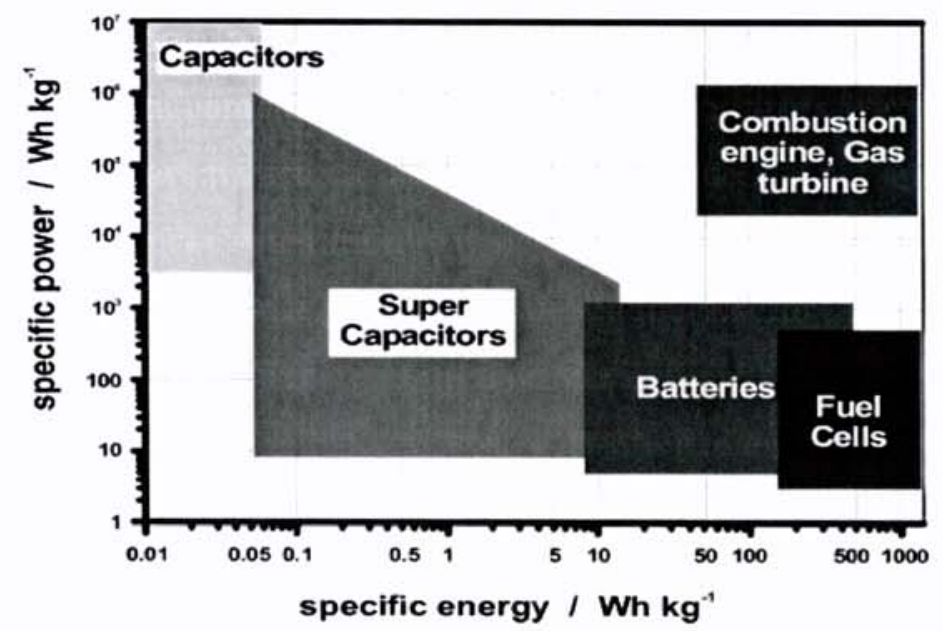

FIGURE 1: CAPACITORS, SUPERCAPACITORS, BATTERIES, FUEL CELLS AND FOSSIL FUEL ENERGY SOURCES SHOWN ON A RAGONE PLOT [1].

\section{SUPERCAPACITOR CHARGE STORAGE MECHANISM}

The charge storage mechanism known as double-layer capacitance has been understood since the mid-19th century. Helmholtz modeled interfacial charge separation between a liquid and a solid, basing his equations on the familiar dielectric parallel plate capacitor (Eqn. 2).

$$
C=\frac{\varepsilon_{0} \varepsilon_{r} A}{d}
$$

The Helmholtz model was later expanded upon by Gouy, Chapman and Stern to incorporate a diffuse layer of ions adjacent to the double-layer, which is dependent on the ion concentration in the electrolyte [8]. The double-layer capacitance arises automatically when a charged electrode is immersed in electrolyte - typical values are around $10-20 \mu \mathrm{F} \mathrm{cm}^{-2}$ for sheet metal electrodes [9]. 
For many years, it was simply considered an effect to take into account during an electrochemical experiment.

\section{SUPERCAPACITOR APPLICATIONS}

Becker, in the 1950's, was first to recognize the potential of applying electrolytic capacitance in energy management [9],[10]. In his 1957 patent, Becker recommended using "sticks of fired tar lampblack" as the electrode material since electrodes with rough or porous surfaces offer more surface area per unit mass for the charge to accumulate (Figure 2a) [10]. At the time, tar lampblack was the highest specific surface area (SSA) form of carbon known.
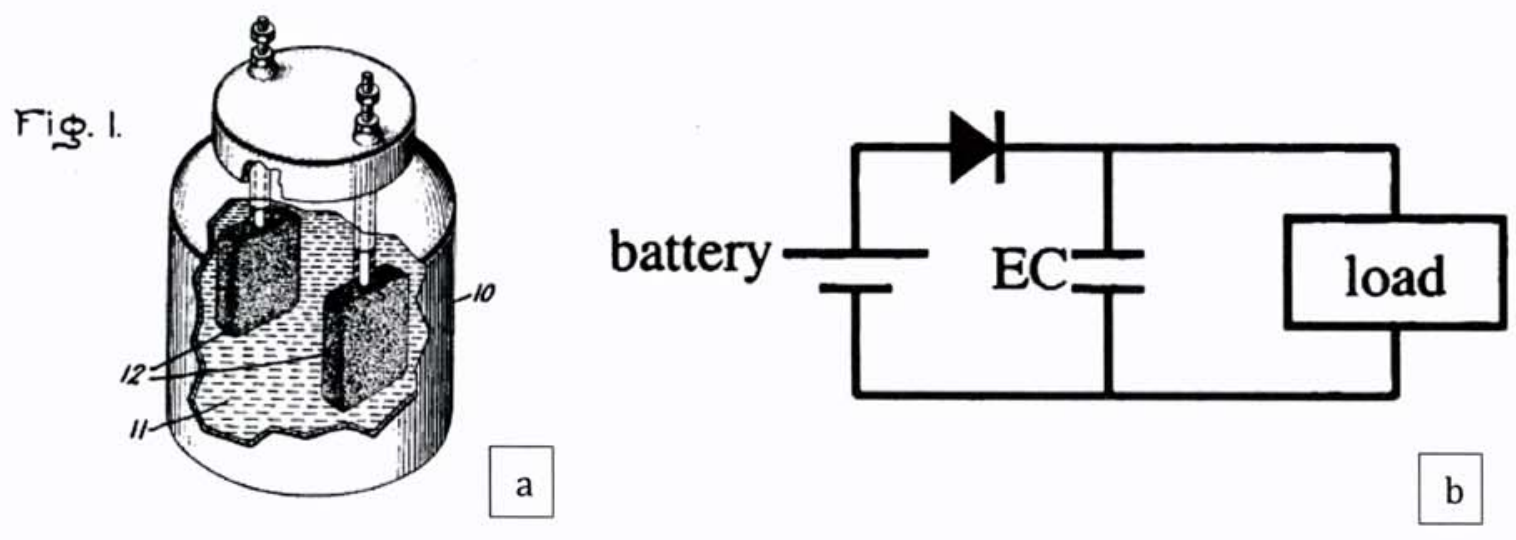

FIGURE 2: ILLUSTRATION OF ORIGINAL SUPERCAPACITOR USING LAMPBLACK, AND PLACEMENT OF AN ELECTROCHEMICAL CAPACITOR IN AS A BACKUP POWER SOURCE [10],[8].

By the end of the $20^{\text {th }}$ century, supercapacitors had found commercial applications in three areas [11]:

- Backup power sources in small consumer electronic devices, in case of short-term failure or voltage drop in primary power source (Figure $2 \mathrm{~b}$ ).

- Main power source for toys and other low power rating devices, where they deliver short pulses of power and can be quickly recharged.

- Power storage for small solar devices such as watches and lanterns.

A fourth major application area driving supercapacitor development has been hybrid engine vehicles. The US Department of Energy has issued calls for supercapacitor development programs, predicting that they would be as relevant as batteries to future energy storage systems [12]. Studies have mainly focused on maximizing energy density by loading high SSA electrode structures with active redox materials. The specific capacitance $\left(C_{s}\right)$ of an electrode can be translated into energy 
density using Eqn. 1, where $E_{s}$ is specific energy in $\mathrm{Wh} \mathrm{kg}^{-1}, C_{s}$ is specific capacitance in $\mathrm{F} \mathrm{g}^{-1}, V$ is potential in volts, $Q$ is charge in coulombs, and $m$ is the mass of active material.

$$
E_{S}=\frac{1}{2} C_{s} V^{2} * \frac{2.78 * 10^{-4} W h}{1 J} \quad\left(\text { Where } C_{s}=\frac{Q}{V * m}\right)
$$

\section{ACTIVE MATERIALS}

Given the importance of energy density, materials with high $C_{s}$ are widely researched. Pseudocapacitive materials tend to have inadequate electrical conductivity, and thus are applied onto conductive scaffolds [13]. A common approach is to apply a metal oxide (commonly $\mathrm{V}_{2} \mathrm{O}_{5}$, $\mathrm{RuO}_{2}$, or $\mathrm{MnO}_{2}$ ), or conductive polymer (commonly polyaniline or polypyrrole) onto an EDLC electrode [14]. The most commonly used electrode material for EDLC capacitors is activated carbon [11]. Carbon materials will be discussed later in this report.

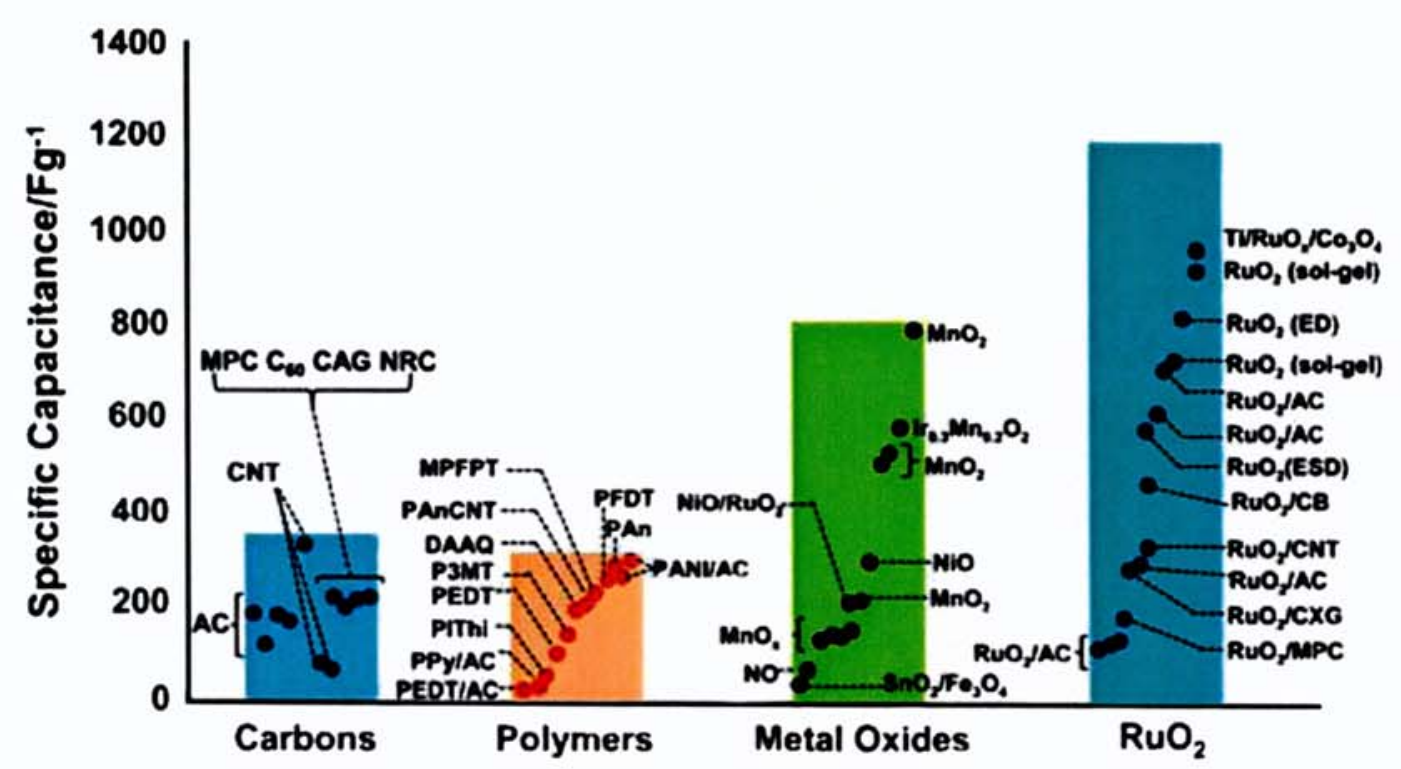

FIGURE 3: THE CAPACITANCE PERFORMANCE FOR BOTH CARBON-BASED EDLC ELECTRODES AND PSEUDOCAPACITOR ELECTRODES [65].

\section{B. SPONGE-BASED SUPERCAPACITOR}

Among the transition metal oxides employed as pseudocapacitive materials, $\mathrm{MnO}_{2}$ has emerged as a leading option. Its relatively low cost coupled with its insignificant environmental impact has made it a favorable alternative to high capacitance materials such as $\mathrm{RuO}_{2}$ [15]. Efforts have focused on optimizing its specific capacitance to meet the theoretical value of $1370 \mathrm{~F} \mathrm{~g}^{-1}$ [16], [17]. In 2011, Chen et al. reported a method for obtaining a specific capacitance of greater than $1200 \mathrm{~F} \mathrm{~g}^{-1}$ at a 
slow scan rate of $1 \mathrm{mV} \mathrm{s}^{-1}$ [7]. Although previous authors had reported higher specific capacitance values at faster scan rates, the electrodes in Chen's study were remarkably flexible and lightweight [17].

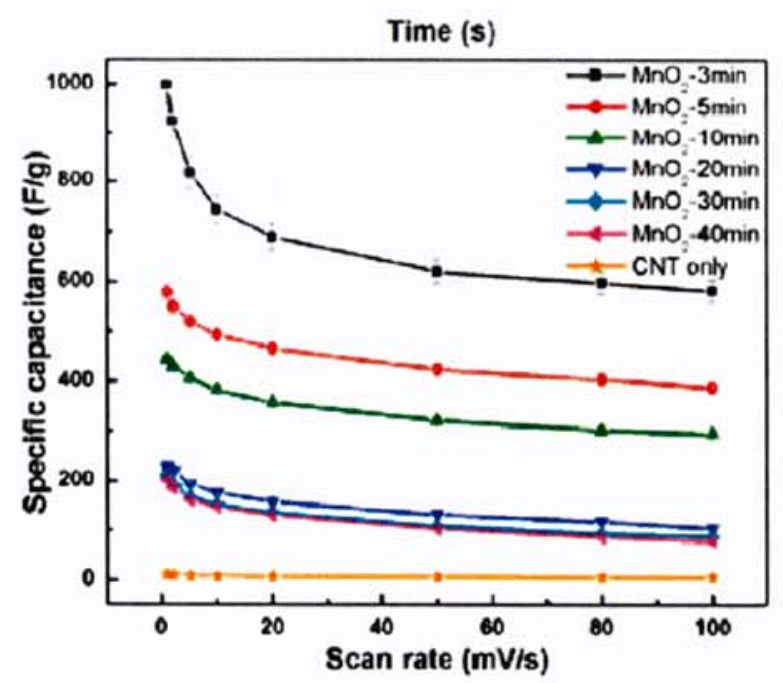

FIGURE 4: SPECIFIC CAPACITANCE NORMALIZED BY THE MASS OF MNO2 FOR VARIOUS DEPOSITION TIMES [7].

To optimize the specific capacitance of $\mathrm{MnO}_{2}$, a thin layer of the active material was distributed over a macroporous scaffold. The deposition was carried out via a galvanostatic method at a current density of $500 \mu \mathrm{A} \mathrm{cm}^{-2}$, with the deposition time being varied to study its effect. As shown in Figure 4, low deposition times led to the highest specific capacitance, which is in keeping with the literature. It has been suggested that the electrolyte cations intercalate mainly at the surface of $\mathrm{MnO}_{2}$ and do not utilize the bulk [16]. Thus, at higher deposition times, the oxide layer thickness increases and its specific capacitance decreases. However, total capacitance (i.e. normalized by total mass rather than $\mathrm{MnO}_{2}$ mass) will benefit from the added thickness. Figure 5 shows the deposited nanoflowers, $\sim 1 \mu \mathrm{m}$ in diameter.
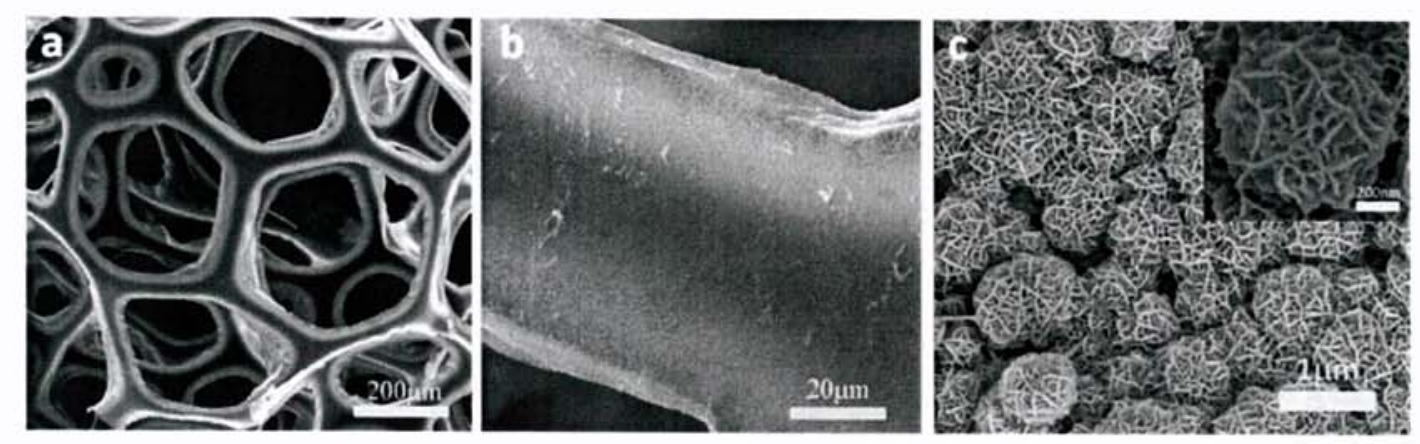

FIGURE 5: POROUS SPONGE ELECTRODE COATED WITH MNO2 NANOPARTICLES [7]. 
The porous conductive scaffold was constructed from a common "kitchen" sponge coated with single-walled carbon nanotubes. The coating method employed is to dip the sponge in a suspension of carbon nanotubes and sodium dodecylbenzensulfonate (SDBS) in water (ratio of $0.8 \mathrm{mg}$ CNT to $1.0 \mathrm{mg} \mathrm{SDBS}$ to $1.0 \mathrm{~mL} \mathrm{H}_{2} \mathrm{O}$ ), dry the sponge, rinse to remove the SDBS, and repeat the cycle several times. As can be seen below, the CNT coating does not significantly impact the flexibility of the sponge (Figure 6).

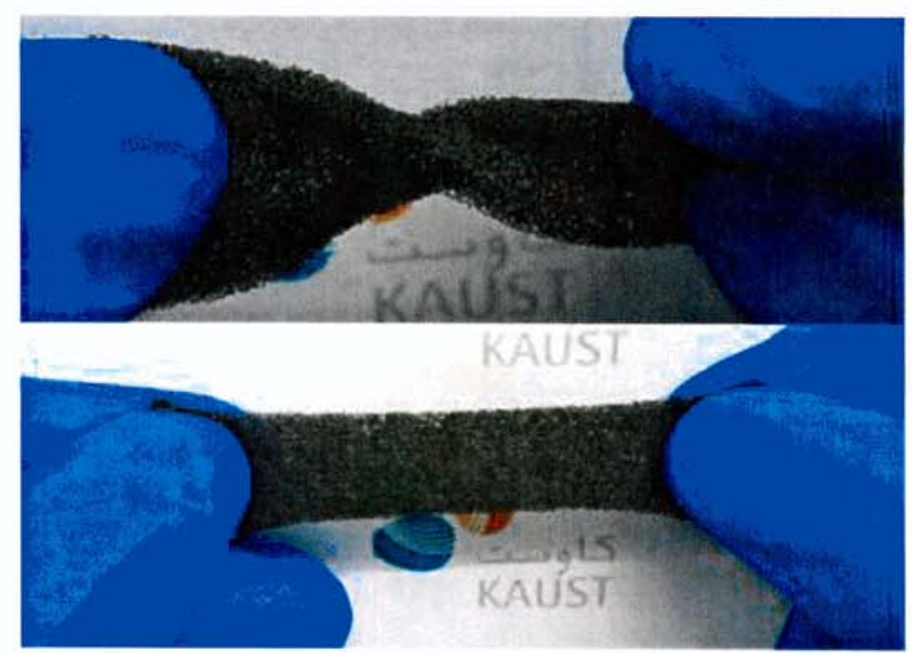

FIGURE 6: SPONGE FOLLOWING SEVERAL DIP-DRY CYCLES [7].

\section{HIGH SURFACE AREA NONWOVENS}

Relative to a sponge, nonwoven fabric offers important advantages as an electrode scaffold. To begin with, the gamut of design possibilities is much wider. There is a greater range of processes available for the manufacture of nonwovens. Whereas sponge is a reticulated foam formed only of flat-edged branches, the fibers that comprise a nonwoven can be formed of multicomponent geometries in a variety of sizes. Additionally, the tensile strength of fabric is significantly higher than sponge, making it better suited to withstand industrial coating processes.

In comparison to woven and knitted fabric structures, nonwovens can offer higher surface area to support the active material. Nonwovens are already widely applied in settings where surface area is key, such as absorbents and filtration media. However, the literature is lacking in any substantial investigation into the relationship between nonwoven processing variables and supercapacitor electrode performance [18]. Roll-to-roll web formation and consolidation methods that were used in the course of this research project are described below. 


\section{HIGH SURFACE AREA FIBERS}

In developing a high surface area nonwoven, fiber selection can contribute greatly. Specific surface area of fibers increases as their diameter (shown in denier and micron) gets smaller (Figure 7). The importance of fiber shape can also be seen: for a given fiber diameter, round fibers have the lowest SSA while complex shapes such as Winged Fiber have a much higher SSA. Maximizing SSA can thus be accomplished with low-diameter fibers and/or complex cross-sectional shapes. In both cases, multicomponent fiber spinning is a viable route. This method can produce round microfibers via the Island-in-the-Sea (I/S) structure, or complex shapes like Winged Fiber and Segmented Pie.
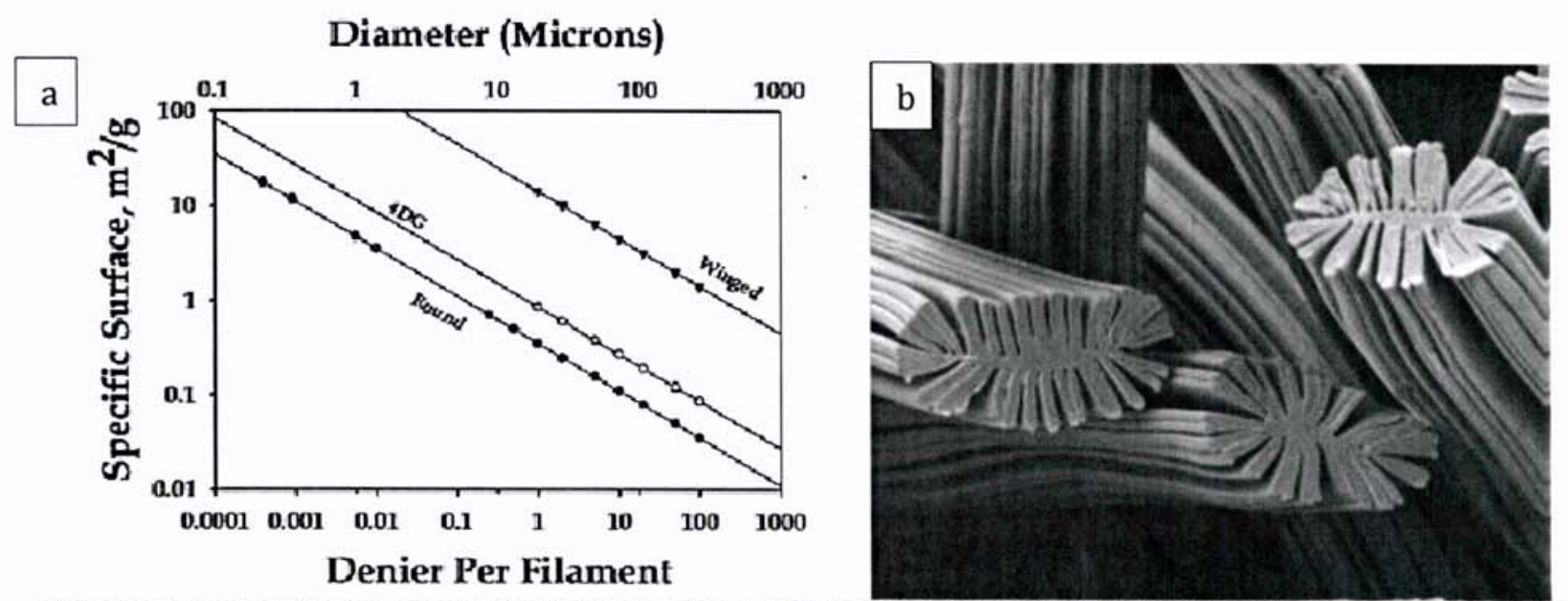

FIGURE 7: (A) SURFACE AREA FOR ROUND, 4DG, AND WINGED FIBERS AS A FUNCTION OF DIAMETER, AND (B) TYPICAL WINGED FIBER SHOWN IN SEM.

Multicomponent fibers are fibers made from more than one type of polymer, which are extruded in various conformations such as side-by-side, core/sheath, or I/S (Figure 8). Following extrusion, they may be kept in filament form or chopped into staple fiber lengths. Later, the sections composed of different polymers may be split or washed so that one polymer dissolves. The remaining polymer may be as small as 0.3 micron in diameter, using the example of an I/S fiber with 360 islands. The fiber as extruded is $\sim 20 \mu \mathrm{m}$ in diameter before the sacrificial PLA sheath is dissolved. 


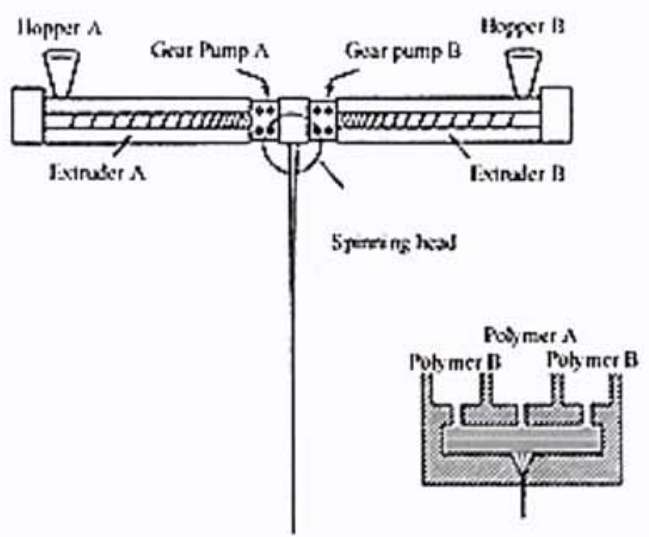

FIGURE 8: TWO EXTRUDERS ALIGNED TO SPIN A BICOMPONENT FIBER COMPOSED OF TWO POLYMERS.
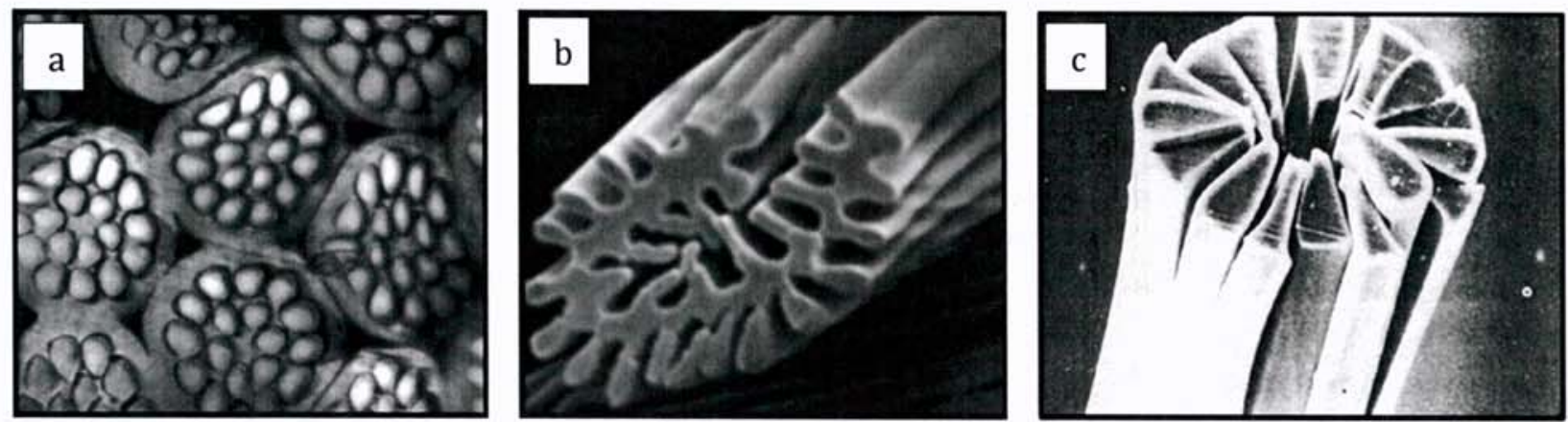

FIGURE 9: CROSS-SECTIONAL SEM OF VARIOUS MICROFIBERS: (A) ISALNDS-IN-THE-SEA AS-EXTRUDED, (B) WASHED WINGED FIBER, (C) SPLIT SEGMENTED PIE.

\section{WEB FORMATION VIA SPUNBONDING AND CARDING}

At NC State University's Nonwovens Institute (NWI), continuous bicomponent fibers can be extruded on a spunbond line and form the web structure in one step. Figure 10 shows a schematic of spunbond curtain spinning, in which the bicomponent fibers are extruded through the spin pack, quenched with cool air, drawn with the attenuating forced air, collected on the belt, and rolled up onto the winder. The web then undergoes a separate consolidation step to improve its strength. 


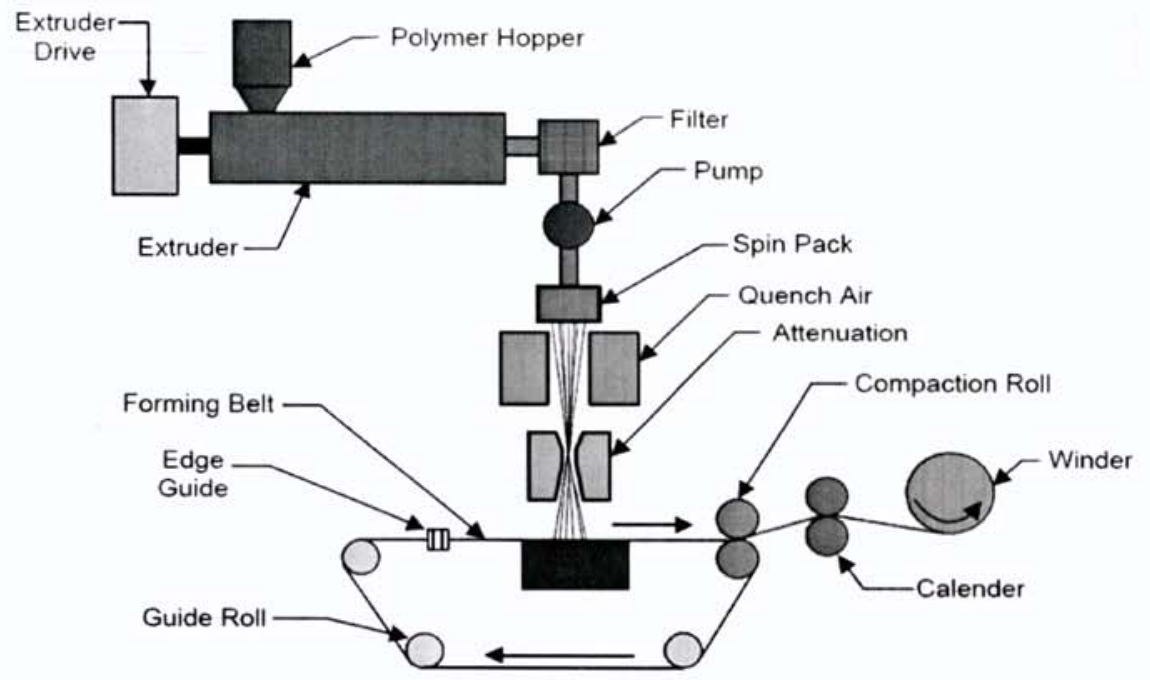

FIGURE 10: SCHEMATIC OF AN OPEN SPUNBOND PROCESS WITH A BELT COLLECTOR.

Alternatively, bicomponent or tricomponent staple fibers can be formed on the unit at NWI's pilot facilities. Here, the filaments are crimped, and cut into staple lengths of $\sim 50 \mathrm{~mm}$. These fibers are carried through a carding machine which prepares a loose sheet for later consolidation. Figure 11 shows the roller system of a typical carding machine, similar to the one in place at the NWI. The rollers are adorned with comb-like wires that break up fiber tufts, individualize and align them and optionally randomize the web. In order to tune the basis weight of the web and improve uniformity, carding can be followed by cross-lapping (Figure 12).

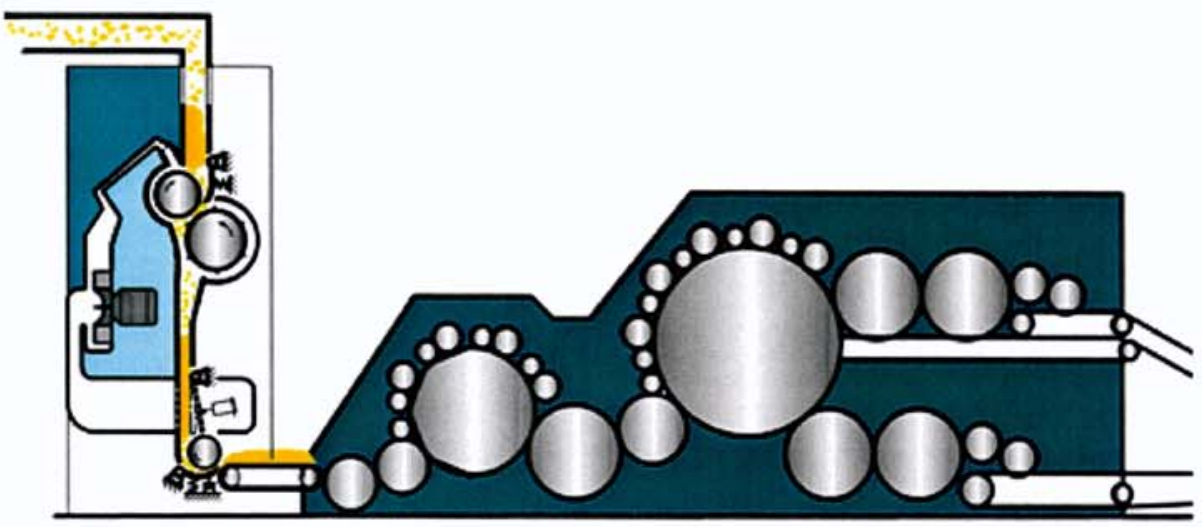

FIGURE 11: CARDING MACHINE FOR NONWOVEN WEB WITH ONE CHUTE FEED (SOURCE: TRUETZSCHLER NONWOVENS).

NWI uses however, a new card from Truetzschler (EWK) that has a series of smaller cylinders, workers and strippers and results in continuous opening, blending and carding during the process potentially leading to improved carding and better uniformity. 


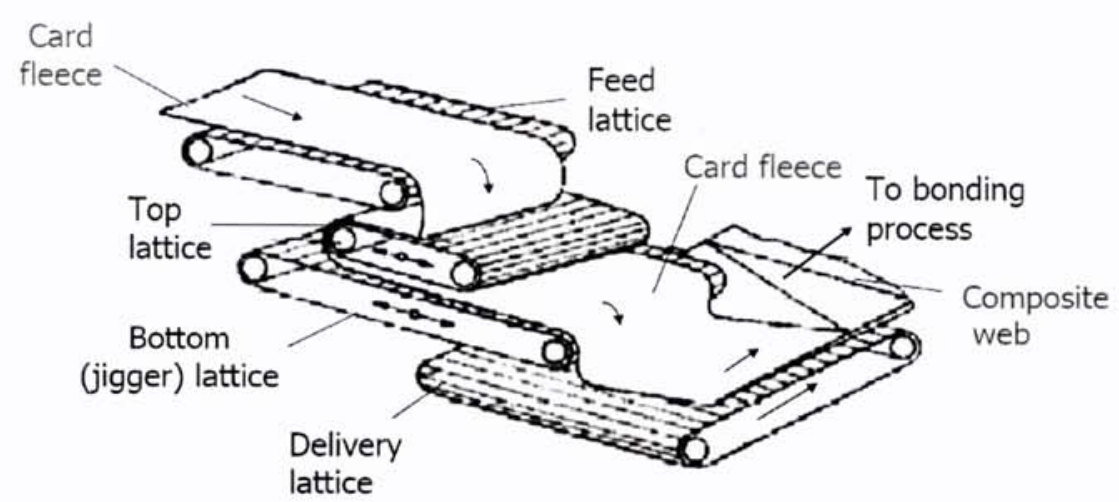

FIGURE 12: THE CROSS-LAPPING UNIT FOLDS A SINGLE WEB TO INCREASE THICKNESS.

\section{WEB CONSOLIDATION VIA HYDROENTANGLING AND NEEDLEPUNCHING}

For both carded and spunbond webs, we can use hydroentangling to mechanically secure the structures. Most nonwovens are thermally bonded and are planar, 2D (pseudo 3D) structures. We use hydroentangling to form a 3D entangled structure composed of fibers and/or filaments. Hydroentangling involves a series of jets (in the form of a jet strip with nozzles arranged in one or more rows) that stay collimated and can transfer significant energy to the fabric to cause fiber-tofiber entangling (Figure 13). Previous NWI research has demonstrated that hydroentangled fabrics, composed of novel bicomponent/tricomponent fibers, allow the formation of strong, lightweight, and high surface area structures. Additionally, the jets can be used to fibrillate and break up bicomponent or tricomponent fibers resulting in fabrics with significant surface area.

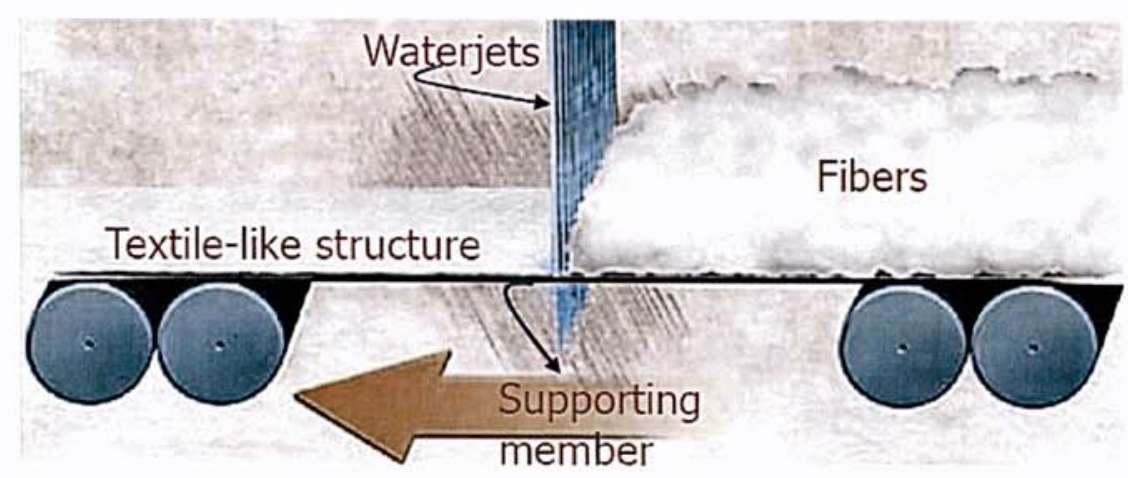

FIGURE 13: ILLUSTRATION OF A CARDED WEB BEING CONSOLIDATED BY WATER JETS ON A HYDROENTANGLING UNIT.

The hydroentangling unit at the NWI is shown in Figure 14. The unit has a total of five manifolds or injectors. Each manifold is fitted with a jet strip. Three manifolds entangle the fabric on the surface on a belt surface while the last two manifolds entangle the fabric on the backside on a porous drum 
surface. The first manifold is used to pre-wet and pre-entangle the web so as not to disturb its structure when it is exposed to higher energies in subsequent jets. The pressure is normally limited to $\sim 50$ bar on the first manifold. The other four however, are limited to 250 bar each. The jet strips are stainless $1 \mathrm{~mm}$ thick strips with The jet strips are stainless $1 \mathrm{~mm}$ thick strips with a series of nozzles spaced normally $\sim 500$ microns apart. The nozzle diameters are normally in the range of 80 to 120 microns. The NWI has a library of nozzle strips that can be used for this program, and has also developed special jet strips with various nozzle geometries that allow a great degree of control over the way in which the structure is consolidated.

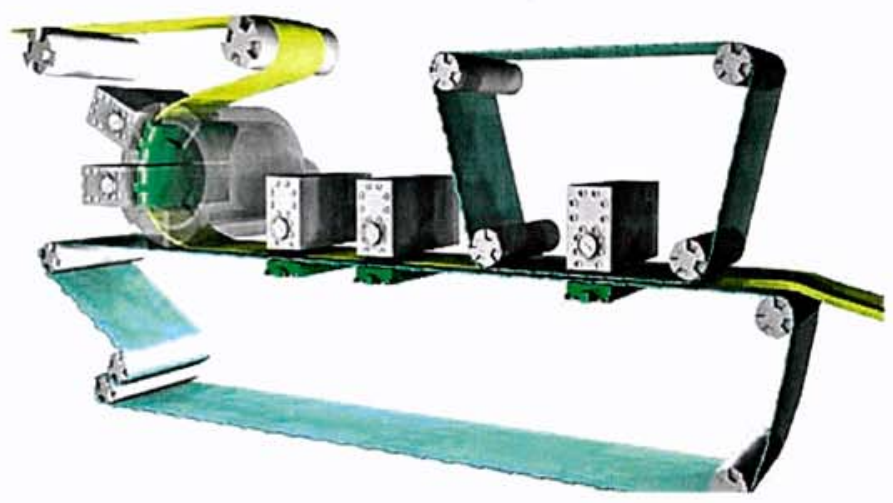

FIGURE 14: SCHEMATIC OF THE HYDROENTANGLING UNIT AT THE NONWOVENS INSTITUTE.

Along with hydroentangling, needlepunching is another mechanical method of web consolidation. Needle looms were first developed in the late $19^{\text {th }}$ century as a means of felting wool fibers on an industrial scale. Wool remained the primary fiber for nonwovens structures until synthetic fibers came into development in the $20^{\text {th }}$ century. At that time, without needlepunching, there would have been no means of entangling these fibers which lack wool's self-locking mechanism.
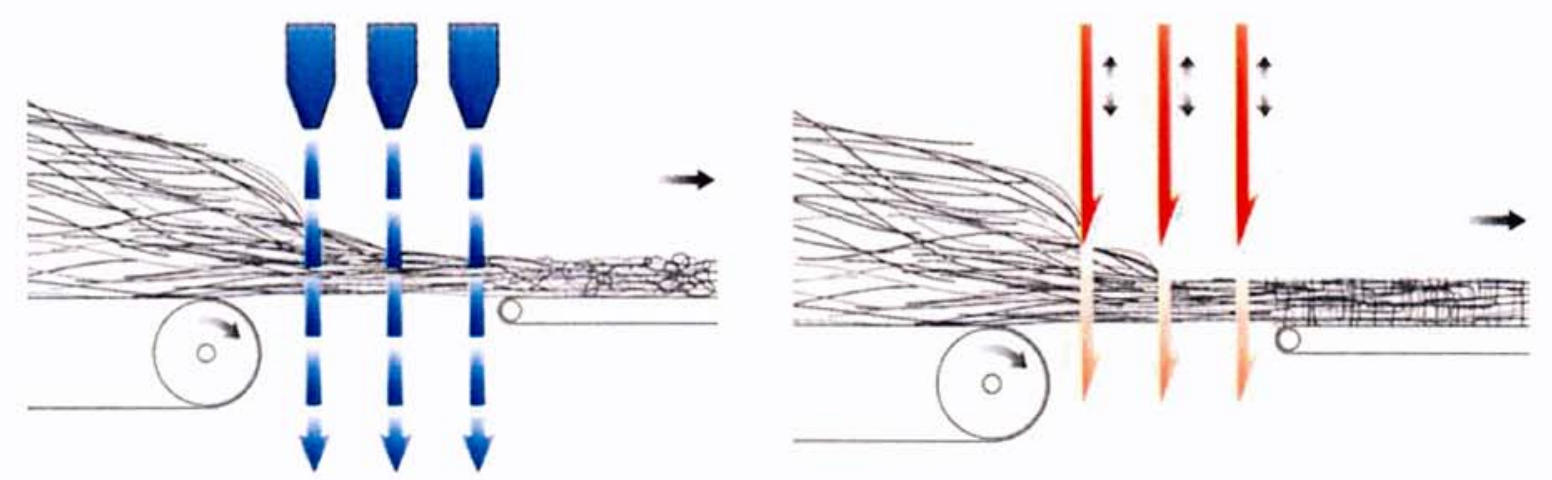

FIGURE 15: TWO METHOD OF MECHANICAL WEB CONSOLIDATION: (A) HYDROENTANGLING USES HIGHPRESSURE WATER JETS AND (B) NEEDLEPUNCHING USES BARBED NEEDLES. 
In a typical needlepunching line, the carded/crosslapped web is fed under a grid of barbed needles which move up and down to lock fibers together. Key process variables are needle type, needle density, punch depth, and punch frequency. Adjusting these settings controls the degree of consolidation applied to the web. Compared to hydroentangling, heavier basis weight webs can be bonded ( $>500 \mathrm{gsm}$ ). Downsides are that the process does not result in the simultaneous splitting of bicomponent fibers, and spunbond webs are challenging to process.
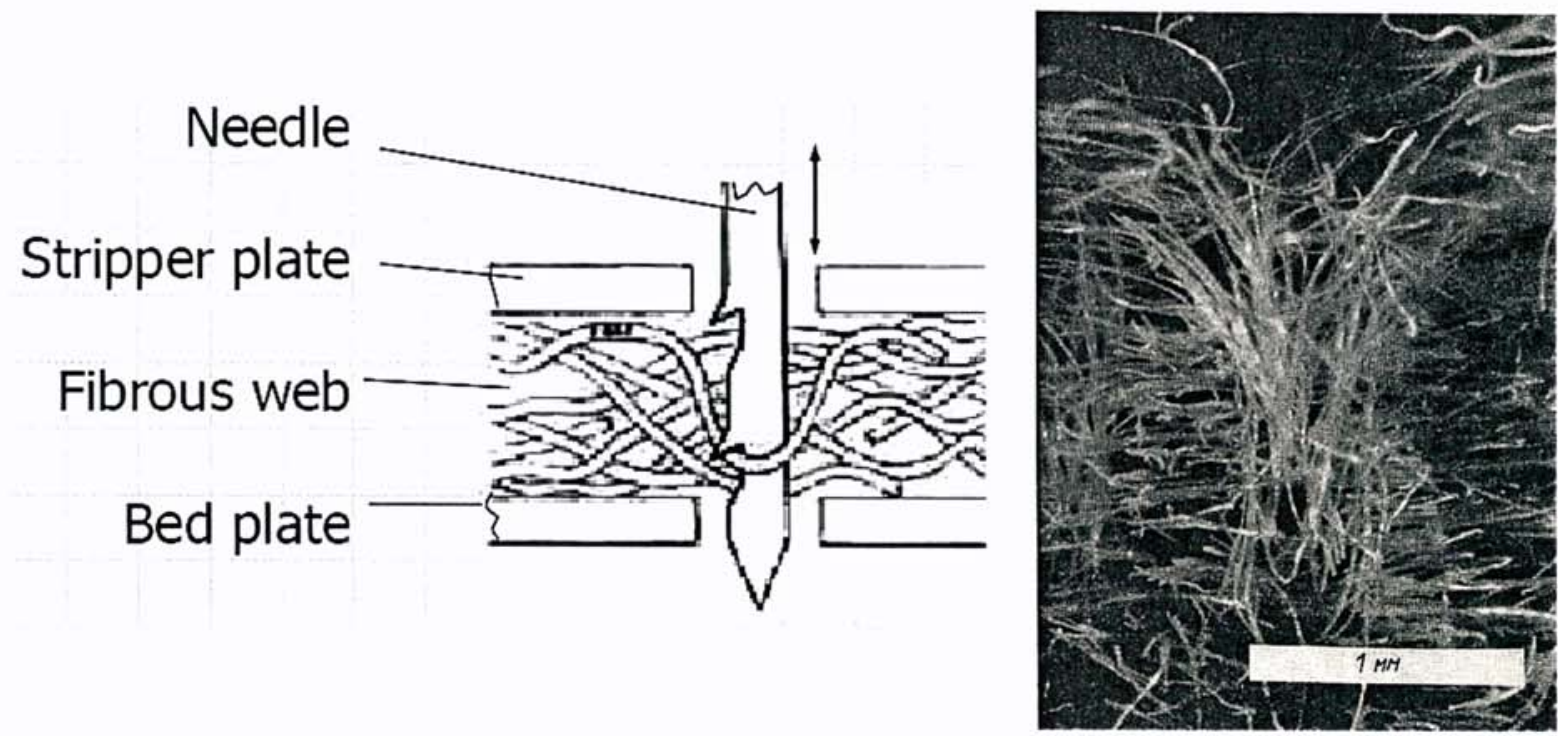

FIGURE 16: CROSS-SECTION OF A NEEDLEPUNCHED WEB SHOWING THE FIBERS PULLED INTO THE ZDIRECTION AND INTERLOCKING (KRCMA, 1971).

\section{CARBON NANOTUBE COATING}

The potential application of carbon nanotubes (CNT) in double-layer capacitors was first suggested in 2002 by Baughman et al. [19]. The authors cite relevant physical properties - high SSA and porosity - coupled with potentially excellent $\left(4 \times 10^{9} \mathrm{~A} \mathrm{~cm}^{-2}\right)$ electrical conductivity.

\section{ELECTRICAL PROPERTIES OF CNTS}

The nanoscale structures are composed of rolled graphene sheets, and may be either single-walled (SWCNT) or multi-walled (MWCNT). The electrical properties are determined by the pattern of aromatic rings around the circumference (Figure 17). Three possible conformations - armchair, zigzag and chiral - are known [19]. While zigzag and chiral CNTs are semiconductors, armchair CNTs are metallic. According to Baughman et al., "electron transport in metallic MWNTs and SWNTs 
occurs ballistically, over long nanotube lengths, enabling them to carry high currents with almost no heating."[19]

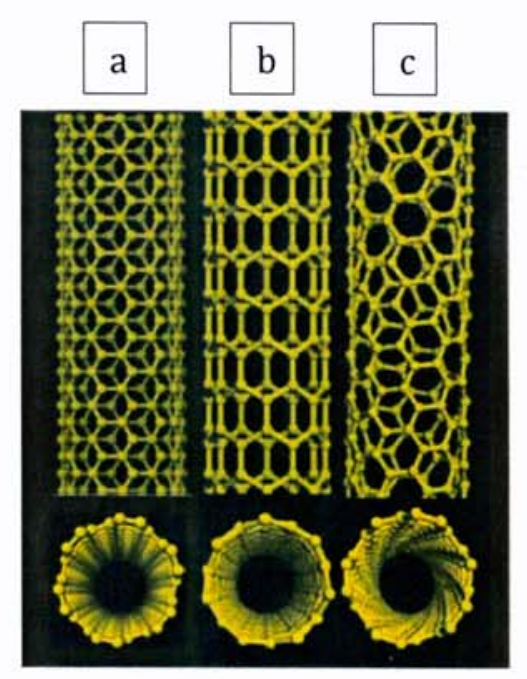

FIGURE 17: MODEL OF THREE MAIN CNT FORMS: ARMCHAIR (A), ZIGZAG (B) AND CHIRAL (C)[19].

Buckysheets, or freestanding networks of pure CNT, were the first form of CNT double layer electrode material [20]. Capacitance values of between 15 and $200 \mathrm{~F} \mathrm{~g}^{-1}$ have been theorized, depending on how much of the nanotube array can be accessed by ions via electrolyte.

\section{CONDUCTIVE CNT COATINGS}

Recent attention has shifted to wrapping CNT networks onto high SSA scaffolds, such as foams and textiles, to promote electrolyte flow throughout a 3D architecture [21]. Hecht et al. first reported the binder-less coating of CNTs onto textiles [22]. Since then, other methods for applying conductive carbon coatings to fabrics have included spraying, brushing, dipping, Mayer rod, and screenprinting [6], [15], [20], [21], [25]. The characteristics of CNT coatings are influenced by the chemical and physical interactions between CNT and host substrate, but a consensus regarding the fundamental mechanism of fiber-CNT interaction has yet to emerge from the literature. 


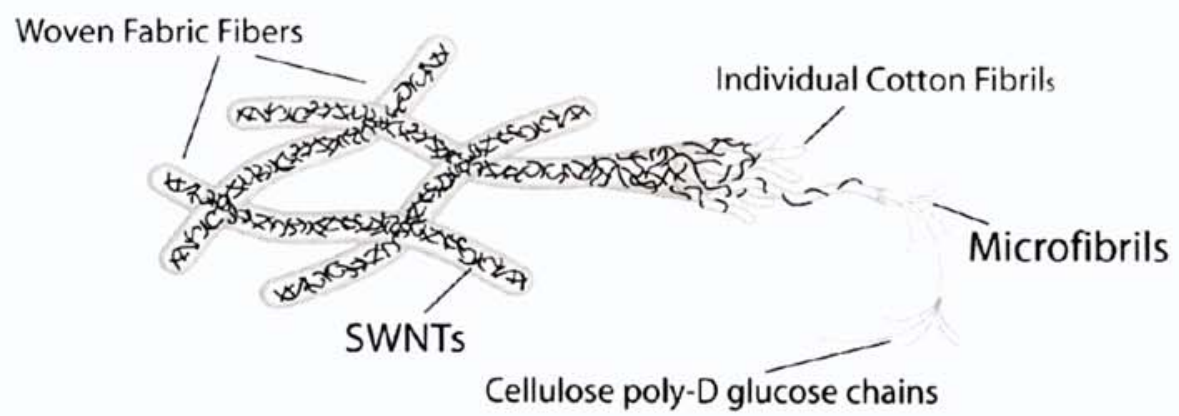

FIGURE 18: SCHEMATIC REPRESENTATION OF CNT "SKIN" WRAPPED AROUND COTTON YARNS [18].

$\mathrm{Hu}$ et al. were the first to publish an extensive study on the use of CNT coated textiles for supercapacitor electrodes (Figure 18) [18]. Two types of fabric were used, but details regarding these fabrics are largely left out of the report. One is described as 'cotton sheet' while the other as a 'woven polyester fabric'. However, in the accompanying SEM images, a knit fabric is shown as the polyester fabric. Additionally, supplier information for the cotton fabric is provided, yet the supplier describes this product as a polyester nonwoven [26]. Later publications from the same group contain similar ambiguities, which cloud the relationship between textile properties and the CNT coating [7], [27].

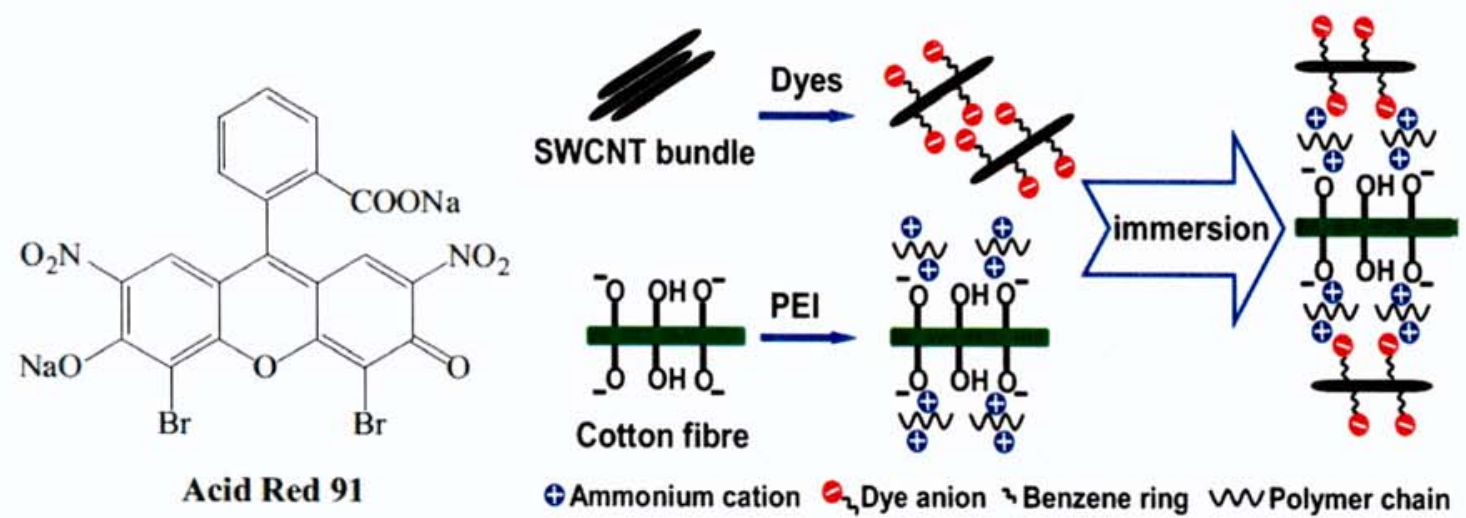

FIGURE 19: ANIONIC ACID RED DYE MOLECULE USED TO DISPERSE CNTS FOR USE IN ILLUSTRATED COATING PROCESS [28].

CNTs exhibit attractive electrical properties, but also have properties that make them difficult to use in coatings. Their hydrophobic nature leads to bundling, or agglomeration, which causes them to drop out of aqueous solution unless modified [22]. Zhang et al. functionalized SWCNTs using acid dye molecules which bonded easily to the CNTs through pi-pi stacking of the aromatic rings [28]. The CNTs dispersed well in solution, but the researchers anticipated that the negatively charged hydroxyl and carboxyl groups on cellulose cotton would not favor bonding with the negatively 
charged CNTs. Thus, modifications were also applied to the cotton yarn prior to immersion (Figure 19).

In the original publication by Hecht et al., all processes employed suspensions $\left(0.2-0.5 \mathrm{mg} \mathrm{mL}^{-1}\right)$ in water stabilized by sodium dodecylbenzenesulfonate surfactant. The suspensions were reported to be stable for months, and the method that produced the most conductive coatings was incubating. These two findings formed the approach to CNT-coating which is most commonly used today. In a 2010 publication by the same group, a washing step was introduced to remove the surfactant molecules from the final coating [18]. Washing resulted in increased electrical conductivity, removing insulating surfactant particles that were impeding the flow of electrons between CNTs. The incubation process was replaced with a "simple dipping" process which was repeated a number of times to increase the CNT coating mass.

Wang et al. followed the same "simple dipping" procedure (Figure 20), using a surfactant-dispersed aqueous CNT solution, but found that a more thorough washing step was required between cycles [29]. Three separate washes were needed to reduce resistance to an acceptable level. Furthermore, although resistivity continued to fall over the course of ten cycles, specific capacitance based on the mass of CNTs began to decrease after five cycles $\left(60 \mathrm{~F} \mathrm{~g}^{-1}\right)$.
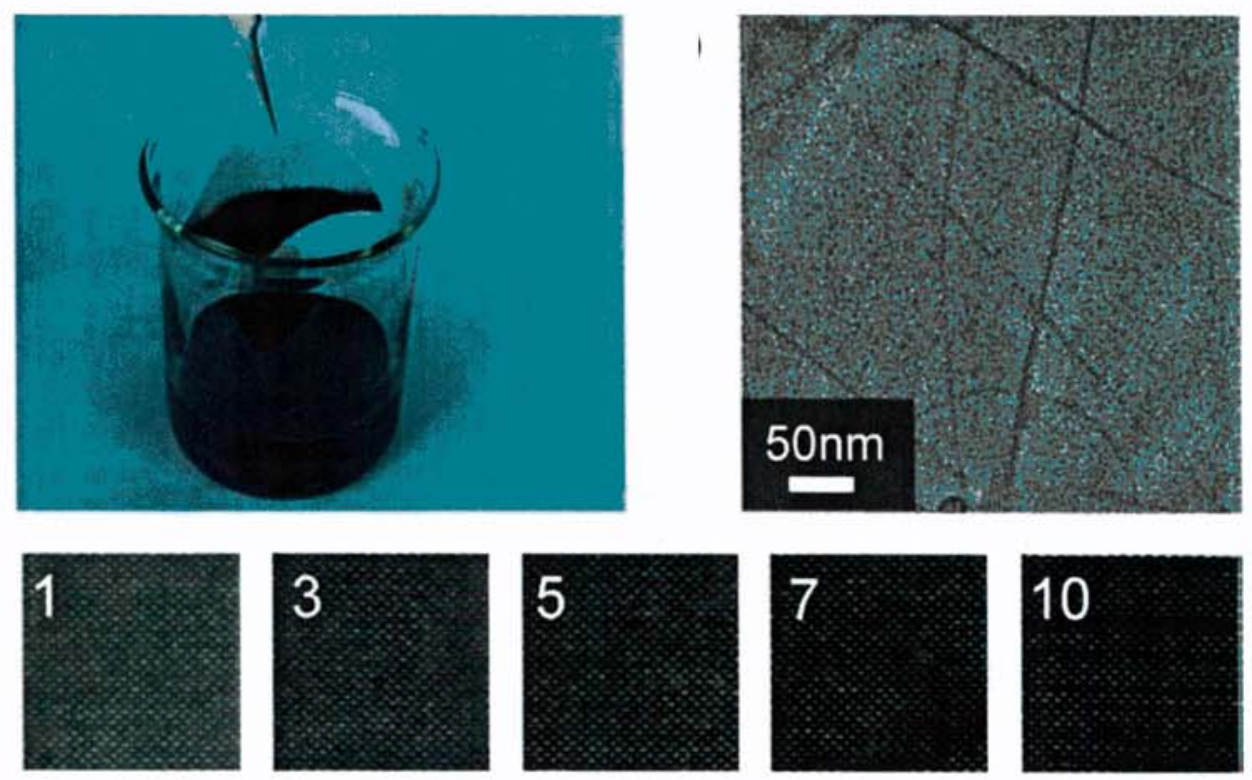

FIGURE 20: PHOTOGRAPHIC IMAGES OF DIPPING PROCEDURE AND CLOTH SURFACE TAKEN THROUGH MULTIPLE CYCLES [29]. 
The dipping method has been adopted by many research groups because of its simplicity. However, these studies overlook the complexity of the interaction between fiber (its glass transition temperature $\mathrm{T}_{\mathrm{g}}$, for instance) and CNT dispersion. Panhuis et al. introduced the analogy of "textile dyeing" for the first time, thus suggesting the possibility of drawing on a more mature science for insight [30]. Goncalves et al. also explored the possibility of treating CNTs exactly as dyestuffs [31]. They immersed cotton and polyester textiles in three types of CNT-water solutions and measured the "incorporation efficiency" by a standard whiteness test. A common exhaustion dying method was used, and various auxiliary additives, based on traditional dyeing of polyester and cotton, were introduced during the process.

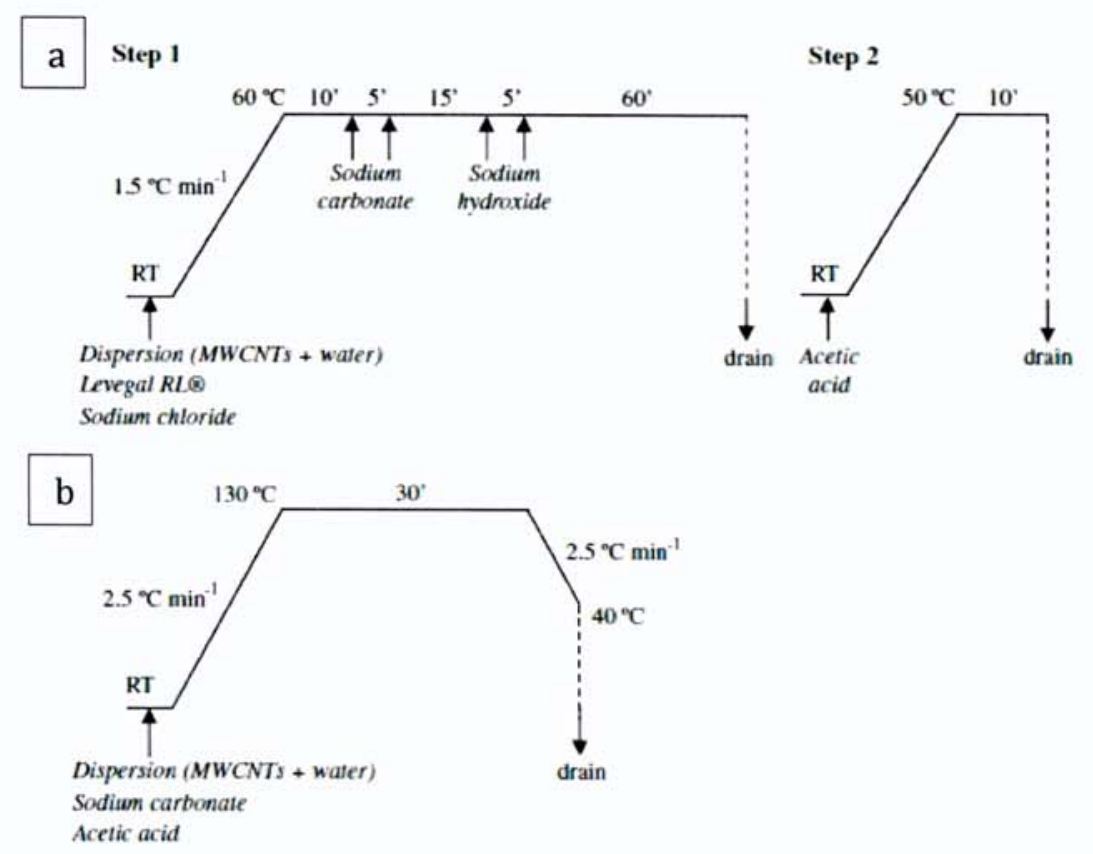

FIGURE 21: DIAGRAM SHOWING EXHAUSTION DYEING CONDITIONS USED FOR COTTON FABRIC (A) AND POLYESTER FABRIC (B) [31].

For CNT-coated polyester, the authors observed that the CNTs seemed to be "growing from the fiber surface", suggesting that they may be partially entrapped in the fiber surface. In this study, polyester had been taken above its $\mathrm{T}_{\mathrm{g}}$ during the immersion process (to $130^{\circ} \mathrm{C}$ ). It is postulated in this study that polyester partially absorbed the nanotubes into the free volume near the surface, whereas they are merely adsorbed or hydrogen bonded to the cotton surface. However, this is the first suggestion of absorption of nanotubes in the literature and requires deeper investigation. 


\section{CNT/FIBER CHEMISTRY}

Throughout the literature, CNT dispersions of various formulas have been reported to be applied to cotton, polyester, rayon, nylon, and wool of various fabric structures - all with reasonable success [28]-[30]. Low uptake has never been reported as a problem, and neither has adhesion, despite the variety of dispersants and substrate polymers. However, the studies from different groups use vastly different conditions and often mis-report details about the textiles [32]. The literature is lacking a thorough, coordinated study into the behavior of CNTs on various types of polymer fiber surfaces.

\section{E. ALTERNATIVE CONDUCTIVE FIBERS}

While CNT coating is a promising approach, other methods for obtaining conductive fibers are widely known. Furthermore, although the high cost of CNT is expected to fall with time, the potential health concerns associated with CNT use warrants an exploration of alternatives [33]. (Reference: Lam, 2006). Metal-polymer composite fibers, primarily coated or co-extruded with metallic particles, have been previously developed for applications ranging from static charge dissipation to electronically-enabled packaging materials [34]. However, electrochemical applications require electrode materials which will not undergo any corrosion within the electrolyte working range, thereby excluding some metal-coated fibers from consideration as supercapacitor electrodes [35].

Carbon, on the other hand, is inert within the $1.23 \mathrm{~V}$ working range of aqueous electrolytes - it also has a history of commercial supercapacitor electrode applications [36]. Therefore, possible alternatives to CNT should be based on conductive carbon materials. Typical carbon electrodes consist of carbon black, biowaste-derived amorphous carbon, or activated carbon granules pasted together with a binder [37]. Carbons may be thermally activated to have high SSA $\left(>2500 \mathrm{~m}^{2} \mathrm{~g}^{-1}\right)$ for EDLC electrodes or decorated with redox species for pseudocapacitor electrodes. In fiber form as well, carbon has been demonstrated to have potential as an electrochemical electrode material [35],[38]. Another area that has received much attention recently is graphene [39]. Graphene coatings and carbon fiber will be discussed below as two possible alternatives. 


\section{GRAPHENE COATING}

The four allotropes of carbon which hold crystalline order are diamond, carbyne, fullerene and graphite [37]. Graphite, composed of stacks of hexagonal carbon arrays, exhibits high electrical conductivity throughout its $\mathrm{sp}^{2}$ bonded network (Figure 22). Individual, atom-thick layers of this form of carbon are known as graphene, and were first isolated in the lab in 2004 by the "Scotch Tape" method [40]. In 2008, Stoller et al. described the electric-double layer capacitance behavior of chemically-modified graphene layers [41]. In KOH electrolyte, specific double-layer capacitance was found to be $128 \mathrm{~F} \mathrm{~g}^{-1}$ for galvanostatic discharge at $20 \mathrm{~mA}$. This abundant, naturally occurring material may be exfoliated into graphene layers by means of simple instruments such as a kitchen blender, resulting in graphite-derived materials generally being inexpensive [42].
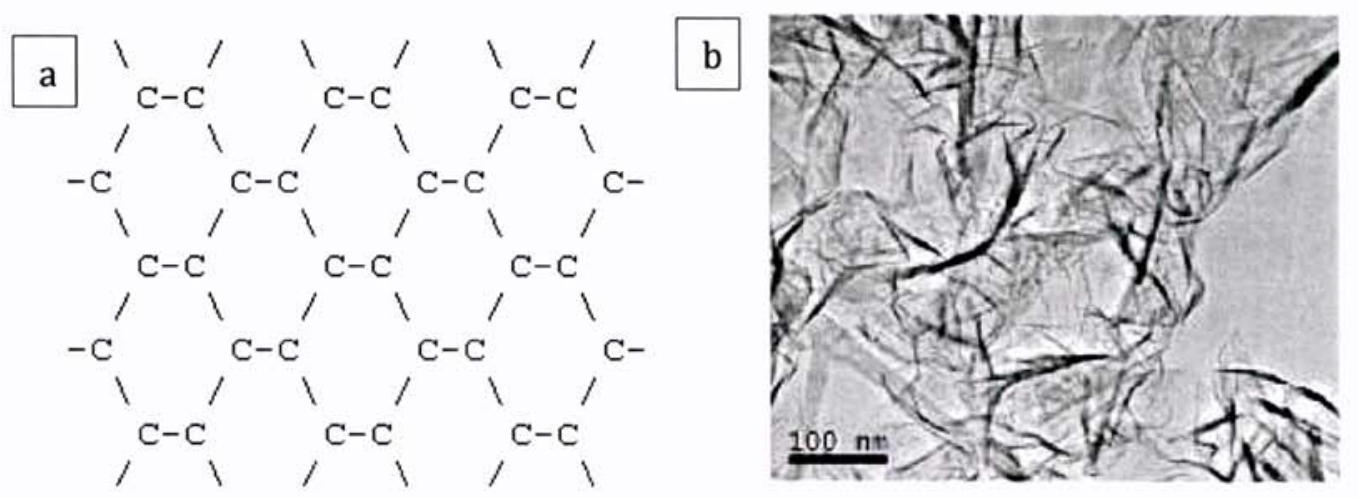

FIGURE 22: (A) IN GRAPHITE LAYERS, THE P-ELECTRON OF EACH ATOM IS DELOCALIZED OVER THE ENTIRE NETWORK [45]. (B) GRAPHENE SHEET CAPTURED WITH TEM [66].

Graphene-coated electrodes can also serve as viable substrates for the deposition of conductive polymers or transition metal oxides, resulting in pseudocapacitors. Several methods for coating graphene onto textiles have been published. Graphene "ink" was prepared by sonicating a combination of graphite, water, and surfactant [23]. This solution reduced resistivity to $700 \Omega / \square$ after $35 \mathrm{dip} /$ dry cycles; the textiles were later deposited with $\mathrm{MnO}_{2}$ nanoparticles (Figure 23). 


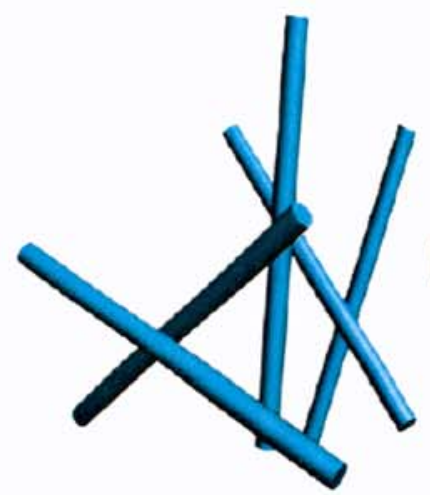

Microfibers in textile

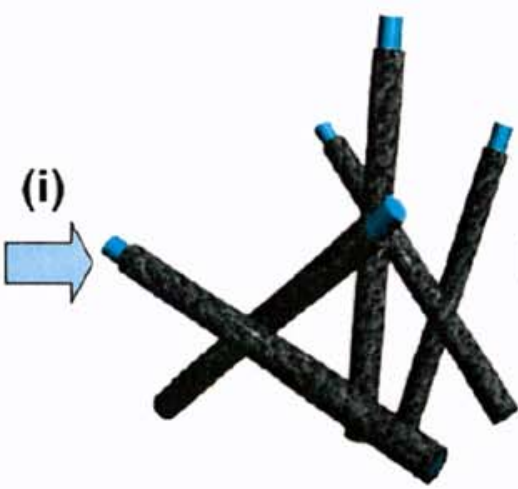

Graphene nanosheets - coated textile fibers (ii)

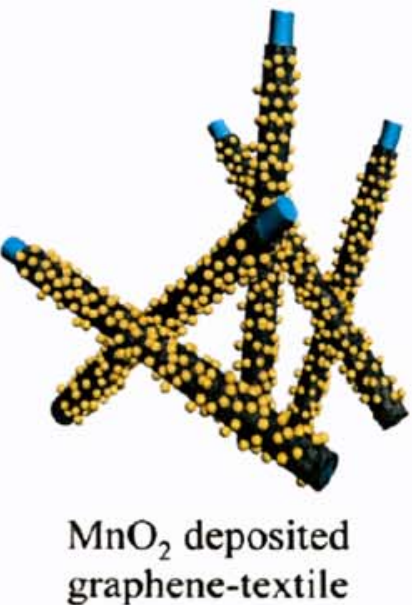

FIGURE 23: SCHEMATIC OF PROCESS STAGES FOR COATING POLYESTER TEXTILE WITH GRAPHENE AND MNO2 [23].

The use of surfactant in a graphene solution can be problematic, much like CNT/surfactant solutions, but graphene is hydrophobic and will not bond to textiles without a dispersing agent. Graphene oxide (GO), on the other hand, readily disperses in water without additives. As reported by Liu et al., GO may be suspended in water at $2 \mathrm{mg} \mathrm{mL}^{-1}$ and applied with a paintbrush to a woven cotton textile [6]. Although using GO bypasses many of the coating challenges associated with graphene, GO holds no value as an electrode material unless it is reduced. Following 50 paint/dry cycles, the GO-coated textile was heated under $\mathrm{Ar}$ to $300^{\circ} \mathrm{C}$ in order to convert the GO to graphene (Figure 24).
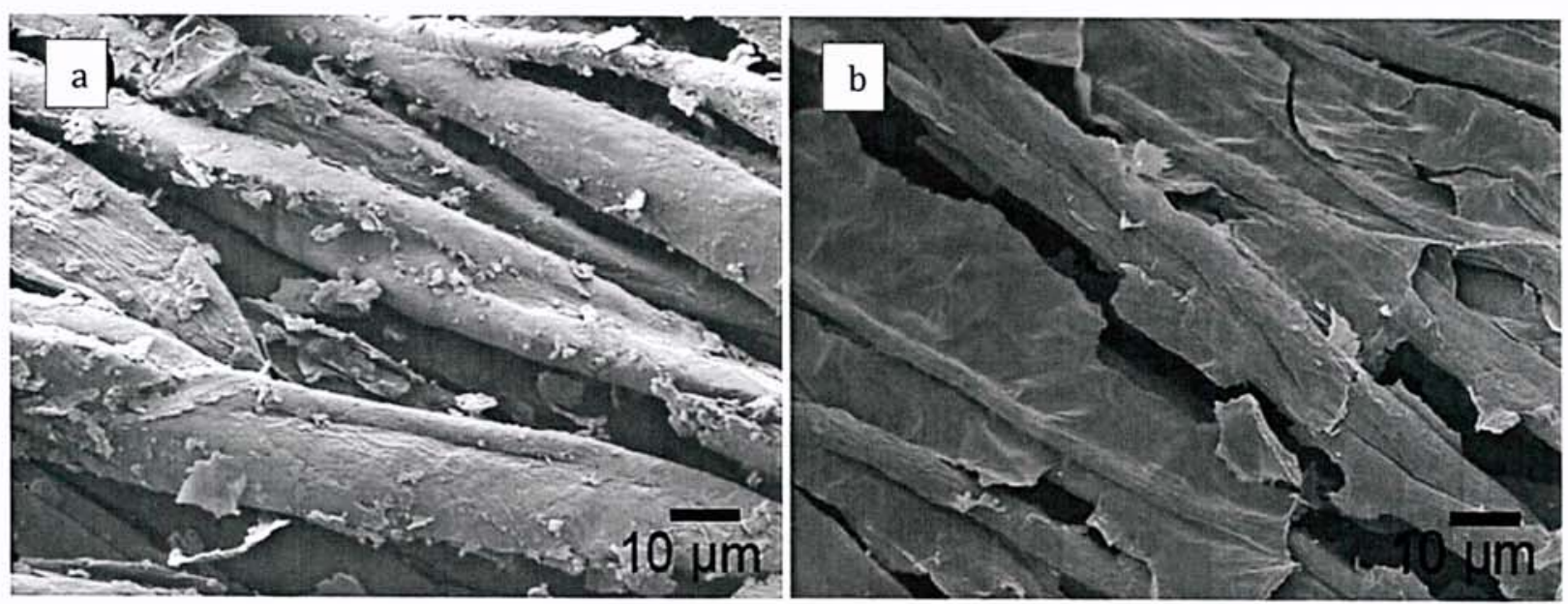

FIGURE 24: COTTON TEXTILE COATED WITH (A) GRAPHENE OXIDE AND (B) GRAPHENE, FOLLOWING REDUCTION [6]. 


\section{CARBON FIBER}

Using carbon fiber overcomes many of the issues associated with coating altogether; the conductive element exists as the bulk of the fiber itself rather than on the surface. Carbon fibers are obtained through the controlled pyrolysis of organic fibers, in which the non-carbon elements are, to a great degree, burned off. The earliest carbon fibers were made from regenerated cellulose. The precursors most commonly used in industry today are polyacrylonitrile (PAN) and isotropic or mesophase pitch [43]. However, researchers also carbonize a variety of common textiles such as denim and woven Kevlar [44], [45]. Precursors may be in fiber, yarn, or textile form.

The nature of the precursor fiber carries through to influence properties, such as yield and orientation, of the final carbon fiber. For instance, Lo examined the various elemental compositions of a group of carbon fibers including Novoloid-, PAN-, and rayon-derived samples [46]. The chemical compositions of the precursors were found to correspond to different carbon yields. On average, the Novoloid precursors resulted in the highest carbon concentration, followed by the PAN-derived and then the rayon-derived. Electrical conductivity was shown to be highest for the Novoloid-derived fibers.

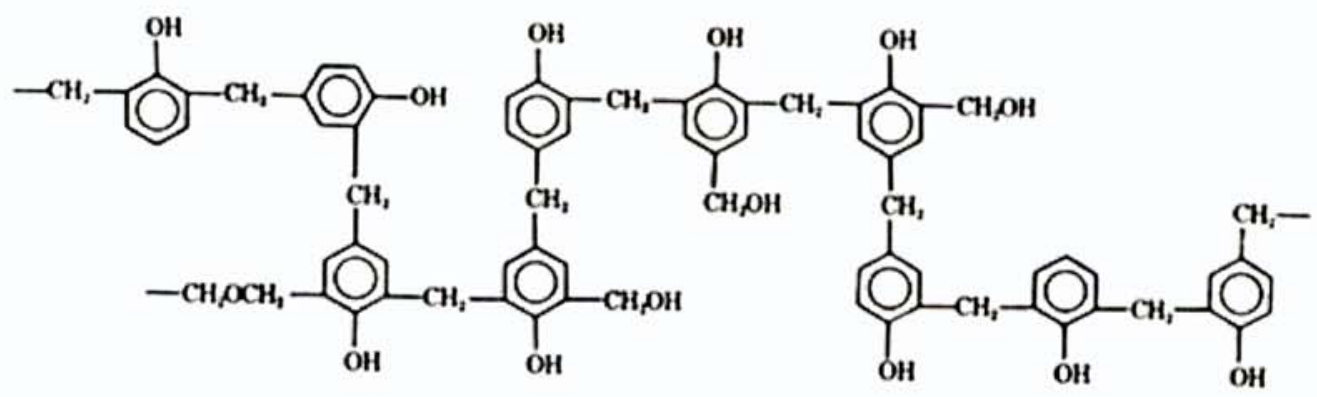

FIGURE 25: REPEAT UNIT OF NOVOLOID FIBER, WHICH HAS A CHEMICAL FORMULA OF C63H55011 [46].

In addition to precursor type, treatment conditions affect the outcome of the carbonization process. A typical conversion for PAN fiber, shown in Figure 26, involves two essential steps - stabilization under an oxidizing atmosphere, which prevents the fiber from melting $\left(200^{\circ} \mathrm{C}\right.$ to $\left.400^{\circ} \mathrm{C}\right)$, and carbonization which sees the exit of all non-carbon elements $\left(400^{\circ} \mathrm{C}\right.$ to $\left.1500^{\circ} \mathrm{C}\right)$. The ramp rate and hold time for each step, as well as special gases, pre- or post-treatment chemicals, and controlled tension may be used to tune the resulting properties [43]. 


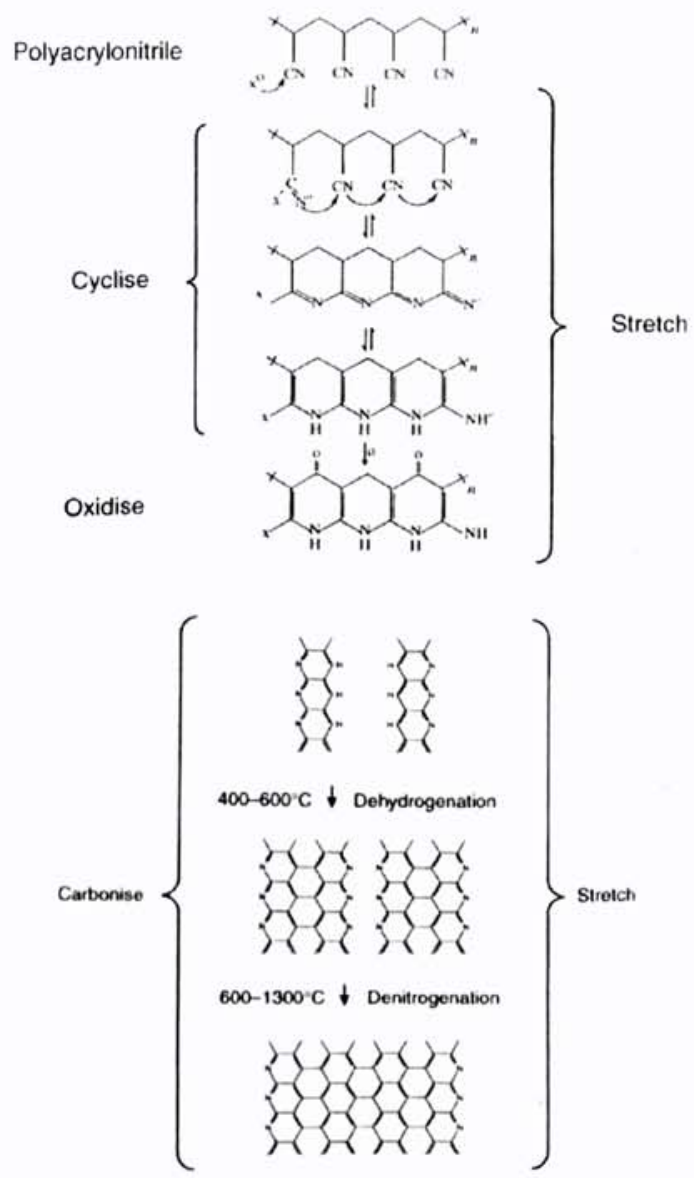

FIGURE 26: EXAMPLE OF PAN CARBONIZATION, SHOWING THE MAIN STEPS OF STABILIZATION AND CARBONIZATION [43].

Two subsequent steps, which are both optional, are graphitization and activation. While graphitization is employed for high-strength applications, activation has been developed for filtration and adsorption applications. Graphitization aims to align the aromatic sheets into a highly ordered form by high-temperature treatment $\left(>2500^{\circ} \mathrm{C}\right)$, thereby maximizing the modulus of the carbon fiber. Activation aims to impart pores or open up existing pores in a carbonized organic precursor by thermal or chemical means, thereby increasing the surface area [37]. Thermal activation is accomplished by placing the carbonized precursor in elevated temperatures under oxidizing gas $\left(\mathrm{CO}_{2}\right.$, air, steam); chemical activation is accomplished by soaking the carbonized precursor in a dehydrating agent $\left(\mathrm{KOH}, \mathrm{H}_{5} \mathrm{PO}_{4}\right)$ followed by heat treatment. Both of these approaches increase porosity by unblocking crevices between the elementary crystallites which compose the charred precursor [37]. Activation can be carried out on fibers and fabrics, resulting in SSA that can be upwards of $2500 \mathrm{~m}^{2} \mathrm{~g}^{-1}$ and composed mainly of micropores $(<2 \mathrm{~nm})$ [47]. The pore 
structure is less tortuous than that of granular activated carbon, which can result in faster ion transport kinetics (Figure 27).
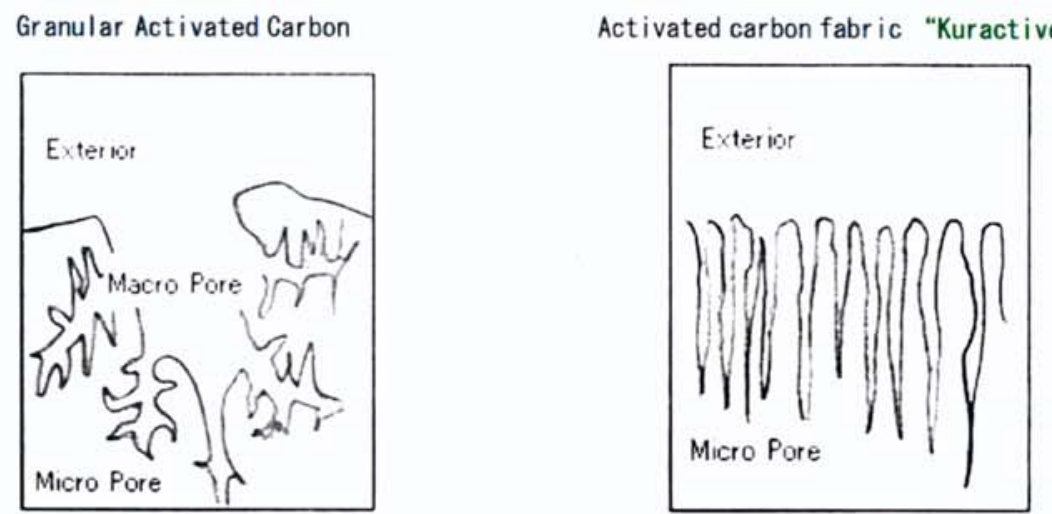

FIGURE 27: SIDE-BY-SIDE COMPARISON OF THE PORE STRUCTURES OF GRANULAR ACTIVATED CARBON AND ACTIVATED CARBON FIBER (SOURCE: KURARAY).

Electrochemical electrodes have been demonstrated from carbon fiber of various precursors (cotton fiber, mesophase pitch, rayon, PAN), various fabric forms (woven, nonwoven, knit, electrospun), and various qualities (activated, carbonized at various temperatures, graphitized) [38], [48], [49], [50]-[52]. Extensive work has been done in researching carbon "felt" for applications in microbial fuel cells and in waste water remediation cells [50], [53]. Figure 28 shows a three-electrode test cell set up to reduce $\mathrm{Cr}(\mathrm{IV})$ to $\mathrm{Cr}$ (III) using a carbon felt working electrode.
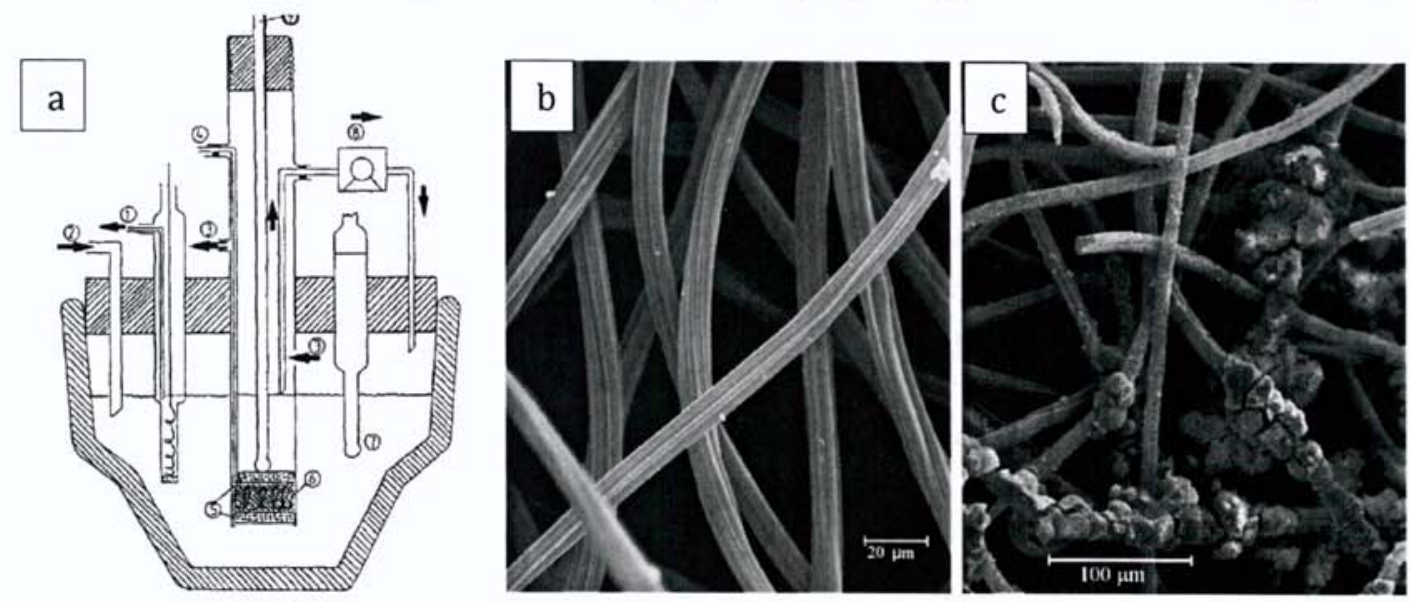

FIGURE 28: (A) SCHEMATIC OF AN ELECTROCHEMICAL CELL WITH A CARBON FELT WORKING ELECTRODE AND [50]. (B) CARBON FELT ELECTRODE WITH (C) DEPOSITED REDUCED HEXAVALENT CHROMIUM (ROBERTS, 2002)

\section{F. $\mathrm{MNO}_{2}$ PSEUDOCAPACITANCE}


Pseudocapacitance is a charge storage mechanism that results from the presence of adsorbed redox species on the surface of an electrode. Transition-metal oxides $\left(\mathrm{V}_{2} \mathrm{O}_{5}, \mathrm{RuO}_{2}\right.$, and $\left.\mathrm{MnO}_{2}\right)$ are understood to provide these fast and reversible redox reactions. Intrinsically conductive polymers (PPy, PANI, PEDOT) have also been extensively explored as a pseudocapacitive material, yet poor cycling life has limited their use in supercapacitors [9]. Among transition-metal oxides, $\mathrm{MnO}_{2}$ has received a great deal of interest for its relative environmental friendliness and low cost, as well as its high theoretical specific capacitance of $1370 \mathrm{~F} \mathrm{~g}^{-1}$ [17].

\section{INFLUENCE OF MORPHOLOGY}

$\mathrm{MnO}_{2}$ has been applied to electrodes in a number of forms. In an early study, thin sol-gel derived amorphous $\mathrm{MnO}_{2}$ film was compared to electrodeposited $\mathrm{MnO}_{2}$ [64]. The sol-gel form showed a higher specific capacitance of $\sim 600-700 \mathrm{~F} \mathrm{~g}^{-1}$ (vs. $300-400 \mathrm{~F} \mathrm{~g}^{-1}$ ). However, both measured about an order of magnitude greater than $\mathrm{MnO}_{2}$ compound obtained through co-precipitation and mixed with PTFE and carbon black [17]. The relatively high thickness of the compound particles indicates that the charge-discharge process is not occurring throughout the entire $\mathrm{MnO}_{2}$ layer [54]. Poor conductivity and slow intercalations kinetics in the bulk of $\mathrm{MnO}_{2}$ further suggest that reactions occur primarily at the surface.
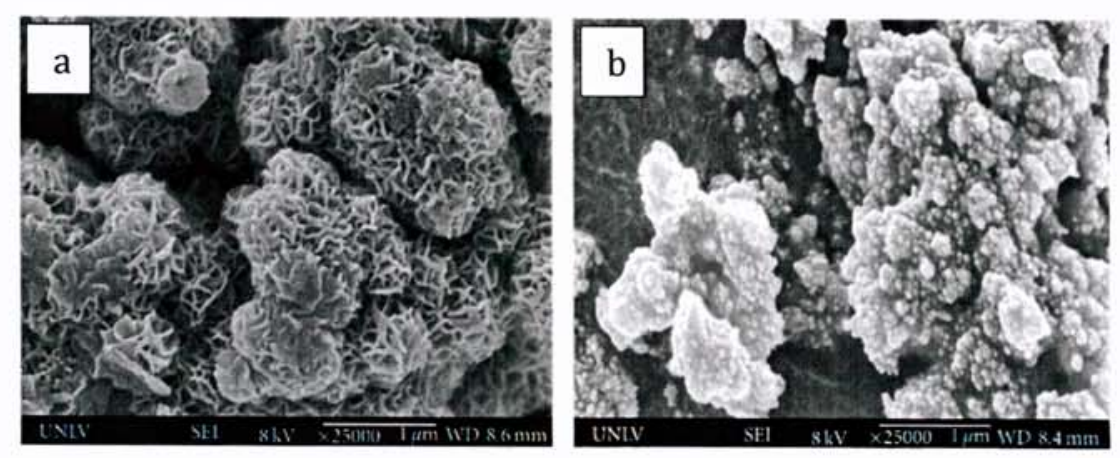

FIGURE 29: BIRNESSITE-TYPE MNO2 IN TWO VARIATIONS: (A) SO-CALLED "BLACK" AND (B) "BROWN" [56].

Crystal structure variations also influence capacitance. Among the $\alpha-, \beta-, \gamma^{-}, \delta-, \varepsilon-$, and $\eta$ - crystalline forms of $\mathrm{MnO}_{2}, \delta-\mathrm{MnO}_{2}$ has the highest specific capacitance per unit area [16]. It is constructed of sheets of edge-shared $\mathrm{MnO}_{6}$ octahedra. Black birnessite has a platelet-like structure, while the brown birnessite is amorphous; the former has a SSA of $\sim 58 \mathrm{~m}^{2} \mathrm{~g}^{-1}$, while the latter is $\sim 28 \mathrm{~m}^{2} \mathrm{~g}^{-1}$ [55]. 


\section{$\mathrm{MNO}_{2}$ REDOX BEHAVIOR}

An example of a possible redox reaction for manganese dioxide is:

$$
\mathrm{MnO}_{2}+x \mathrm{C}^{+}+y \mathrm{H}^{+}+(x+y) \mathrm{e}^{-} \leftrightarrow \mathrm{MnOOC}_{\mathrm{x}} \mathrm{H}_{\mathrm{y}}
$$

The intercalation and deintercalation of electrolyte cations is elaborated on in a schematic laid out by Pang et al. (Figure 30). The initial state, $\mathrm{Mn}$ (III) in $\mathrm{MnOOH}$, is charged to $\mathrm{Mn}$ (IV) by the loss of a cation or proton. Meanwhile, the other electrode remains in the reduced state. During discharge, the two electrodes reach equilibrium as $\mathrm{MnO}_{2} \mathrm{H}_{1-\delta}$ forms, and depart from equilibrium to the two different forms when charged again.

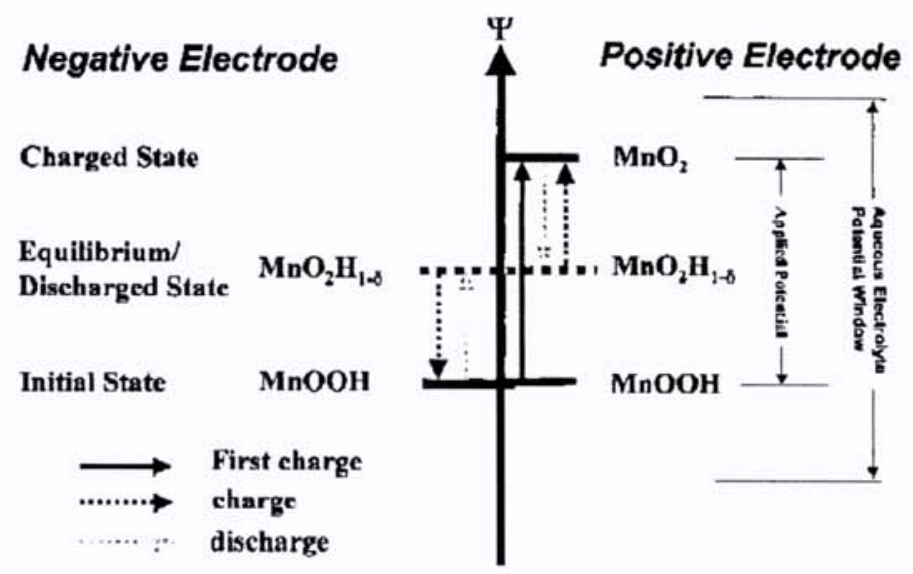

FIGURE 30: SCHEMATIC ILLUSTRATION OF THE CHARGE-STORAGE MECHANISM BETWEEN TWO MNO2 ELECTRODES [64].

Typically, the cyclic voltammogram (CV) of a redox reaction is characterized by a peak that extends beyond the double-layer capacitance current [35]. However, in keeping with other transition metal oxides such as $\mathrm{RuO}_{2}$ and $\mathrm{IrO}_{2}, \mathrm{MnO}_{2}$ exhibits a rectangular $\mathrm{CV}$ as a consequence of a series of multiple reactions taking place between Mn(III) and Mn(IV) [9], [11] (Figure 31b). This precludes the simple method of teasing out the pseudocapacitive current to estimate the pseudocapacitance from a CV. 

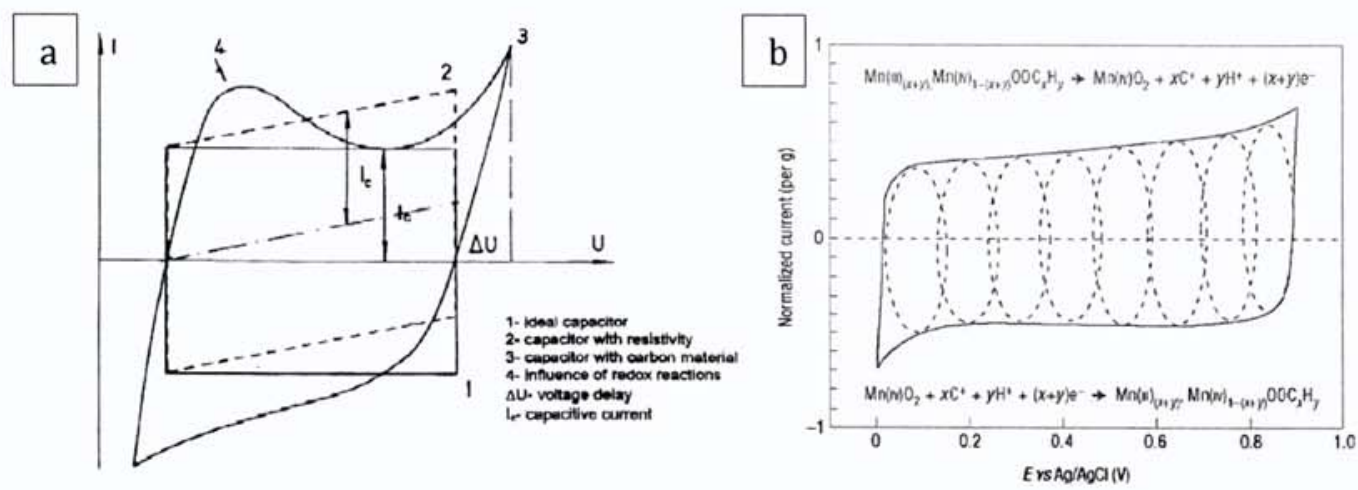

FIGURE 31: (A) GUIDE TO INTERPRETING CV CURVE WITH VARIOUS CHARACTERISTIC EFFECTS [35], AND (B) MODEL OF THE RECTANGULAR MNO2 CV CURVE SHOWING A SEQUENCE OF REACTIONS [11].

\section{SPECIFIC CAPACITANCE VALUES}

It is common for researchers to target the theoretical capacitance of $\mathrm{MnO}_{2}$, reporting values on the basis of $\mathrm{MnO}_{2}$ mass. However, this requires minimal amounts of the active material to be loaded onto the electrodes in the effort to maximize the results [9]. On the other hand, high loading of active materials is required when overall device performance is considered [56]. A review of the literature finds that this fact is often overlooked in the course of research. Here, specific capacitance values are reported on both a $\mathrm{MnO}_{2}$ mass basis and a total device mass basis. These two metrics are optimized respectively by light loadings and heavy loadings.

Additionally, specific capacitance values achieved in the literature are highly dependent on the scan rate or current density applied. From three different studies in the literature, values of $471 \mathrm{~F} \mathrm{~g}^{-1}$, $710 \mathrm{~F} \mathrm{~g}^{-1}$, and $944 \mathrm{~F} \mathrm{~g}^{-1}$ for $\mathrm{CNT} / \mathrm{MnO}_{2}$ electrodes were reported, corresponding to scan rates of $10 \mathrm{mV} \mathrm{s}^{-1}, 2 \mathrm{mV} \mathrm{s}^{-1}$, and $1 \mathrm{mV} \mathrm{s}^{-1}$, respectively [57]-[59]. 


\section{PRELIMINARY WORK DONE}

\section{A. HYPOTHESIS REPORTED BY CHEN, ET AL.}

The starting point for this investigation was the approach reported by Chen et al., which utilized a thin, $1.0 \mathrm{~mm}$ slice of sponge as the scaffold for a CNT / $\mathrm{MnO}_{2}$ supercapacitor [7]. As described earlier in this report, the electrode relied on a two-step coating process. First, a $1 \mathrm{~cm} \times 2 \mathrm{~cm}$ ribbon of the sponge was dipped in CNT / water / SDBS solution to be made conductive. The next step was to galvanostatically deposit $\mathrm{MnO}_{2}$ nanoflowers with a $500 \mu \mathrm{A} \mathrm{cm} \mathrm{cm}^{-2}$ current. Deposition time was varied from 3 minutes to 40 minutes. At a slow scan rate of $1 \mathrm{mV} \mathrm{s}^{-1}$, the 3 minute deposition resulted in a specific $\mathrm{MnO}_{2}$ pseudocapacitance of over $1000 \mathrm{~F} \mathrm{~g}^{-1}$. As deposition time increased, the $\mathrm{MnO}_{2}$ pseudocapacitance increased in total but decreased per unit mass. Considering that the theoretical value of specific capacitance for $\mathrm{MnO}_{2}$ is $1370 \mathrm{~F} \mathrm{~g}^{-1}$ based on the stoichiometry of the reaction, the values obtained by this method at low deposition times appeared promising [16], [17].

The authors linked the impressive performance of the electrode to what was termed the "doubleporous structure" of $\mathrm{MnO}_{2}$ nanoflowers on macroporous sponge. The open structure of the sponge permitted facile flow of electrolyte throughout the electrode. Nonwoven fabric represents an alternative 3D material to use as electrode scaffold. $1 \mathrm{~mm}$ thin sheets of sponge lack the mechanical durability required to survive roll-to-roll coating processes. Therefore, the prospect of applying the reported procedure to nonwovens was worth investigating. Furthermore, existing technologies enable pore structure, specific surface area, and surface chemistry of nonwovens to be tailored for a variety of end-uses. In this research, the aim was to optimize the distribution of active materials and promote circulation of electrolyte. A first step in developing such an electrode was to verify the CNT coating and $\mathrm{MnO} 2$ deposition procedures reported by Chen et al. We describe below the shortcomings to the process which were discovered, and changes which were introduced to overcome those challenges.

\section{B. MODIFIED CNT COATING PROCEDURE}

\section{MATERIALS}

Carbon nanotubes were acquired from Carbon Solutions, Inc. (Riverside, CA). P3-SWNTs are singlewalled nanotubes, produced by the electric arc discharge method and purified in nitric acid. They 
were chosen for the high degree of carboxylic acid functionalization (Figure 32). This renders the CNTs dispersible in a range of solvents with the aid of a sonic horn. The nanotubes tend to occur as bundles with an average diameter of $2-4 \mathrm{~nm}$ and average length of $1.0 \mu \mathrm{m}$ [60]. The manufacturer further states that the ratio of semiconducting to metallic nanotubes produced by this method is $2: 1$.

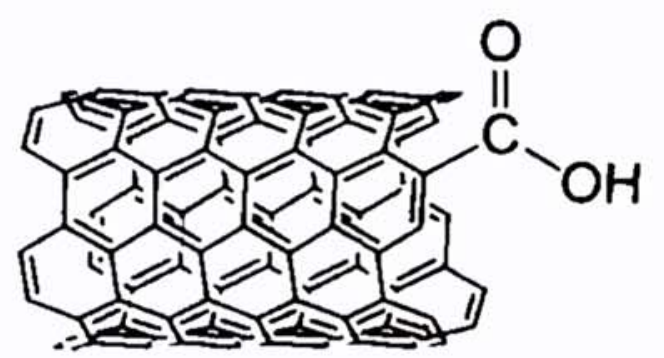

FIGURE 32: P3-SWNT WITH FUNCTIONAL CARBOXYLIC ACID GROUPS (CARBON SOLUTIONS, INC.).

The solvent used most commonly in the literature is a water/surfactant combination, where the surfactant is an organic amphiphilic molecule such as sodium dodecylbenzenesulfonate (SDBS) added to aid dispersion [61]. A major disadvantage associated with this approach is that the residual surfactant left on the fabric impedes conductivity among the CNT bundles. Rinsing with pure deionized water only partially removes the residual SDBS, leaving some particles trapped on the fabric surface (Figure 33).

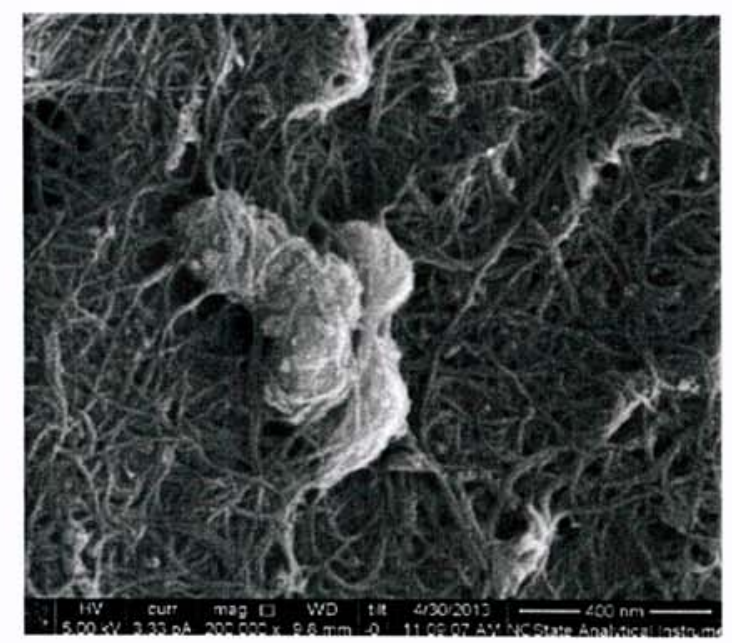

FIGURE 33: NETWORKED BUNDLES OF NANOTUBES PINNING SURFACTANT TO THE SUBSTRATE.

Ethanol was found to be an effective alternative solvent, providing a more direct route to obtaining a fabric with low electrical resistance. Without the use of any surfactant molecules, P3-SWNTs are able to remain well-dispersed in pure ethanol for long periods following sonication. The omission of 
surfactant in turn eliminates one step of the process - the rinsing - resulting in a shorter coating cycle.

Of significance is the relatively high resistance drop following one cycle with ethanol/CNT. Figure 34 shows mass gain and resistance drop for a nylon nonwoven following 5 water/surfactant/CNT cycles (Figure $34 \mathrm{a}$ and c) and 4 ethanol/CNT cycles (Figure $34 \mathrm{~b}$ and d). In both cases, a rinsing step is included to show that rinsing has no effect in the case of ethanol/CNT. It can be seen that mass gain is very hard to track in the case of water/surfactant/CNT, since the mass of surfactant is included in the measurements. Furthermore, rinsing results in an incomplete removal of the surfactant, so the measured mass may rise or fall from one cycle to the next. The slower resistance drop for the water/surfactant/CNT case as compared to the ethanol/CNT case is again due to the residual SDBS molecules, which disrupt conductivity.

$\mathrm{H}_{2} \mathrm{O}$-based
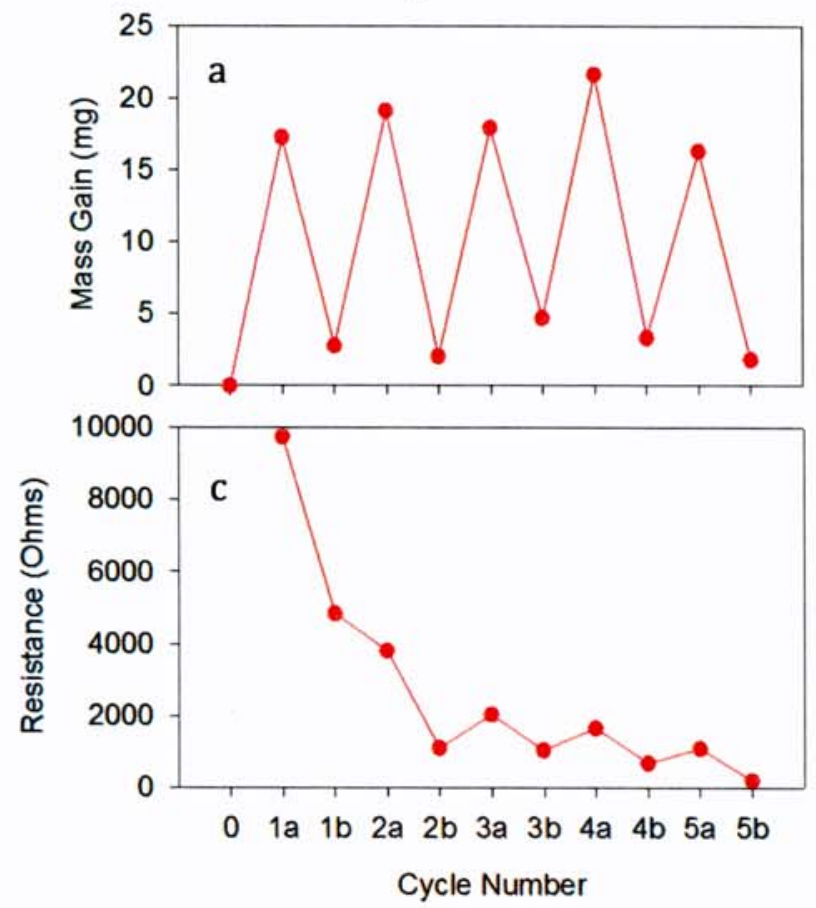

EtOH-based
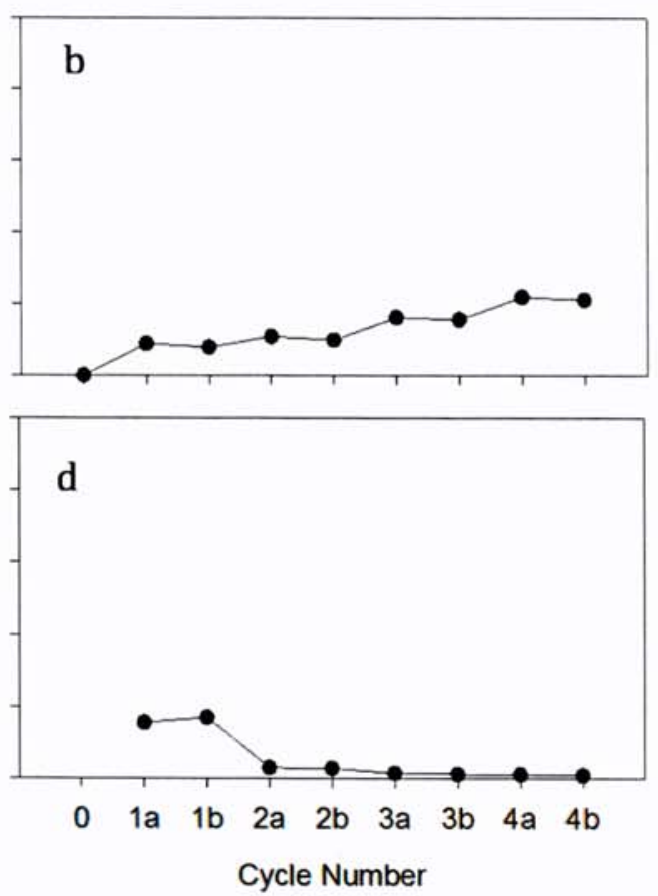

FIGURE 34: WATER-BASED CNT COATING COMPARED TO ETHANOL-BASED COATING, SHOWING MASS GAIN $(A+B)$ AND RESISTANCE DROP $(C+D)$ FOLLOWING THE DIP AND WASH PARTS OF THE CYCLE.

\section{APPLICATION TO FABRICS}

To prepare the CNT coating solution, a ratio of $1 \mathrm{mg}$ P3-SWNT to $1 \mathrm{~mL}$ ethanol was used. The P3SWNTs were combined with ethanol and placed in an ultrasonic bath (Branson 2800) for 5 
minutes. This pre-mixed solution was then further dispersed with a sonic horn (QSonica, 500 watt, $20 \mathrm{kHz}$ ) for 0.5 or $1.0 \mathrm{hr}$. All fabrics were pre-rinsed in ethanol to remove all grease and impurities left from the production processes. A sample size of $6.5 \mathrm{~cm}$ diameter (circular) was cut and immersed in $20-40 \mathrm{~mL}$ of the ethanol/CNT mixture. Notches were cut at the top and bottom for hanging in the drier and measuring resistance.

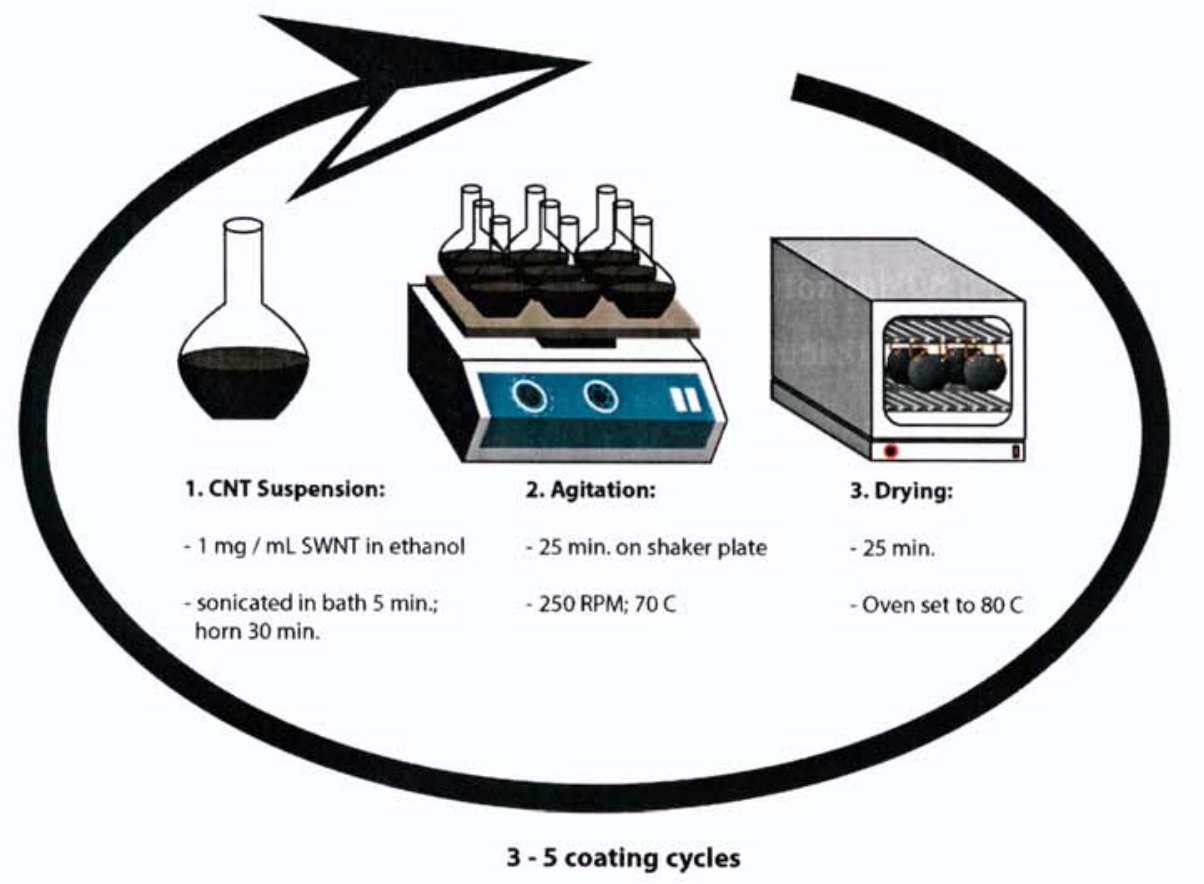

FIGURE 35: METHOD FOR APPLYING CNT COATING ONTO FIBER SURFACES.

Rather than following the simple dip-dry procedure outlined in the literature, samples were placed on a shake plate for 25 minutes at $250 \mathrm{rpm}$. This agitation resulted in a higher uptake of CNT, roughly doubling the uptake as compared to the dip-dry procedure. Additionally, an elevated temperature of $70^{\circ} \mathrm{C}$ was used. This immerse-shake-dry cycle was repeated as many times as needed to reach a desired CNT uptake for a particular fabric.

The initial range of fabrics developed an asymmetric coating when dried lying flat in the furnace. As the ethanol/CNT was heated, the ethanol evaporated and, on its way out, transported a significant amount of CNT to the top fabric surface. Two notches were cut out of the top of the samples so that they could hang and dry vertically, resulting in a homogenous coating. However, with the fabric types used later in the research, the open fabric structure allowed better convection and this step became unnecessary. 


\section{C. $\mathrm{MNO}_{2}$ DEPOSITION PROCEDURE}

\section{CHANGES TO MNO2 ELECTRODEPOSITION}

In the work performed by Chen et al., $\mathrm{MnO}_{2}$ was electrodeposited onto a CNT/sponge substrate via a galvanostatic technique. Approximately $1 \mathrm{~cm}^{2}$ of the substrate was dipped into a solution containing $20 \mathrm{mM} \mathrm{Mn}\left(\mathrm{NO}_{3}\right)_{2}$ and $100 \mathrm{mM} \mathrm{NaNO}_{3}$ and a current density of $500 \mu \mathrm{A} \mathrm{cm}^{-2}$ was applied [7]. When this technique was applied to nonwoven substrates, a number of problems occurred, including highly variable $\mathrm{MnO}_{2}$ deposition (in both amount and distribution) as well as preferential corrosion of the electrode leads (due to solution wicking up the nonwoven and interacting with the lead). This behavior is likely due to the high resistance of the CNT/nonwoven substrate, which leads to electrochemistry occurring at the points of lowest resistance: either the metal electrode lead or near the surface of the solution, depending on how much electrolyte wicking occurred. Figure 36 shows an example of a gradient in $\mathrm{MnO}_{2}$ concentration on a sponge substrate.

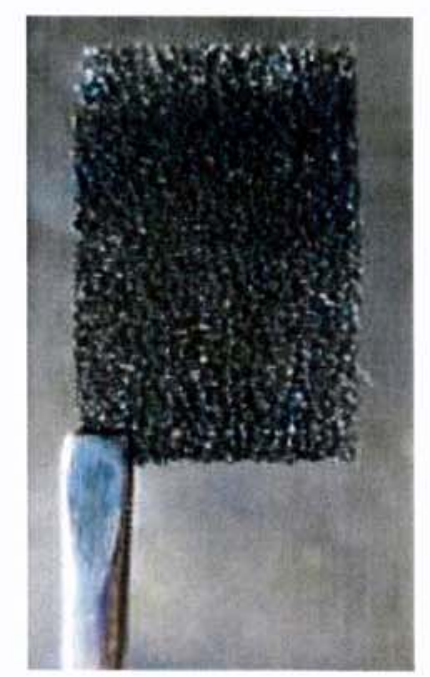

FIGURE 36: EXAMPLE OF $\mathrm{MNO}_{2}$ GRADIENT AFTER ELECTRODEPOSITION ONTO A PU SPONGE.

To better understand the electrochemistry of $\mathrm{MnO}_{2}$ deposition, linear sweep voltammetry (LSV) was performed on both a CNT/nonwoven and a gold substrate. The results of this work vary significantly between the two materials (Figure 37). The nonwoven shows significant current flow at even low potentials, while the gold surface has a well-defined inflection point near $0.8 \mathrm{~V}$ vs. $\mathrm{Ag} / \mathrm{AgCl}$. This potential corresponds well to those reported in the literature. For the nonwoven, an applied current of $500 \mu \mathrm{A}$ results in a potential of only $0.6 \mathrm{~V}$, which is too low for $\mathrm{MnO}_{2}$ to form. 
Thus, rather than a galvanostatic method, a potentiostatic method was used for preparing electrodes, with the applied potential being $1 \mathrm{~V}$ vs. $\mathrm{Ag} / \mathrm{AgCl}$.

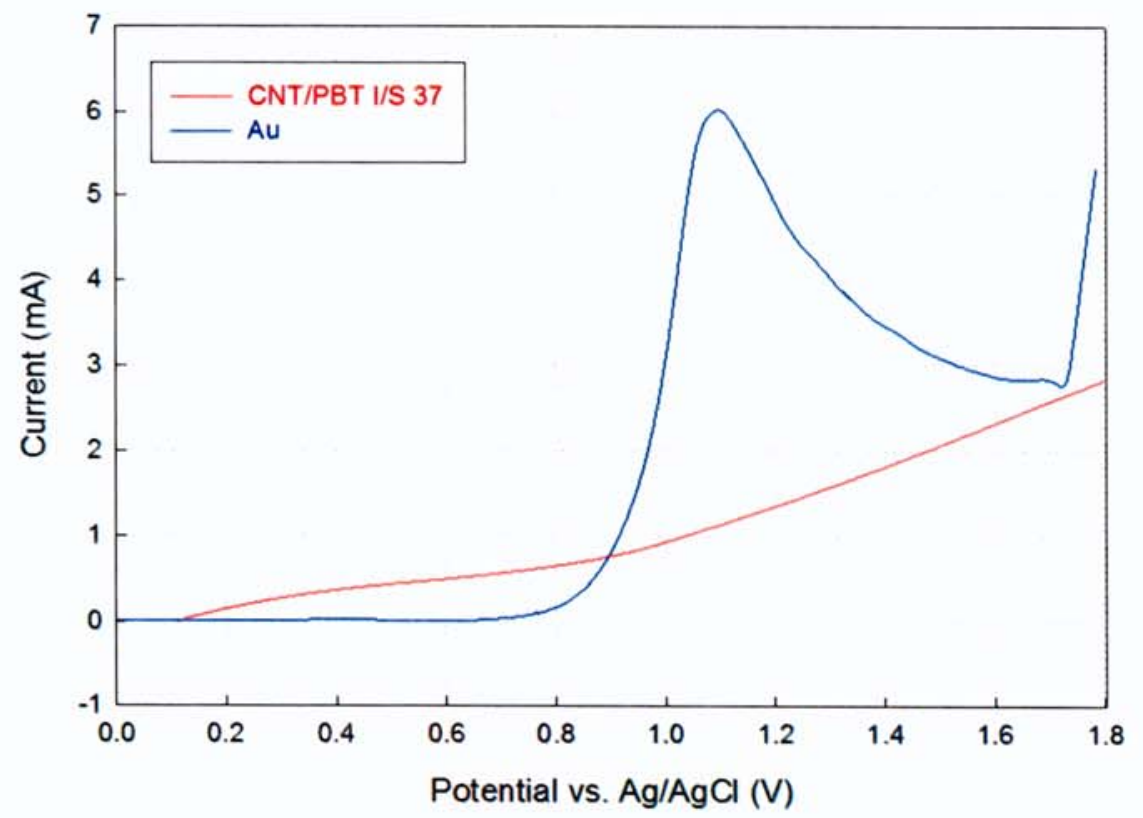

FIGURE 37: LINEAR SWEEP VOLTAMMOGRAMS FOR CNT ELECTRODE (RED) AND GOLD ELECTRODE (BLUE) IN MNSO4 SOLUTION.

Potentiostatic deposition does not, however, fix the problem of $\mathrm{MnO}_{2}$ deposition occurring in a gradient based on the distance the point in the nonwoven is from the electrode lead. To have an even distribution of $\mathrm{MnO}_{2}$, further modification of the preparation method was required. Rather than the dip setup used, a masked deposition cell was used (Figure 38). The major improvement in the new configuration is that the stainless steel backing piece is in contact with the entire nonwoven sample. The steel has a resistance that is effectively zero relative to the resistance of the $\mathrm{CNT} /$ nonwoven material, thus, $\mathrm{MnO}_{2}$ is equally likely to deposit evenly over the entire exposed surface. There will, however, be a gradient in $\mathrm{MnO}_{2}$ through the thickness of the material, but a gradient in this direction will not result in $\mathrm{MnO}_{2}$ loading variances for each electrode. Finally, the use of 316 stainless steel precludes the corrosion that was observed on the electrode leads when using the dip coating technique. 

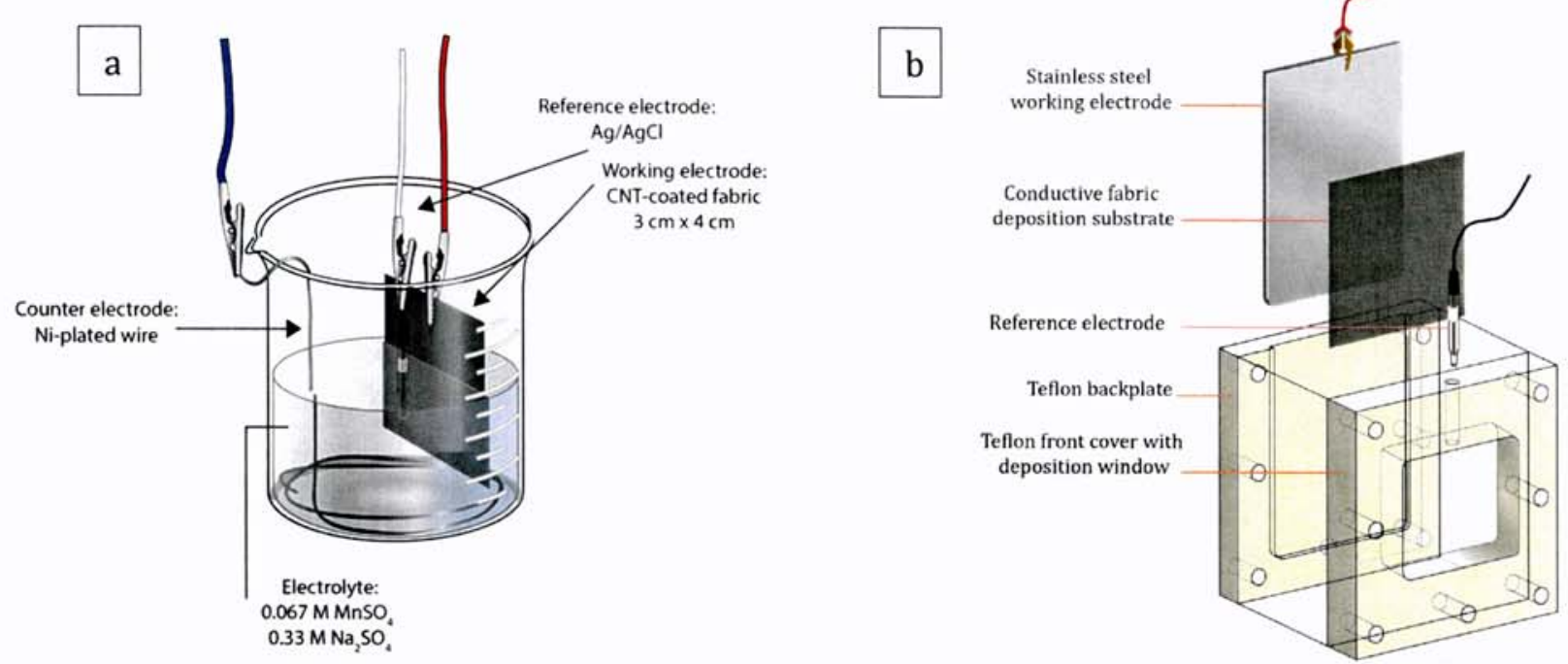

FIGURE 38: ELECTRODEPOSITION SETUPS FOR DIP TECHNIQUE (A) AND MASKED TECHNIQUE (B).

The theoretical mass of $\mathrm{MnO}_{2}$ deposited (based on total charge passed through the circuit), compares well to the values obtained from comparing the mass of samples before and after deposition. Furthermore, XPS of the $\mathrm{MnO}_{2}$ coated samples shows that the oxidation state of the Mn ions matches those that would be expected for $\mathrm{MnO}_{2}$ (Figure 39) and SEM micrographs show the expected flowerlike nanostructures (Figure 40). Thus, the modified electrdeposition procedure results in uniform and reproducible $\mathrm{MnO}_{2}$ coating of the electrodes.

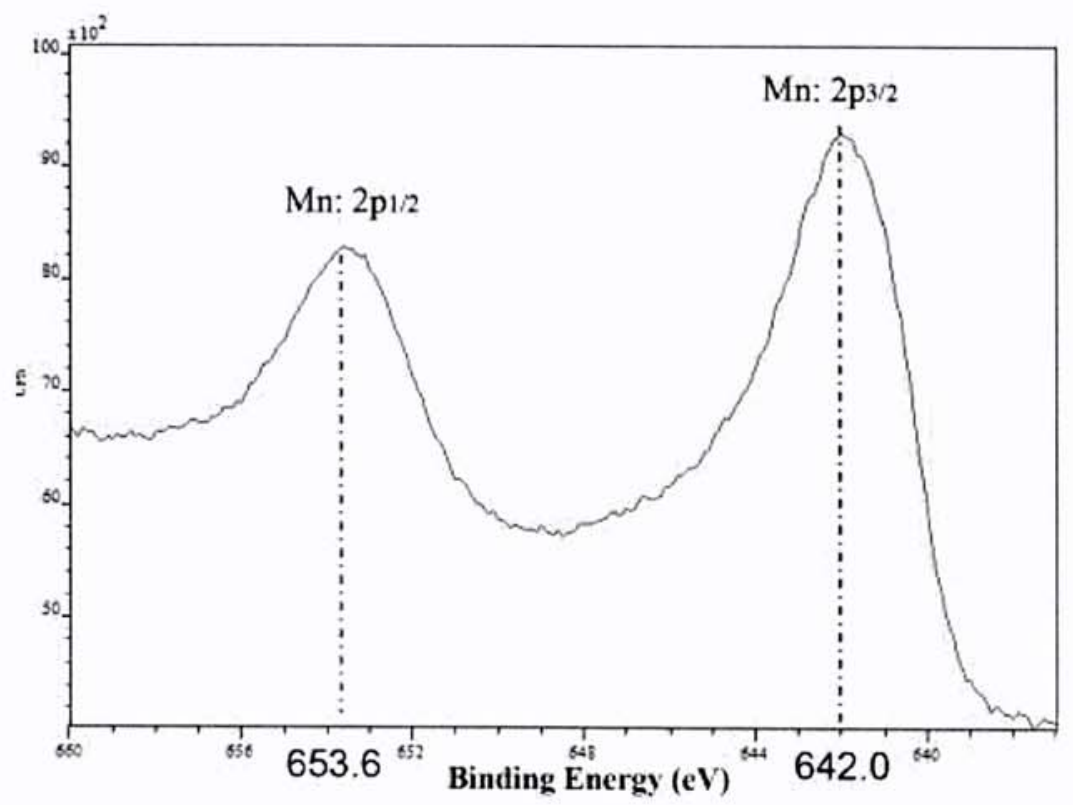

FIGURE 39: XPS RESULTS OF MNO2 COATED NONWOVENS. 

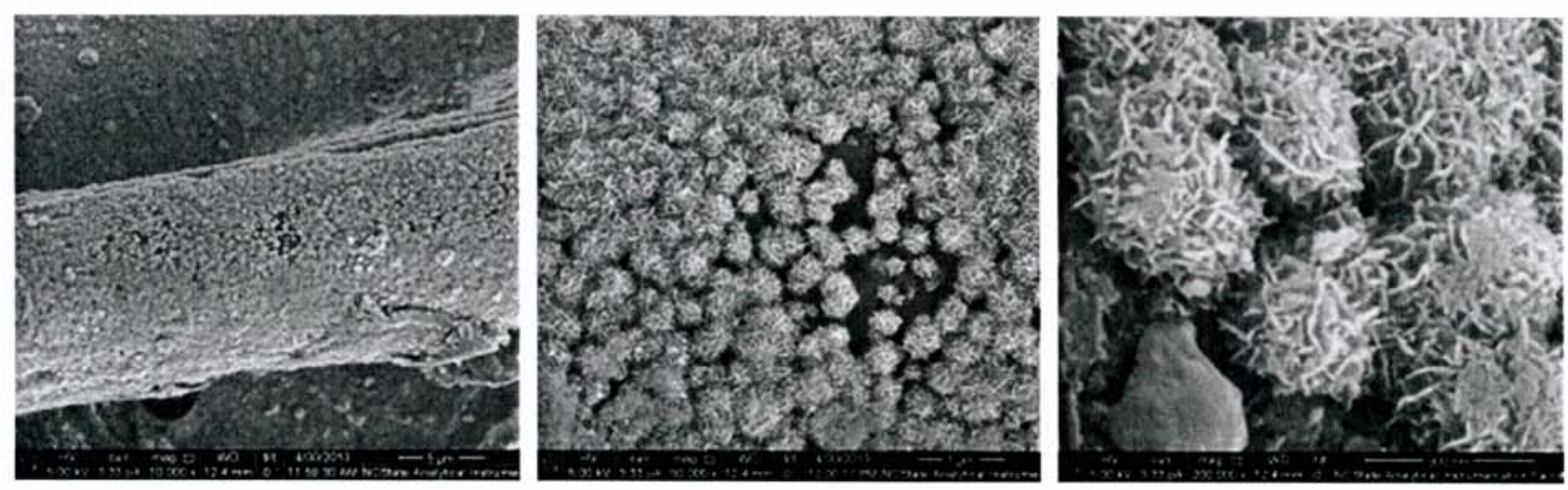

FIGURE 40: MNO2 NANOPARTICLES GROWN ON CNT-COATED FIBER, SHOWN AT 10,000X, 50,000X, AND 200,000X (LEFT TO RIGHT). 


\section{TESTING PROTOCOL}

\section{A. RESISTANCE TESTING}

Electrical resistance was tested by a two-probe method, applying a $1.0 \mathrm{~V}$ potential (BioLogic VMP3 potentiostat/galvanostat) across an edge of the treated specimen with a constant spacing (Figure 41). This method provides values that can be used to reliably compare the different samples we prepare in the lab. It does not, however, produce results that can be normalized as surface resistivity. Surface resistivity (in $\Omega / €$ ) has been reported by groups using a four-point probe, yet these measurements are also reported to vary extensively with fabric compression.

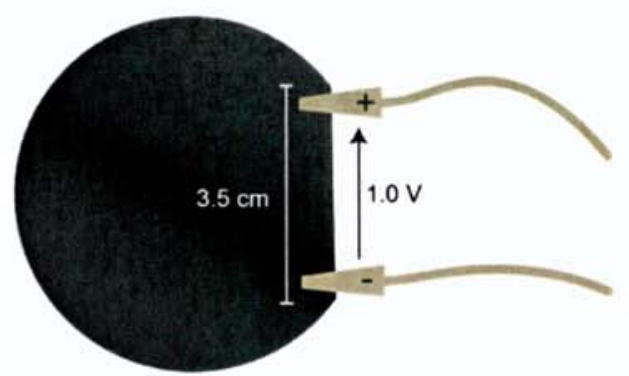

FIGURE 41: A TYPICAL 6.5 CM DIAMETER SAMPLE TESTED ALONG THE EDGE CUT TO 3.5 CM.

Since the goal of the research was not to create fabrics with a specific surface resistivity, but rather to investigate how treatment parameters affect performance, changes in resistance were tracked using the method outlined above. As would be expected, resistance dropped as coating mass increased.

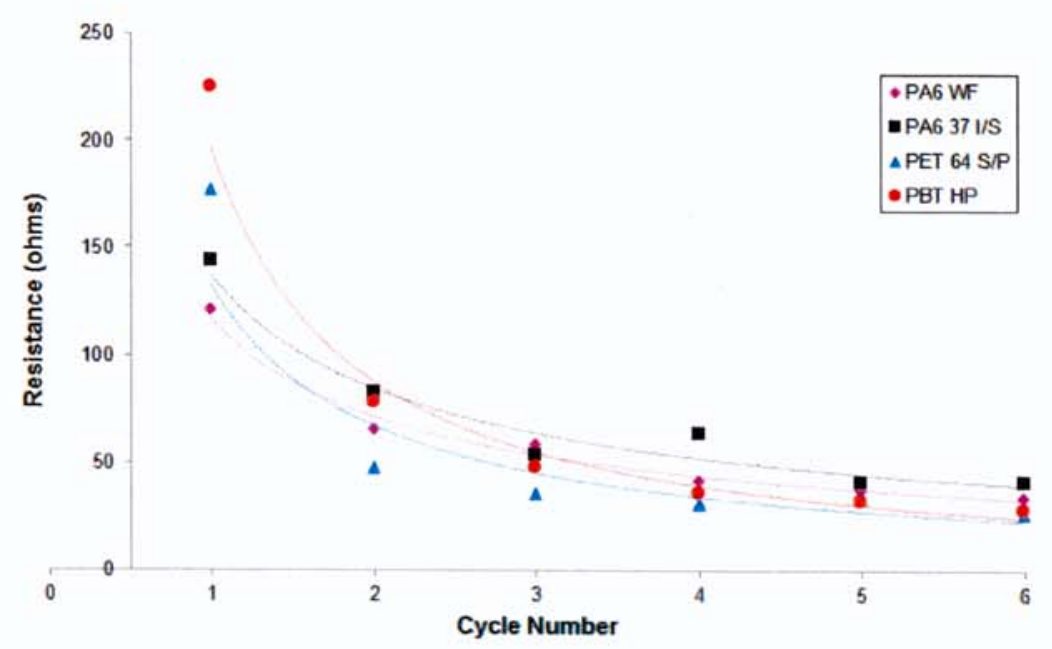

FIGURE 42: RESISTANCE MEASURED AFTER EACH CNT COATING CYCLE FOR FOUR TYPES OF FABRIC. 
The majority of the resistance drop occurred within the first two cycles, with resistance dropping marginally in subsequent steps. Figure 42 shows that further coating steps would likely cause resistance to drop in increasingly smaller increments. The potential advantages of low resistance, such as higher electrodeposition current and increased double-layer capacitance, are offset by the buildup of CNT sheets between fibers. At a certain point, even for low-SVF fabrics, buckypaper will form and restrict access to the fabric interior - a point that is expanded upon later in this report. Applying as heavy a coating as possible before introducing buckypaper formation resulted in the lowest practical resistance being obtained. Thus, rather than monitoring resistance, the more effective factor to monitor is visible CNT caking.

\section{B. CELL TESTING PROCEDURE}

Electrode performance was evaluated using a sandwich cell setup and galvanostatic charge/discharge testing. Test cells were composed of two pieces of PTFE, two 316 stainless steel current collectors, and a filter paper separator. Cell compression ratios were controlled by varying the thickness of the current collectors. In contrast to the work by Chen et al., a $0.5 \mathrm{M} \mathrm{Na}_{2} \mathrm{SO}_{4}$ electrolyte was used after being found to provide comparable performance as a $1 \mathrm{M}$ electrolyte.

\section{DOUBLE LAYER CAPACITANCE}

Double layer capacitance was measured for CNT-coated electrodes prior to $\mathrm{MnO}_{2}$ deposition. Total capacitance ( $C_{T}=\frac{Q}{E}$ ) was calculated from a chrono-potentiometry scan with current set to $0.5 \mathrm{~mA}$ over a voltage window of $0.8 \mathrm{~V}$. When normalized by CNT mass $\left(m_{c 1}, m_{c 2}\right)$, the specific double layer capacitance $\left(C_{D L}\right)$ plateaued around $60 \mathrm{~F} \mathrm{~g}^{-1}$ of CNT (Eqn.3). This maximum value is in keeping with the literature [29], and is likely a result of the trade-off between increased electrode conductivity and decreased utilization of individual CNT as the fabric is carried through additional coating cycles.

$$
C_{D L}=C_{T} *\left[\frac{m_{c 1}+m_{c 2}}{m_{c 1} * m_{c 2}}\right]
$$

Specific double layer capacitance may also be normalized by total electrode mass (fabric mass plus CNT mass). Since additional CNT coatings contribute relatively little to the overall electrode mass, specific capacitance continues to increase with each cycle. Figure 43 shows the linear relationship between CNT loading and double-layer capacitance, when normalized by total electrode mass. The 
average increase in specific double-layer capacitance is $0.57 \mathrm{~F} \mathrm{~g}^{-1}$ for each additional weight percent of CNT coated onto the fabrics.

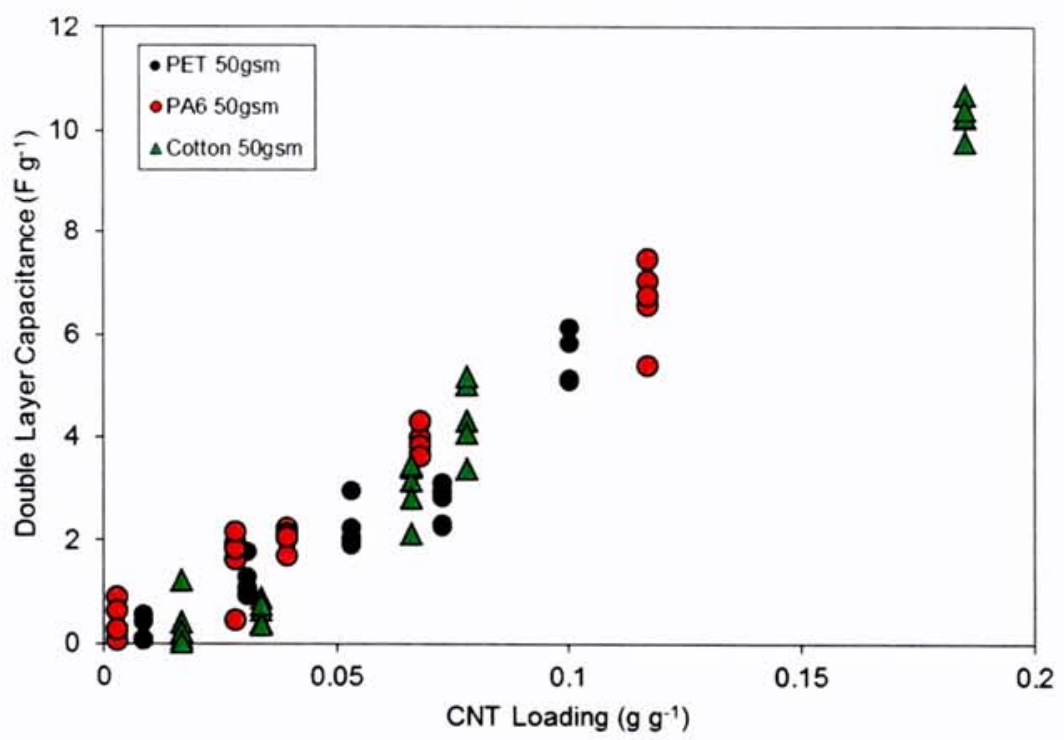

FIGURE 43: SPECIFIC CAPACITANCE BASED ON MASS LOADING OF CNT FOR THREE LOW-SVF FABRICS.

This linear relationship breaks down when buckypaper begins to form, as was observed with highSVF fabrics (>10\%) and with the cotton sample at high loadings ( $>25 \%$ ). Along with visual evidence, double-layer capacitance measurements can therefore be used to indicate caking (Figure 44.)

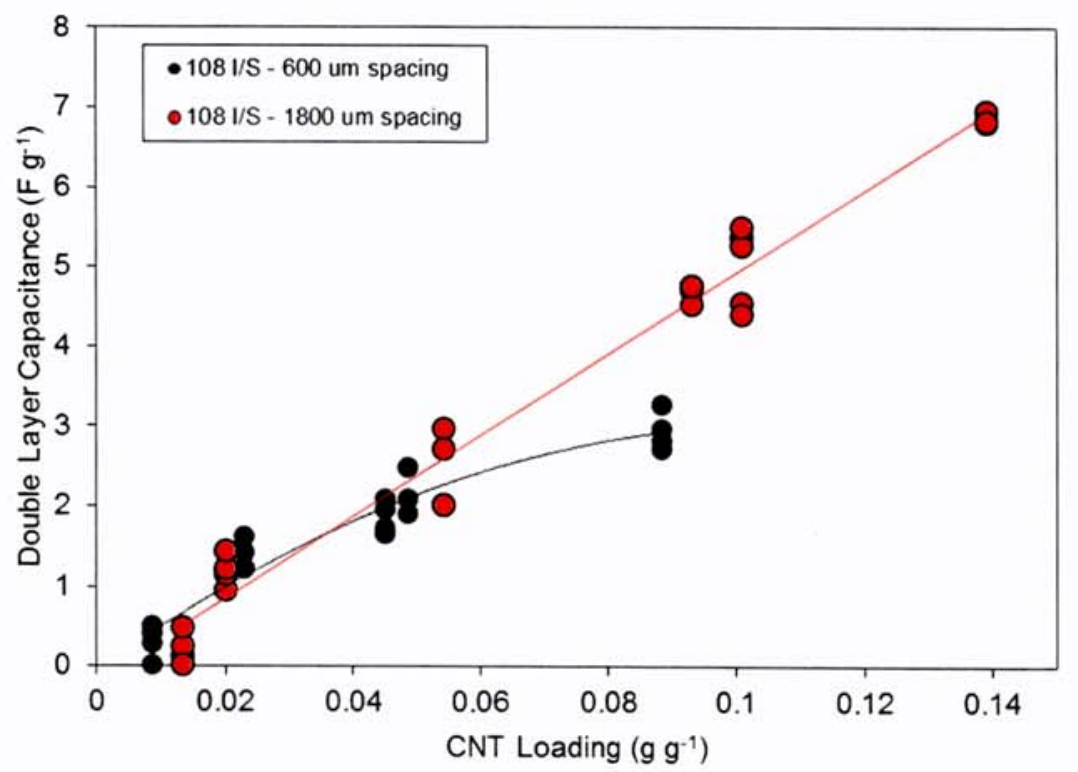

FIGURE 44: SPECIFIC DOUBLE-LAYER CAPACITANCE FOR PA6 I/S FABRIC WITH 600 MICRON HYDROJET SPACING (CLOSED) AND 4800 MICRON SPACING (OPEN), WITH VARIOUS LEVELS OF CNT MASS LOADING. 


\section{PSEUDOCAPACITANCE}

Pseudocapacitance, like double-layer capacitance, is based on charge separation the electrode surface. Unlike true capacitance, it involves electron-transfer (i.e. Faradaic) reactions. Its name derives from the fact that the reversible redox species are surface-adsorbed, so that they factor into equivalent circuits in parallel to double-layer capacitance. The effects are considered additive, so in order to measure only pseudocapacitance of a $\mathrm{MnO}_{2} /$ CNT coated electrode $\left(c_{s}\right)$, the capacitance due to the double-layer effect $\left(C_{s}\right)$ is simply subtracted out (Eqn. 4 , where $M$ is the total mass of an electrode and $m$ is the $\mathrm{MnO}_{2}$ mass of an electrode).

$$
\frac{1}{C_{T}}=\frac{\left(M_{1} C_{s}+m_{1} c_{S}\right)+\left(M_{2} C_{s}+m_{2} c_{S}\right)}{\left(M_{1} C_{s}+m_{1} c_{s}\right) *\left(M_{2} C_{s}+m_{2} c_{S}\right)}
$$

In keeping with the project goal of maximizing the pseudocapacitance of $\mathrm{MnO}_{2}$, specific pseudocapacitance was initially normalized based only on the $\mathrm{MnO}_{2}$ mass. However, as will be explained in detail further in the report, a more relevant metric is the combined double-layer and pseudocapacitance, both normalized by total electrode mass. 


\section{INFLUENCE OF FIBER PROPERTIES}

\section{A. POLYMER TYPE}

Polymer chemistry plays a fundamental role in how a fiber surface interacts with dyes, solvents, dirt, pigment, or other molecules, and thus was an important variable to consider in choosing a CNT scaffold. Chen et al. successfully applied a CNT layer onto the sponge in their study, which is described in their report as cellulose. However, upon comparison of the reported SEM to the cellulose foam SEM collected in this work, there are distinct differences in the morphology. Indeed, the type of regular, polyhedral cellular structure of the reported sponge is characteristic of elastomer foam cells (Figure $45 \mathrm{a}+\mathrm{c}$ ). Cellulose foam, on the other hand, bears little resemblance with its crooked, irregular cell structure (Figure 45b).
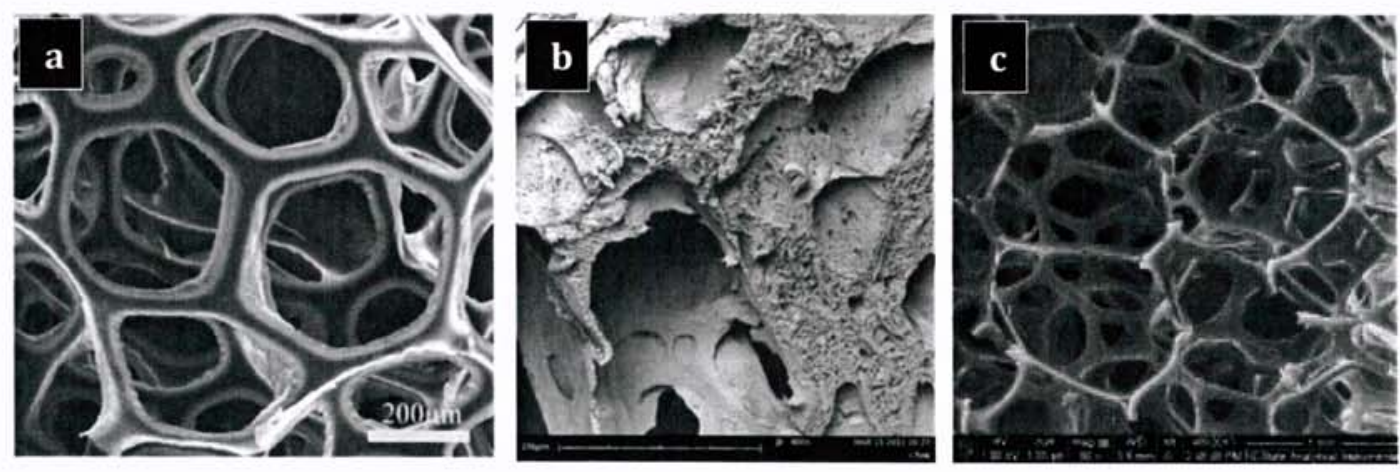

FIGURE 45: FROM LEFT TO RIGHT - SEM OF REPORTED SPONGE (CHEN, ET AL.), SEM OF CELLULOSE SPONGE, SEM OF POLYURETHANE SPONGE.

To confirm the polymer type of the reported sponge, a variety of common sponges were acquired. Those with cellular structures similar in shape to the reported sponge were subjected to FTIR, which showed a $77.8 \%$ match to a blend of Spenkel L-91 and Desmocap 11-A

+ S4 green sponge
Composite bor Masch 1

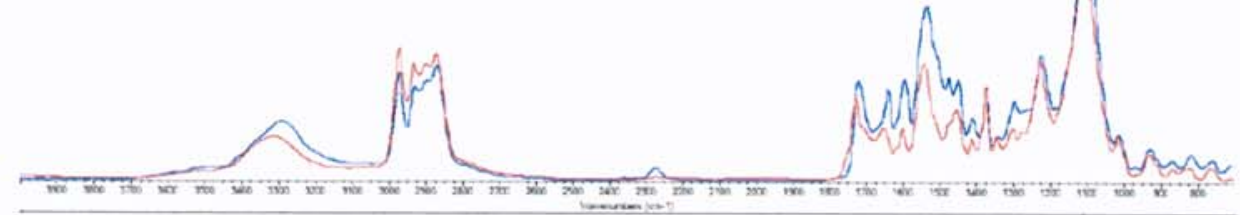

Figure 46). Both commercial products are trade names for polyurethane foam, making it likely that the reported sponge was formed of polyurethane rather than cellulose polymer [62]. 


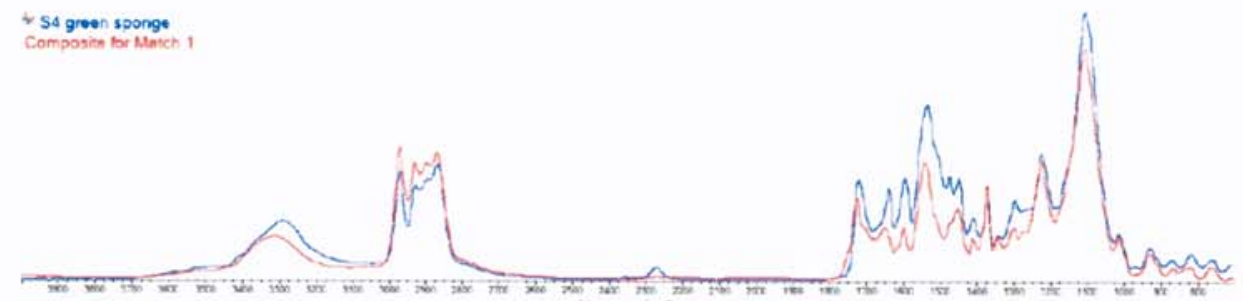

FIGURE 46: FT-IR SPECTRA OF SPONGE (BLUE LINE) AND COMPOSITE SPECTRA OF POLYURETHANE FOAM (RED LINE).

When initiating the fabric selection process, a compatibility study was carried out over a wide range of polymer types. Polyamide (PA6), polyethylene terephthalate (PET), polybutylene terephthalate (PBT), and polypropylene (PP) fibers were subjected to several dip-dry cycles. The PP winged fiber had low uptake, and the coating exhibited non-homogeneities with many uncoated patches visible. This can be explained by the well-known nature of polypropylene surface energy, which was confirmed by our contact angle measurements (Table 1). Compared to the other samples, the polypropylene fabric was shown to have a vastly lower surface energy, indicating low wettability in a range of solvents.

TABLE 1: WATER CONTACT ANGLE AND DIIODOMETHANE CONTACT ANGLE MEASUREMENTS FOR HIGH SSA NONWOVENS OF VARIOUS POLYMER TYPES

\begin{tabular}{|lclc|}
\hline & $\begin{array}{c}\text { Water } \\
\text { contact angle }\end{array}$ & $\begin{array}{c}\text { Diiodomethane } \\
\text { contact angle }\end{array}$ & $\begin{array}{c}\text { Surface } \\
\text { energy }\end{array}$ \\
\hline Polypropylene (Winged Fiber) & $137.3^{\circ}$ & $124.6^{\circ}$ & $2.44 \mathrm{mN} \mathrm{m}^{-1}$ \\
\hline Polyamide (37 I/S) & $125.2^{\circ}$ & $<1^{\circ}$ & $60.14 \mathrm{~m} \mathrm{~N} \mathrm{~m}^{-1}$ \\
\hline Polybutylene terephthalate (37 I/S) & $128.1^{\circ}$ & $<1^{\circ}$ & $61.50 \mathrm{~m} \mathrm{~m} \mathrm{~m}^{-1}$ \\
\hline Polyethylene terephthalate (64 I/S) & $133.3^{\circ}$ & $<1^{\circ}$ & $64.00 \mathrm{mN} \mathrm{m}^{-1}$ \\
\hline
\end{tabular}

Despite the observation that a variety of polymers interacted reasonably well with the CNT coating, several publications have indicated that polymer type can determine CNT coating quality [31], [63]. Consensus or a set of guidelines have yet to emerge - thus, we studied the CNT uptake for three different polymers (cellulose, polyamide, and polyester) while keeping the fabric structure variables constant (50 gsm needlepunched web). The cellulose web was able to adsorb roughly double the mass of nanotubes that polyester and polyamide fibers could (Table 2), which may be attributed to the six $-\mathrm{OH}$ groups associated with each cellulose repeat unit. 
TABLE 2: CNT MASS UPTAKE FOLLOWING FOUR CYCLES OF CNT/ETHANOL COATING.

\begin{tabular}{|c|c|}
\hline $\begin{array}{c}\text { Needlepunched } \\
\text { nonwovens } \sim \text { 50gsm, 6 } \\
\text { denier }\end{array}$ & $\begin{array}{c}\text { CNT mass uptake } \\
\text { (g g-1) }\end{array}$ \\
\hline Polyamide & 13.24 \\
\hline Cellulose & 22.74 \\
\hline Polyester & 11.14 \\
\hline
\end{tabular}

Polyamide also contains polar groups that will bond with the functionalized nanotubes, although each repeat unit has fewer groups than cellulose. In fibers without functional groups, such as PET and PBT, it is possible for pi-pi stacking to occur between the aromatic rings in the CNT and the polymer backbone. Thus, all three fibers types have a mechanism by which the CNT bond can be explained, while PP has neither surface functional groups nor aromatic rings (Figure 47).<smiles>CCOCCOC(=O)c1ccc(C(=O)OCCOO)cc1</smiles><smiles>CCC(C)CC(C)CC(C)(C)C</smiles>

FIGURE 47: REPEAT UNIT OF POLYETHYLENE TREPHTHALATE (POLYESTER) WITH AN AROMATIC RING (LEFT) AND REPEAT UNIT OF POLYPROPYLENE POLYMER (RIGHT).

The superior uptake of cellulose gives cotton fiber an advantage in terms of double-layer capacitance. However, at mass loadings of $>20 \%$, that increase begins to slow down as a result of buckypaper formation. Even though the web is quite open ( $2.3 \%$ SVF), CNT bridges will form above this threshold. Another limitation associated with cellulose fibers is that the fibers swell when immersed in aqueous solutions. Thus, during electrodeposition, $\mathrm{MnO}_{2}$ nanoparticles are prevented from forming inside the fabric. Unlike the PA6 and PET nonwovens with comparable structure, the $\mathrm{MnO}_{2}$ collects entirely on one surface (Figure 48). 


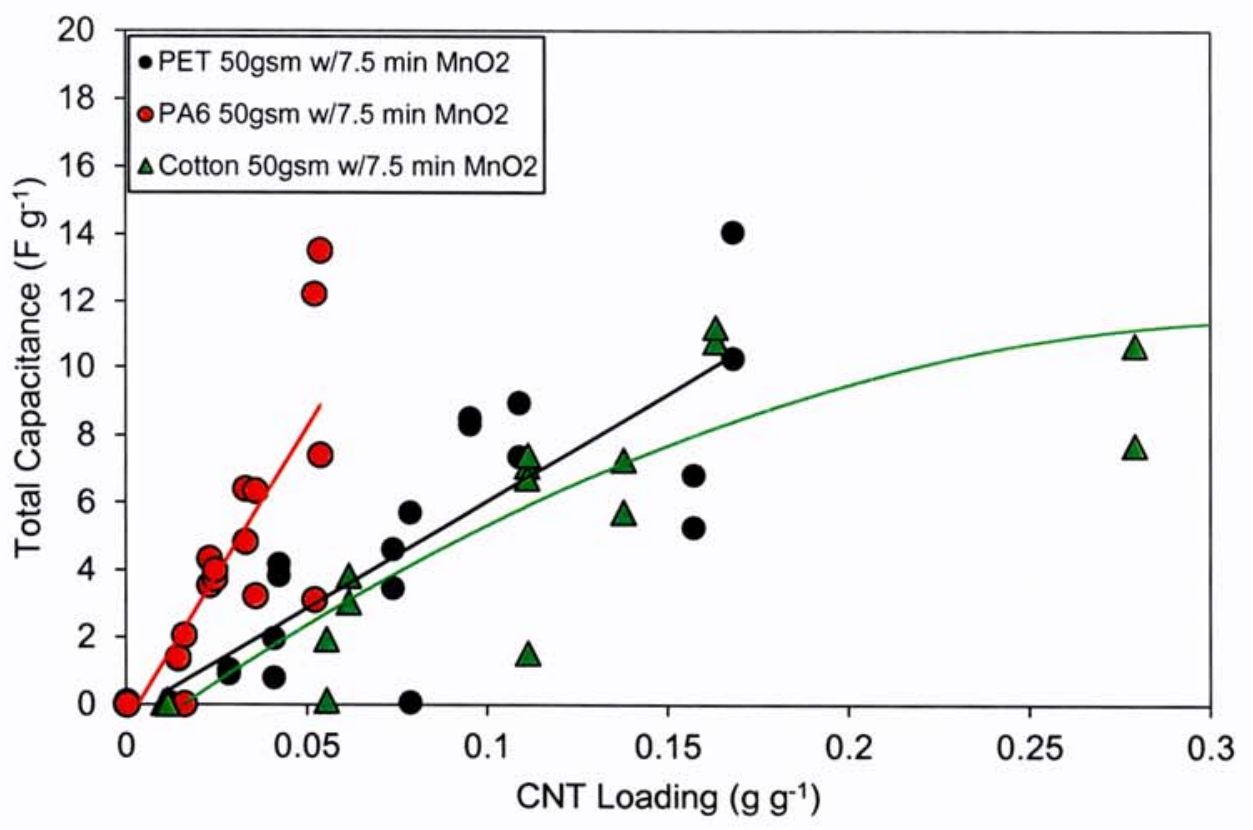

FIGURE 48: SPECIFIC TOTAL CAPACITANCE OF NONWOVENS FROM VARIOUS POLYMERS AS A FUNCTION OF CNT LOADING. ALL HAVE 7.5 MINUTES MNO2 DEPOSITION.

\section{B. FIBER SHAPE}

\section{UNCONVENTIONAL CROSS-SECTIONS}

One of the key parameters in obtaining high specific capacitance is using an electrode with high SSA. Several low diameter, and thus high SSA, bi-component fibers were produced during this study. For example, winged fibers were produced in two polymer types - PA6 and PP. This fiber, recently developed by the NWI, is formed in a bi-component spinning method where the core has 32 lobes and is $\sim 30 \mu \mathrm{m}$ in diameter after the sacrificial PLA sheath is dissolved.

Another type of bi-component microfiber used during this project is Islands in the Sea (I/S). These fibers can be extruded with up to 360 islands embedded in a PLA matrix. The fiber as extruded is $20 \mu \mathrm{m}$ in diameter, and following a mild caustic wash, the liberated islands will be as small as 0.3 microns (Figure 49). Spunbond processes have been used to form fabrics with 37 and 108 islands (PA6) and these have been hydroentangled at different pressures and with different jet spacing to control consolidation. 

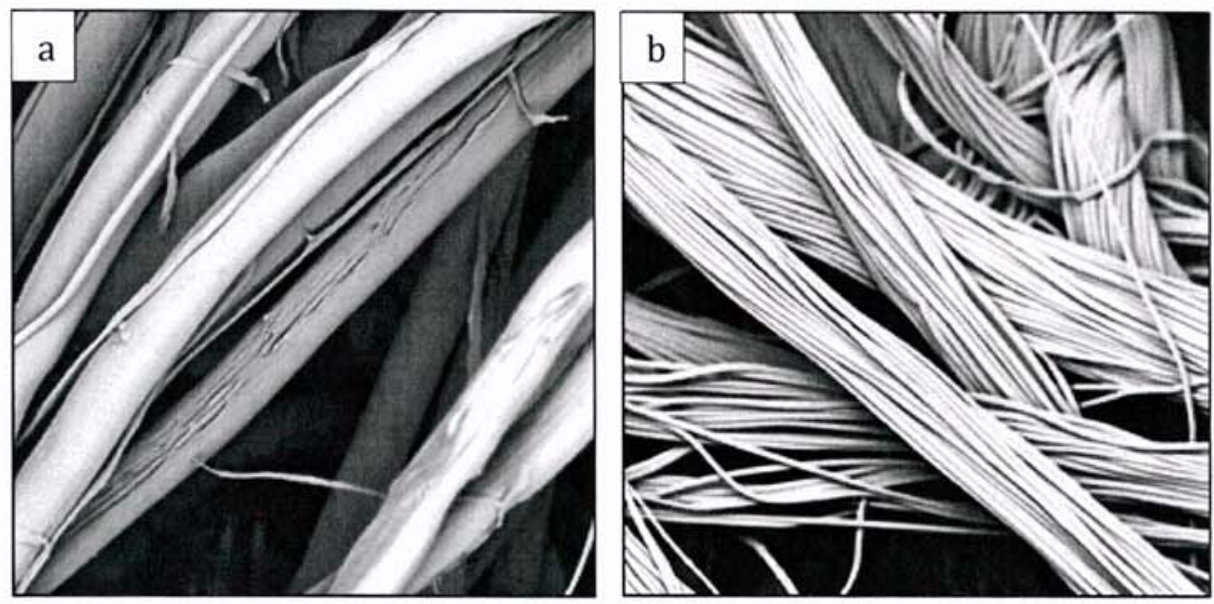

FIGURE 49: SEM IMAGES AT 2000 X SHOWING 37 I/S FABRIC (A) BEFORE AND (B) AFTER PLA IS WASHED AWAY WITH NAOH SOLUTION.

4DG fibers have a similar lobed cross-section as seen in Winged Fibers (but with fewer lobes). The cross-sectional diameter is $\sim 47 \mu \mathrm{m}$. PA6 4DG fibers were consolidated by means of needle punching. Other fiber geometries employed were pentalobal segmented pie, and kidney-shaped (for the natural cellulose fibers).

\section{EFFECT OF FIBER SHAPE ON REPRODUCIBILITY}

Even having eliminated CNT caking as a source of error in the electrode fabrication process, the performance of these nonwoven electrodes still had a high degree of scatter, which made isolating the effect the addition of $\mathrm{MnO}_{2}$ to an electrode had on its performance difficult. In an effort to reduce this source of error, several low SVF nonwovens were screened for the reproducibility of their double layer capacitance over a range of CNT loading values. Nonwovens chose for this work were all based on PET, but covered a range of linear density values $(3,6$, or 15 denier $)$ as well as fiber geometries (round, pentalobal, 4DG - shown in Figure 50). All samples had a basis weight of 200 gsm and an SVF of approximately 0.035 . 

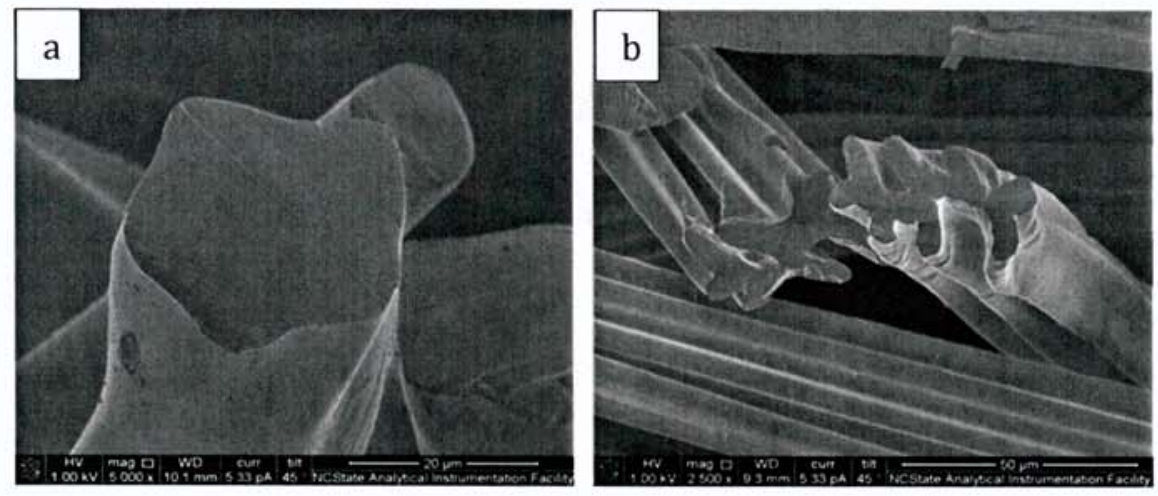

FIGURE 50: CROSS-SECTION OF PENTALOBAL (A) AND 4DG (B) FIBERS.

The double layer capacitance for some of these samples is shown in Figure 51.

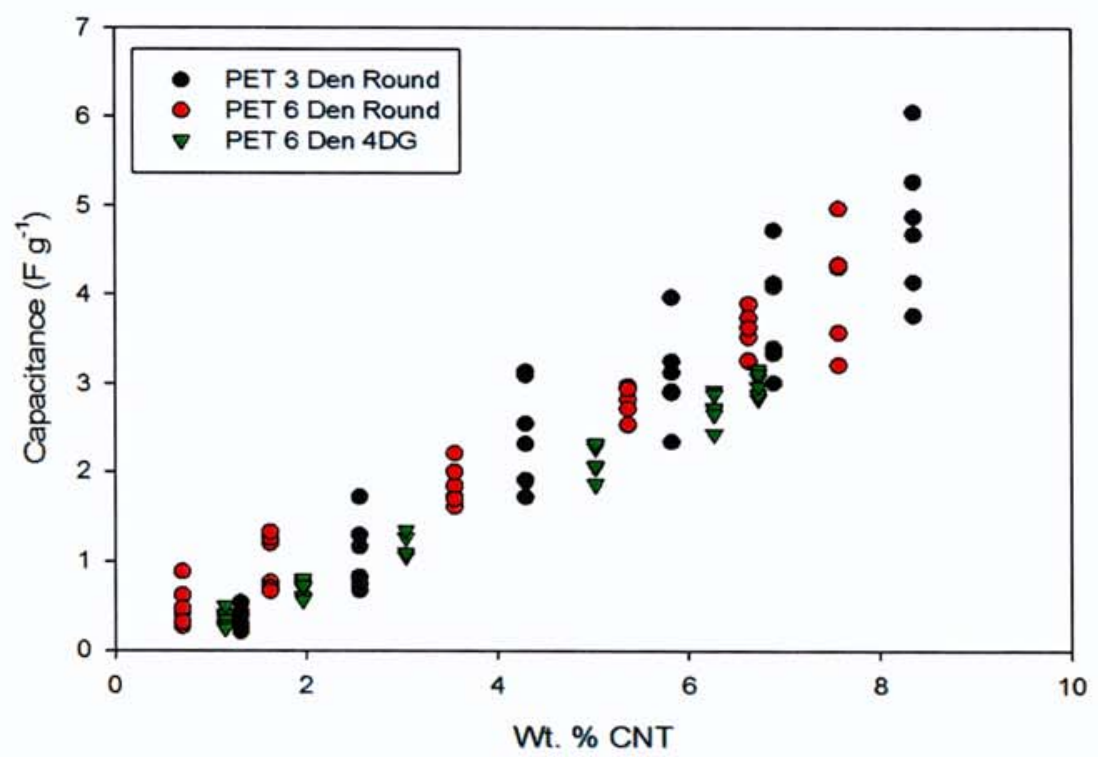

FIGURE 51: DOUBLE-LAYER CAPACITANCE FOR NEEDLEPUNCHED PET FIBERS OF VARIOUS GEOMETRIES.

Both of the round fibers shown had significant variability in measured capacitance, while the 4DG samples had very consistent performance. It may be that the high surface area of the 4DG fiber helps to average out any inhomogeneities present in the nonwoven. Having identified a good nonwoven material to use as a substrate, $\mathrm{MnO}_{2}$ was added to CNT coated nonwovens, and the specific capacitance, based on the mass of $\mathrm{MnO}_{2}$, was measured. The results are shown in Figure 52 . 


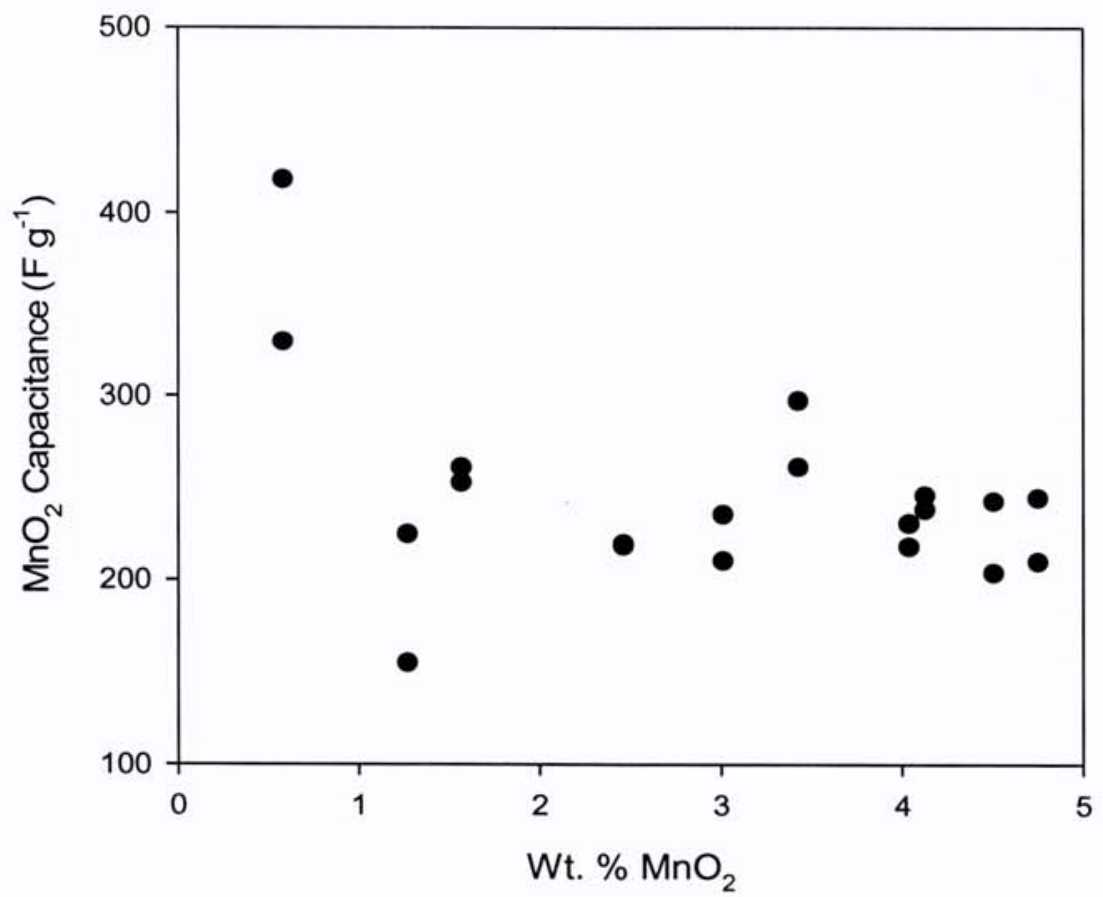

FIGURE 52: SPECIFIC PSEUDOCAPACITANCE FOR MNO2/CNT 4DG ELECTRODES WITH VARIOUS MNO2 LOADINGS.

At low loading values ( $<1$ wt. $\% \mathrm{MnO}_{2}$ ), measured capacitance begins to approach the values reported by Chen et al. However, specific capacitance rapidly decreases until plateauing near $220 \mathrm{~F}$ $\mathrm{g}^{-1}$. Such a plateau is unexpected, as increasing $\mathrm{MnO}_{2}$ loading means increasing the thickness of the pseudocapacitive layer, which should result in decreasing specific capacitance. When the electrode is examined after the application of $\mathrm{MnO}_{2}$, the coating is found to be extremely asymmetric, with the side facing the electrolyte having macroscopically visible $\mathrm{MnO}_{2}$, while the side in contact with the stainless steel backing has no visible $\mathrm{MnO}_{2}$. For deposition times greater than 20 minutes, a small amount of $\mathrm{MnO}_{2}$ can be observed on the backing side. As $\mathrm{MnO}_{2}$ has a low electrical conductivity, it seems that the formation of a thick layer of $\mathrm{MnO}_{2}$ on the electrolyte side lowers the rate at which $\mathrm{Mn}^{2+}$ is consumed by the electrodeposition process for the surface, allowing the formation of $\mathrm{MnO}_{2}$ farther into the nonwoven. Thus, the specific capacitance of the $\mathrm{MnO}_{2}$ is result of an average between thick layers of $\mathrm{MnO}_{2}$ (low specific capacitance) and thin layers of $\mathrm{MnO}_{2}$ (high specific capacitance), which results in the observed plateau in capacitance. 


\section{A. EFFECT OF SOLID VOLUME FRACTION}

Electrodes based on a high surface area nylon winged fiber were prepared and tested, with the results being shown in Figure 53. While the total capacitance of the electrode shows a roughly linear increase with $\mathrm{MnO}_{2}$ loading, the specific capacitance based on $\mathrm{MnO}_{2}$ mass has a very high 
degree of scatter. In an effort to better understand the reason for this scatter, SEM micrographs of the surfaces of the electrode material were collected (Figure 54). The active material, both CNT and $\mathrm{MnO}_{2}$, is found to collect on the surfaces of the nonwovens, with the interior of the material containing little if any of these materials.
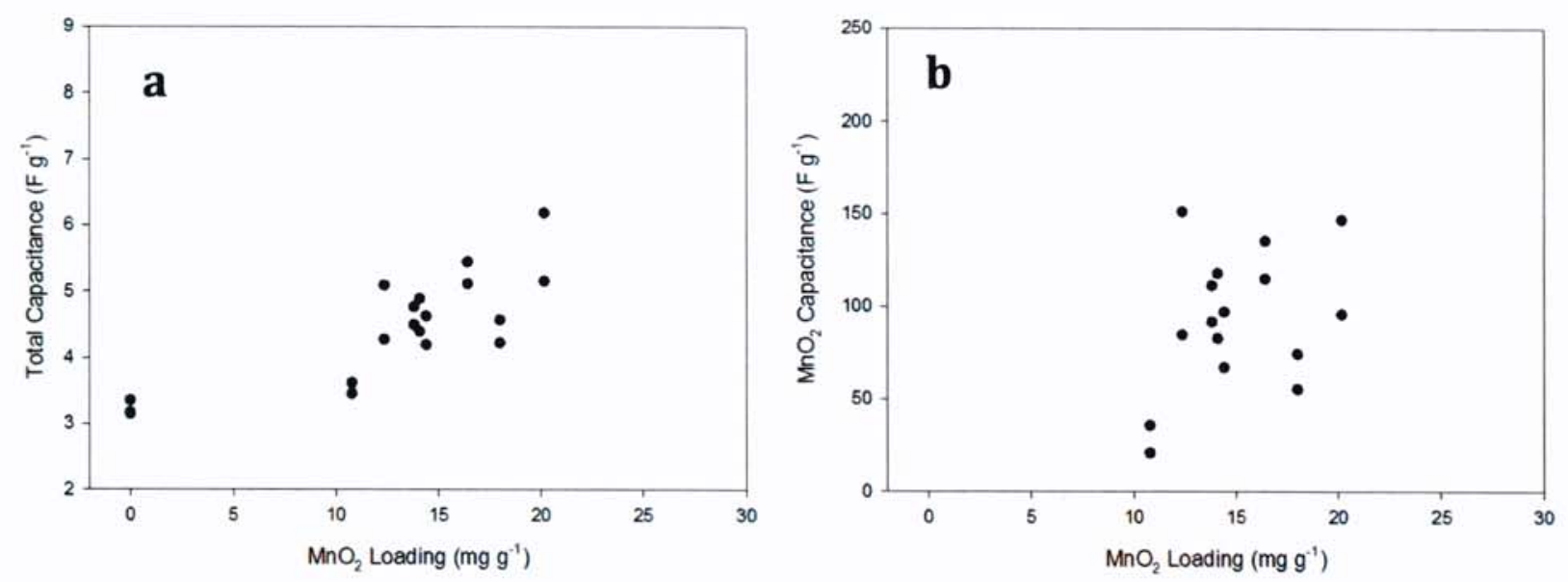

FIGURE 53: SPECIFIC CAPACITANCE BASED ON ELECTRODE MASS (A) AND MNO2 MASS (B) FOR PA6 WINGED-FIBER NONWOVEN ELECTRODES.

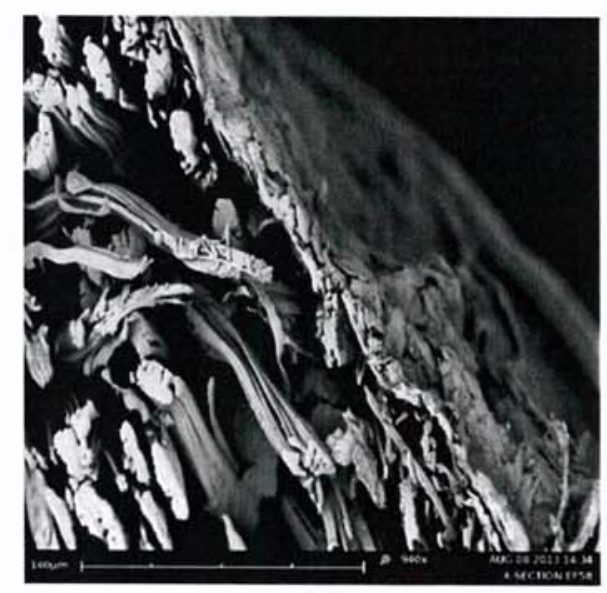

FIGURE 54: CROSS-SECTIONAL SEM OF PA6 WINGED FIBER WITH CNT AND MNO2.

A closer examination of a cross section of the material (Figure 55) shows that almost all of the $\mathrm{MnO}_{2}$ deposition occurs within the first $200 \mu \mathrm{m}$ of the sample. As these samples are approximately 500 $\mu \mathrm{m}$ in thickness, this indicates that the majority of the sample is not being used as an electrode. 

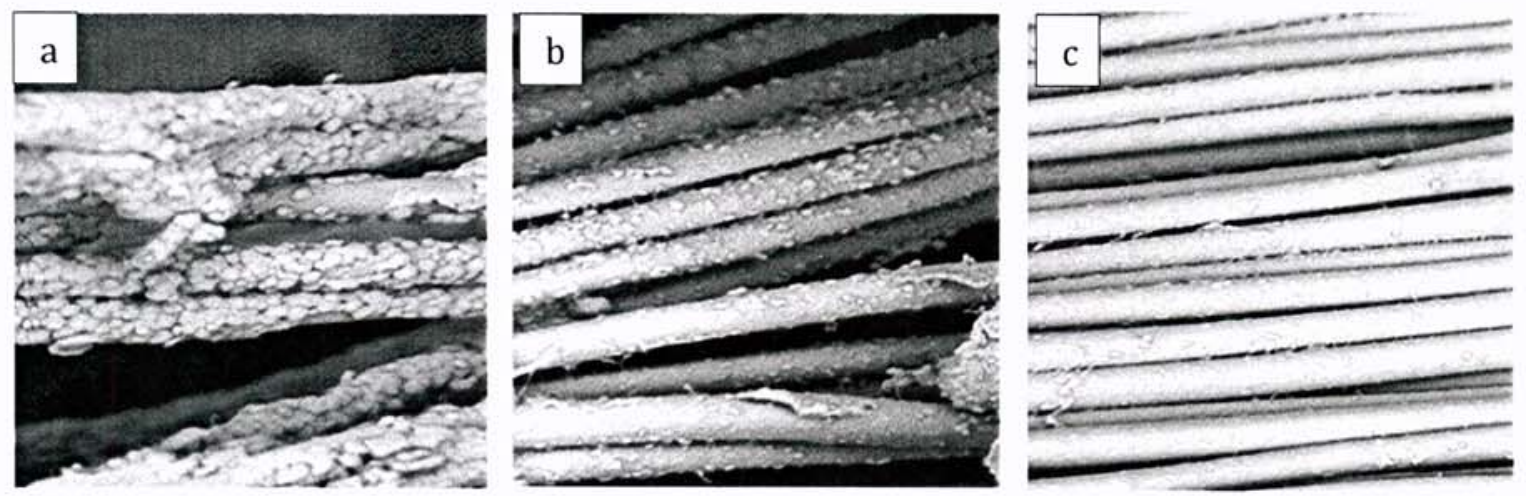

FIGURE 55: DEPTH PROFILE OF MNO2 DEPOSITED ON CNT-COATED PA6 I/S FIBERS, AT SURFACE (A), 100 MICRON (B) AND 200 MICRON (C).

Nonwoven materials can be excellent filters, and in this case, are filtering the CNT out of the ink, forming a cake on the surface of the material. This type of structure is characterized by a high solidvolume fraction (SVF). The volume occupied by fabric is composed of solid matter and air - SVF is that fraction composed of solid matter. It is typically calculated as:

$$
S V F=\frac{\rho_{\text {web }}}{\rho_{\text {fiber }}}=\frac{W}{L * \rho_{\text {fiber }}}
$$

Where $\rho_{w e b}$ is the density of the web, $W$ is the basis weight of the web, $\rho_{\text {fiber }}$ is the density of the polymer, and $L$ is the web thickness.

In an effort to circumvent such filtering behavior, the SVF of the high surface area materials were examined and compared to the polyurethane sponge used in the work by Chen et al. (Figure 56). The sponge is largely void space (SVF $=0.015$ ) whereas the selected nonwovens are significantly more solid having SVF values that range from 0.1 to 0.45 . To determine if using nonwovens with lower SVF values would result in a more dispersed CNT coating, electrodes were prepared with nonwovens having SVF values of approximately 0.03 . In addition, these nonwovens contained 10 wt. \% co-PET, which has a lower melting point than the bulk of the material. As such, intermediate SVF values could be obtained by modifying the fabrics via hot pressing. Another means to modifying the SVF of a nonwoven is to adjust how the material is consolidated. For this work, nylon $108 \mathrm{I} / \mathrm{S}$ fibers were hydroentangled with water jet spacing values of 600 or $4800 \mu \mathrm{m}$. SVF values for these materials are shown in Figure 57. 


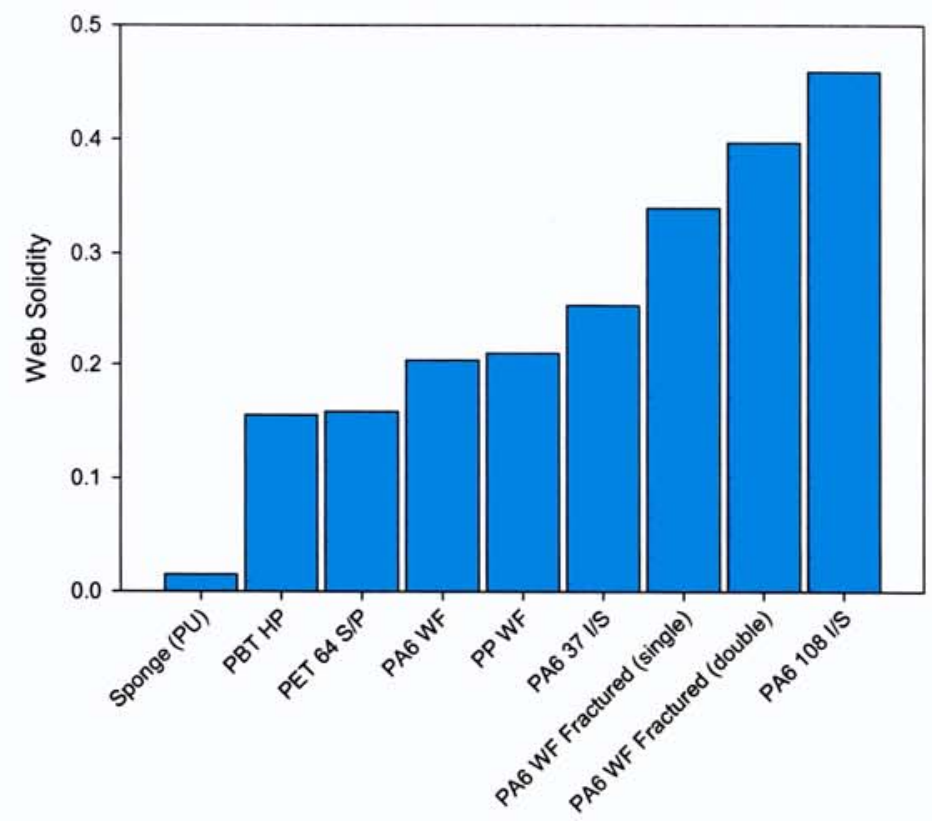

FIGURE 56: SVF FOR A RANGE OF SUBSTRATES, INCLUDING THE POLYURETHANE SPONGE.

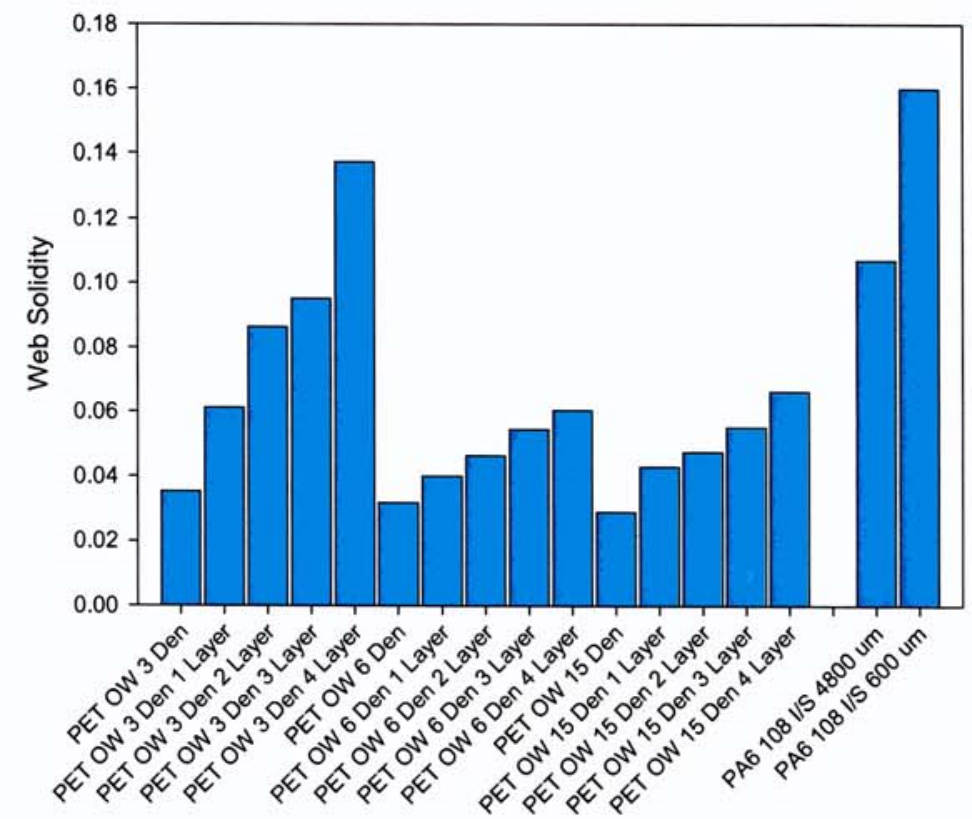

FIGURE 57: SVF VALUES FOR PET ROUND FIBERS AFTER HOT PRESSING AND FOR PA6 108 I/S WITH VARIABLE HYDROJET SPACING.

An examination of the surface of the PET 3 denier round nonwovens (Figure 58a) shows that CNT is even dispersed throughout the material and no evidence of the formation of a layer of buckypaper is observed. In contrast, when the material is compressed, buckypaper formation is observed for 
both the 0.086 and 0.138 SVF samples (Figure $58 \mathrm{~b}+\mathrm{c}$ ). The formation of buckypaper is confirmed through an examination of the cross section of these materials, with a thick layer being observed on the surface, while interior fibers are seen to have little, if any, CNT present on their surface.
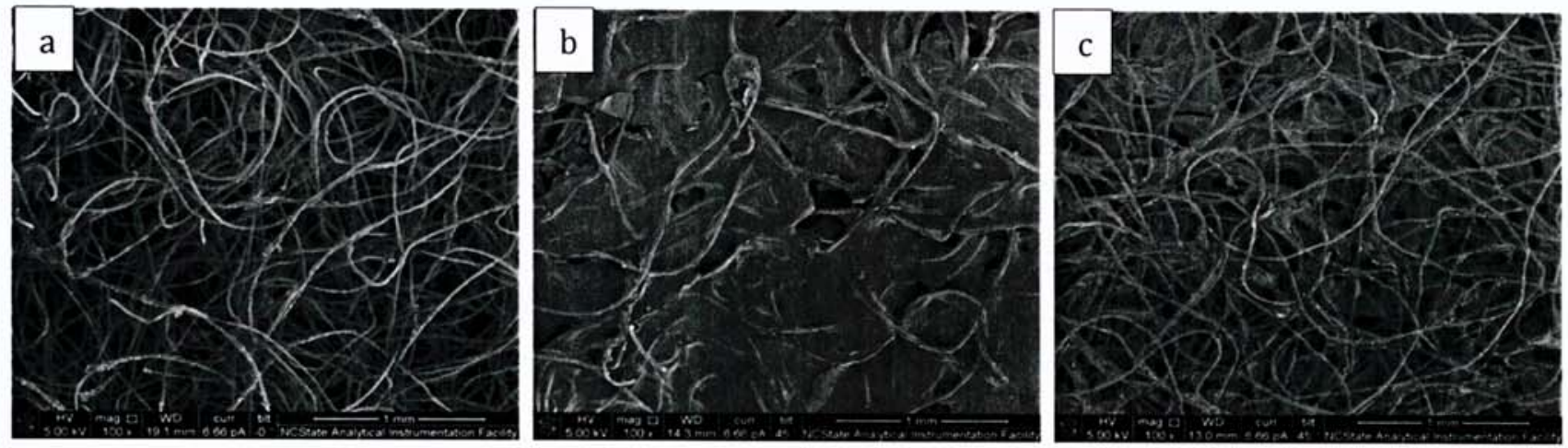

FIGURE 58: SEM OF THE SURFACE LAYER OF CNT/PET NEEDLEPUNCHED NONWOVENS WITH VARIOUS SVF VALUES.

\section{B. OTHER APPROACHES TO LIMIT CAKING}

Two additional approaches were explored to avoid caking while maintaining use of microfibers. The first approach, using a dilute ethanol/CNT dispersion $\left(0.2 \mathrm{mg} \mathrm{mL}^{-1}\right.$ instead of $\left.1.0 \mathrm{mg} \mathrm{mL}^{-1}\right)$, successfully eliminated the formation of a surface cake. Figure 59 illustrates the flexibility of the fabric treated in this way. However, this approach was deemed impractical due to the number of cycles required to reach the final CNT uptake. Ten cycles were needed to match the uptake obtained with one cycle of the standard method.
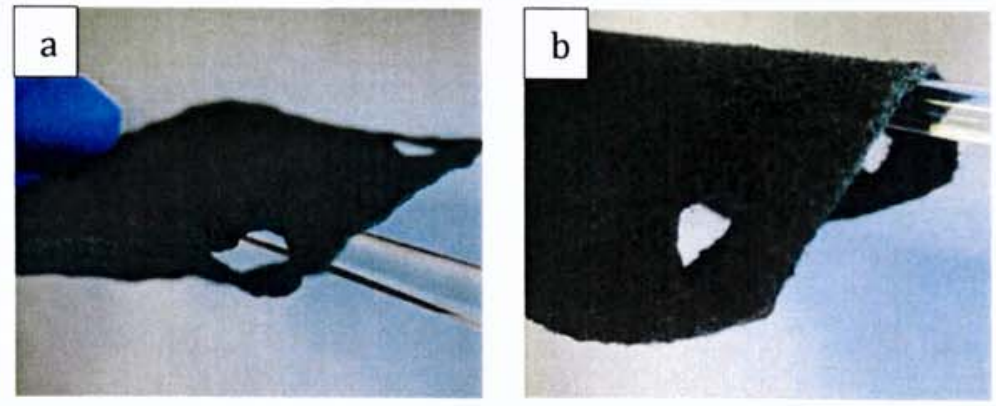

FIGURE 59: PA6 WINGED FIBER FABRICS COATED WITH THE STANDARD CNT DISPERSION (A) AND A DILUTE SOLUTION (B).

The second approach was to remove the cake after the final coating step. It was achieved by pressing strongly adhesive tape against the surface fibers and then pulling the tape off, essentially removing the entire surface. The force of delaminating the surface fiber layer from the inner fiber 
layer resulted in uneven thickness of the remaining inner fiber layer. In sum, the most effective approach was to simply using low-SVF fabrics with a more open structure. When there is more open space between fibers, the CNTs are less likely to bridge the fibers, and "buckypaper" is less likely to form.

\section{BASIS WEIGHT}

Deposition of $\mathrm{MnO}_{2}$ throughout the entire nonwoven is desirable, as it increases the amount of energy that can be stored in a given mass of the electrode. Although long deposition times $>20$ min) can accomplish this, such a lengthy process is problematic for use in any sort of large scale production. An alternative to longer deposition times is using thinner materials. As the fiber properties and SVF of the material are fixed, a thinner material is synonymous with a lower basis weight material. Nonwovens made from PET, PA6, and cotton fibers were needlepunched into 3 separate $50 \mathrm{gsm}$ webs. Following a coating process which applied approximately $\sim 11 \%$ wt. CNT to each sample, $\mathrm{MnO}_{2}$ was deposited for 5,10 , or 25 minutes. The longer deposition times are capable of producing high capacitance values, but with poor reliability. In general, 50 gsm webs exhibit low thickness uniformity. Thus, intermediate basis weights were explored.

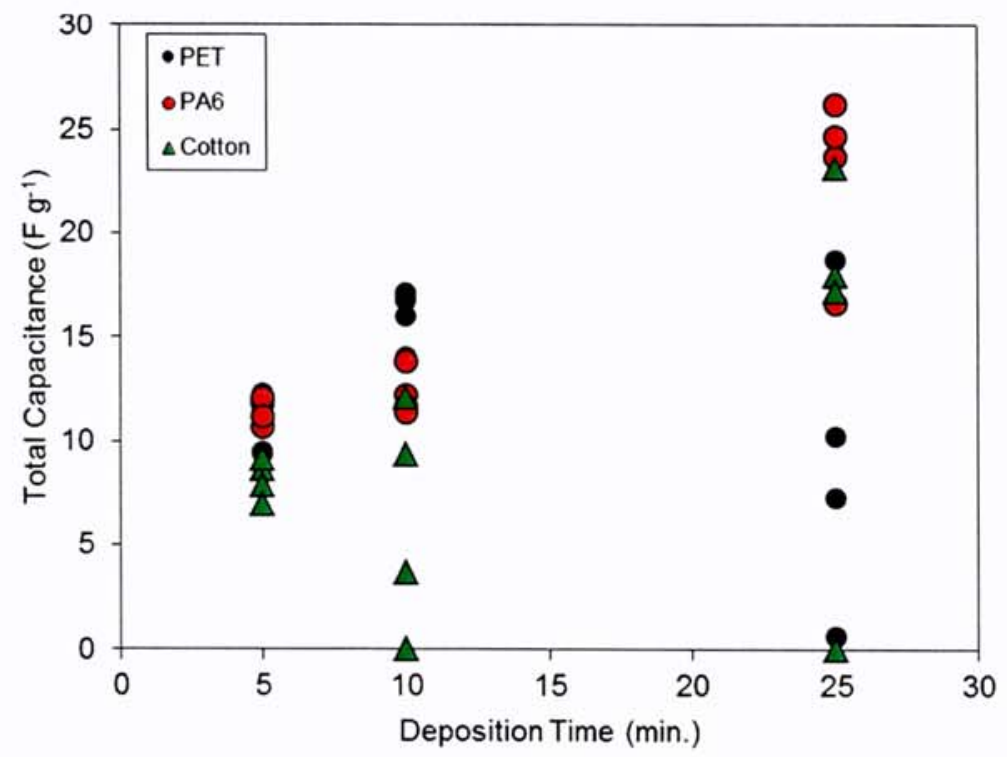

FIGURE 60: TOTAL CAPACITANCE VALUES FOR 50 GSM FABRICS WITH CNT/MNO2 DEPOSITED FOR VARIOUS DURATIONS.

Nonwovens containing $100 \mathrm{wt}$ \% PET 4DG 6 denier fibers (in contrast to the previous 200 gsm samples which contained 10 wt. \% co-PET) and having a weight basis of either 50 or 100 gsm were prepared. The web of the 50 gsm samples was sparse and the material lacked the mechanical 
durability required to survive the agitation used as part of the CNT coating process. The 100 gsm samples, in contrast, were well suited to the coating process. The $100 \mathrm{gsm}$ nonwoven was coated with a range of CNT loading values and the double layer capacitance was measured, with the results being shown in Figure 61. As with the 200 gsm samples, the 100 gsm samples offered very good reproducibility and the measured capacitance values were in line with those previously reported, indicated that the lack of co-PET does not have a significant effect on electrodes based on these materials.

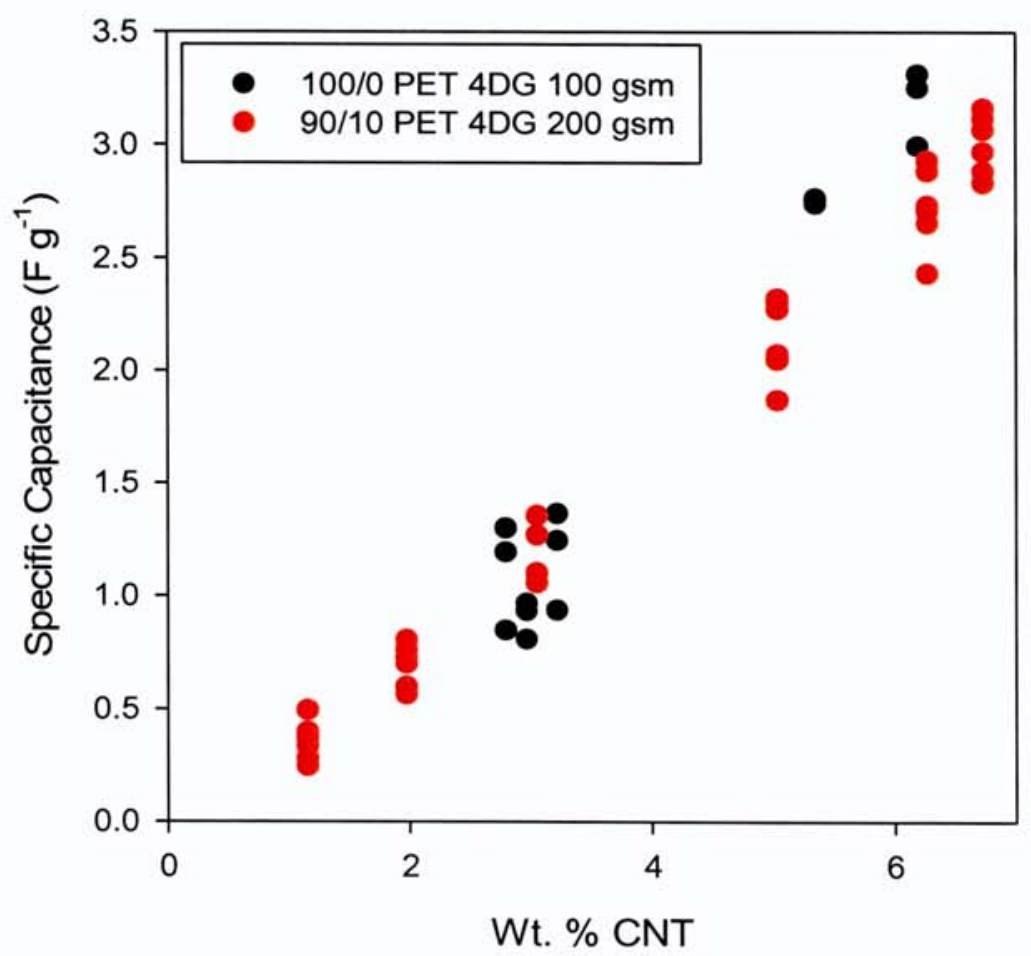

FIGURE 61: SPECIFIC DOUBLE-LAYER CAPACITANCE FOR 100GSM 4DG CNT-COATED ELECTRODES, SHOWN AGAINST RESULTS FOR 200GSM.

$\mathrm{MnO}_{2}$ was deposited onto the 100 gsm electrodes and their performance was quantified, with the results being compared to those of the $200 \mathrm{gsm}$ samples in Figure $62 \mathrm{a}$. When the same test conditions are applied, the $100 \mathrm{gsm}$ electrodes have specific capacitance values that are approximately half that of the 200 gsm samples. However, it is important to remember that cell testing was performed via constant current charge/discharge cycling, with the same discharge current $(500 \mu \mathrm{A})$ being applied to each cell. Given that the 100 gsm samples have less mass than the 200 gsm samples, at the same wt. $\% \mathrm{MnO}_{2}$, the 200 gsm samples have twice as much $\mathrm{MnO}_{2}$ present and thus higher total capacitance. Therefore, when the two materials are discharged using the same 
current, the 100 gsm samples are being drained at twice the rate of the 200 gsm samples. Given that pseudocapacitance is a kinetic process, the measured capacitance of $\mathrm{MnO}_{2}$ is highly dependent on the rate at which a device is charged/discharged. When the 100 gsm samples are tested using a slower discharge rate, the measured specific capacitance values correspond well with those previously obtained from the 200 gsm samples (Figure $62 \mathrm{~b}$ ).
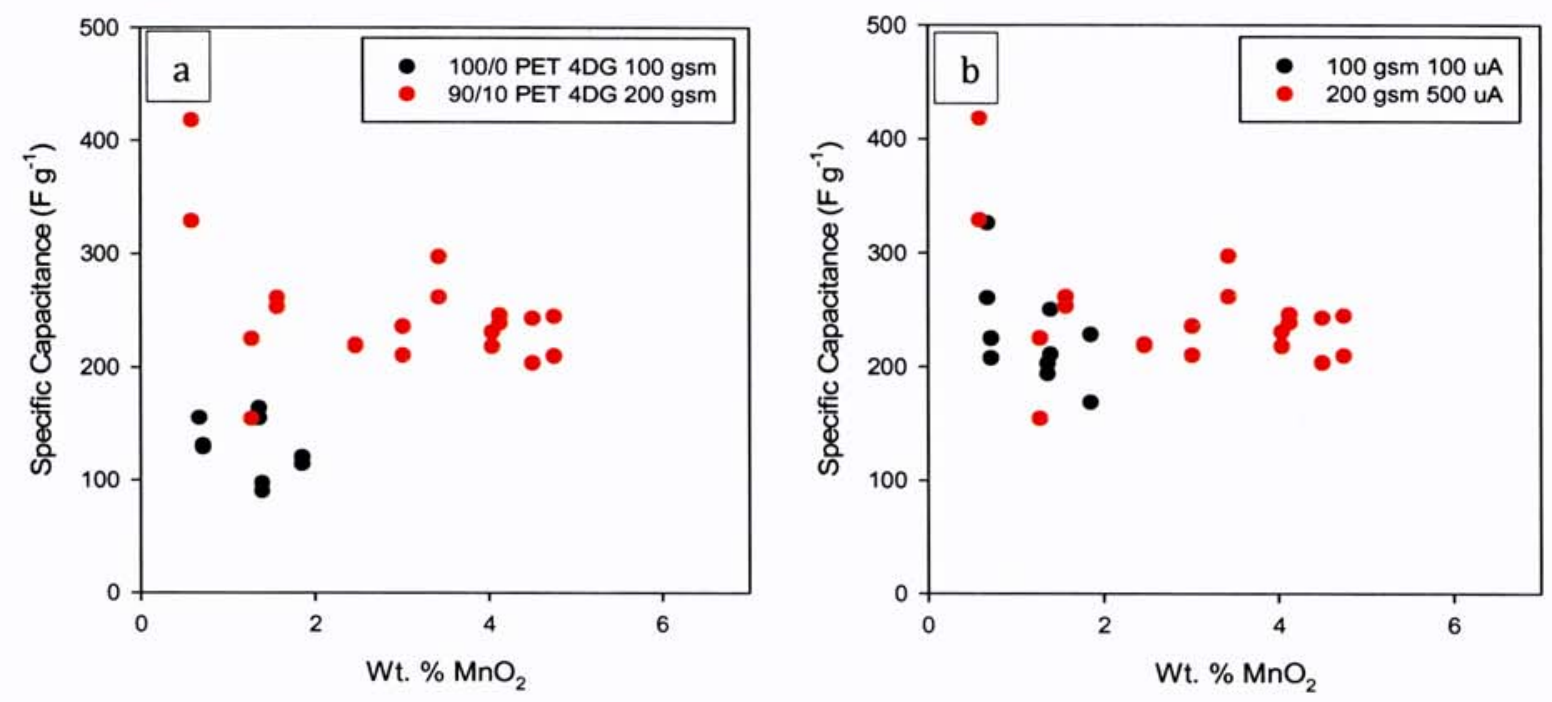

FIGURE 62: SPECIFIC PSEUDOCAPACITANCE OF 100 GSM ELECTRODES TESTED AT 0.5 MA (A) AND 0.1 MA(B), COMPARED TO 200GSM ELECTRODES (BOTH AT 0.5 MA). 
The initial proposal set a goal of delivering a nonwoven electrode with specific capacitance based on $\mathrm{MnO}_{2}$ mass of greater than $1000 \mathrm{~F} \mathrm{~g}^{-1}$. To obtain these values, an electrode must have a very thin layer of $\mathrm{MnO}_{2}$ and be cycled at a very slow rate. Chen et al. obtained their reported values of $1250 \mathrm{~F}$ $\mathrm{g}^{-1}$ at a $1 \mathrm{mV} \mathrm{s}^{-1}$ cycled rate, which corresponds to an approximately 17 minute discharge time [7]. While such restrictions can result in impressive numbers in the lab, they preclude the fabrication of a device that can meet any sort of realistic energy and power requirements.
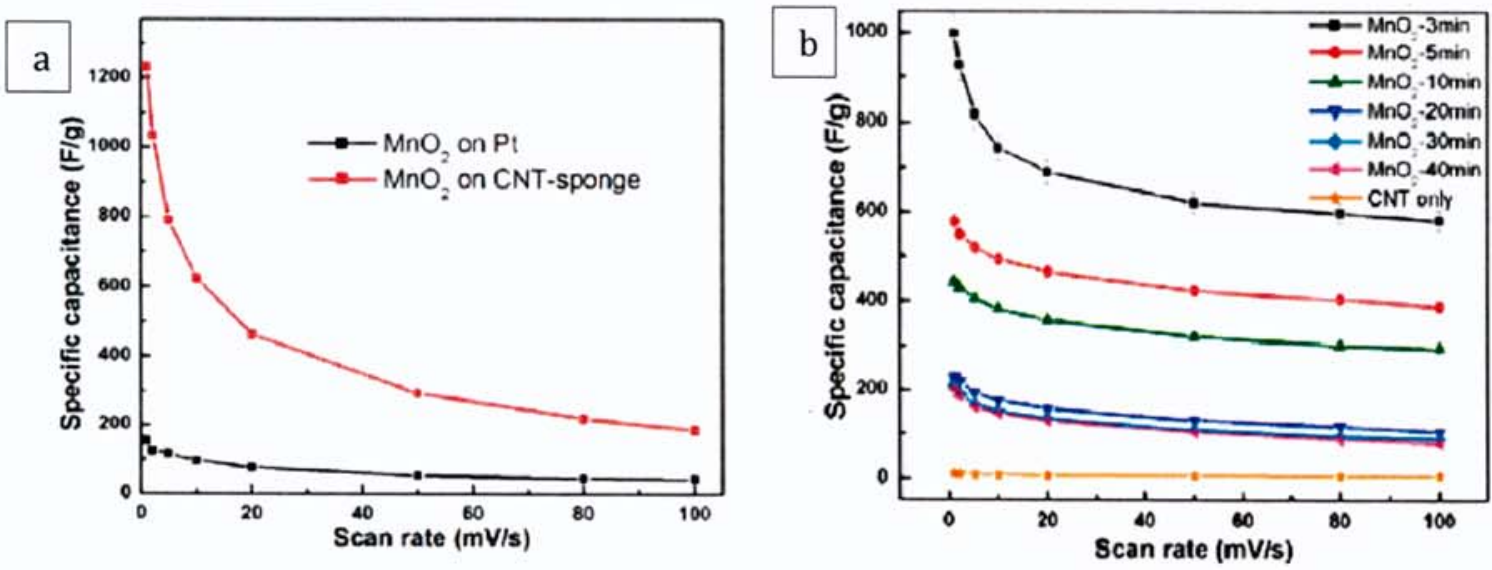

FIGURE 63: FROM CHEN, ET AL. (2011). SPECIFIC MNO2 CAPACITANCE AS A FUNCTION OF SCAN RATE FOR (A) MNO2 ON PLANAR ELECTRODE VS. SPONGE ELECTRODE, AND (B) MNO2 ON SPONGE ELECTRODE FOR A RANGE OF DEPOSITION TIMES.

Furthermore, there are several ambiguities surrounding the reported value of $1250 \mathrm{~F} \mathrm{~g}^{-1}$ [7]. Figure 63 contains two plots from the report, in which plot (a) displays a maximum value of $1250 \mathrm{~F} \mathrm{~g} \cdot{ }^{-1}$ at the slow scan rate of $1 \mathrm{mV} \mathrm{s}^{-1}$. The data in this plot is derived from a test of CNT-sponge with a 5 minute $\mathrm{MnO}_{2}$ deposition. However, plot (b) displays specific capacitance values for CNT-sponges with varying durations of $\mathrm{MnO}_{2}$ deposition, and it can be seen that the 5 minute deposition no longer reaches $1250 \mathrm{~F} \mathrm{~g}^{-1}$. At the same scan rate of $1 \mathrm{mV} \mathrm{s}^{-1}$, a maximum value of $\sim 600 \mathrm{~F} \mathrm{~g}^{-1}$ is displayed. The lack of clarity surrounding these values presents challenges to setting up test conditions that reproduce the results. However, as stated above, these results are likely not the most impactful measure of electrode performance.

During this study, in addition to determining the specific capacitance of an electrode based on $\mathrm{MnO}_{2}$ mass, the total capacitance (based on total mass) of an electrode was also calculated. These results, for the 200 gsm PET 4DG nonwoven substrate, are shown, along with the specific capacitance of $\mathrm{MnO}_{2}$, in Figure 64b. While increasing loading does result in a decrease in performance per unit of 
$\mathrm{MnO}_{2}$, the increase in the amount of $\mathrm{MnO}_{2}$ outweighs such a decrease. This results in an approximately linear increase in the total capacitance of the electrode. As the specific capacitance of $\mathrm{MnO}_{2}$ does not appear to change over the range of 2 to $5 \mathrm{wt}$. \%, maximizing total capacitance can be achieved by maximizing the amount of $\mathrm{MnO}_{2}$ present in the sample. However, achieving a wt. \% greater than 4 in a 200 gsm nonwoven requires deposition times greater than 15 minutes, which is not only prohibitively long for practical production, but also increases scatter.

Rather than deposit $\mathrm{MnO}_{2}$ for longer times, higher loading values can be obtained by using the same deposition times on a lower basis weight material. When a 100 gsm PET 4DG sample is coated with $\mathrm{MnO}_{2}$ for the same length of time as a $200 \mathrm{gsm}$ sample over twice the $\mathrm{MnO}_{2}$ is deposited. When the performance of these 100 gsm nonwovens is compared to the 200 gsm nonwovens, both specific capacitance based on $\mathrm{MnO}_{2}$ mass and the total capacitance of the electrode are comparable to the 200 gsm samples (Figure 64).
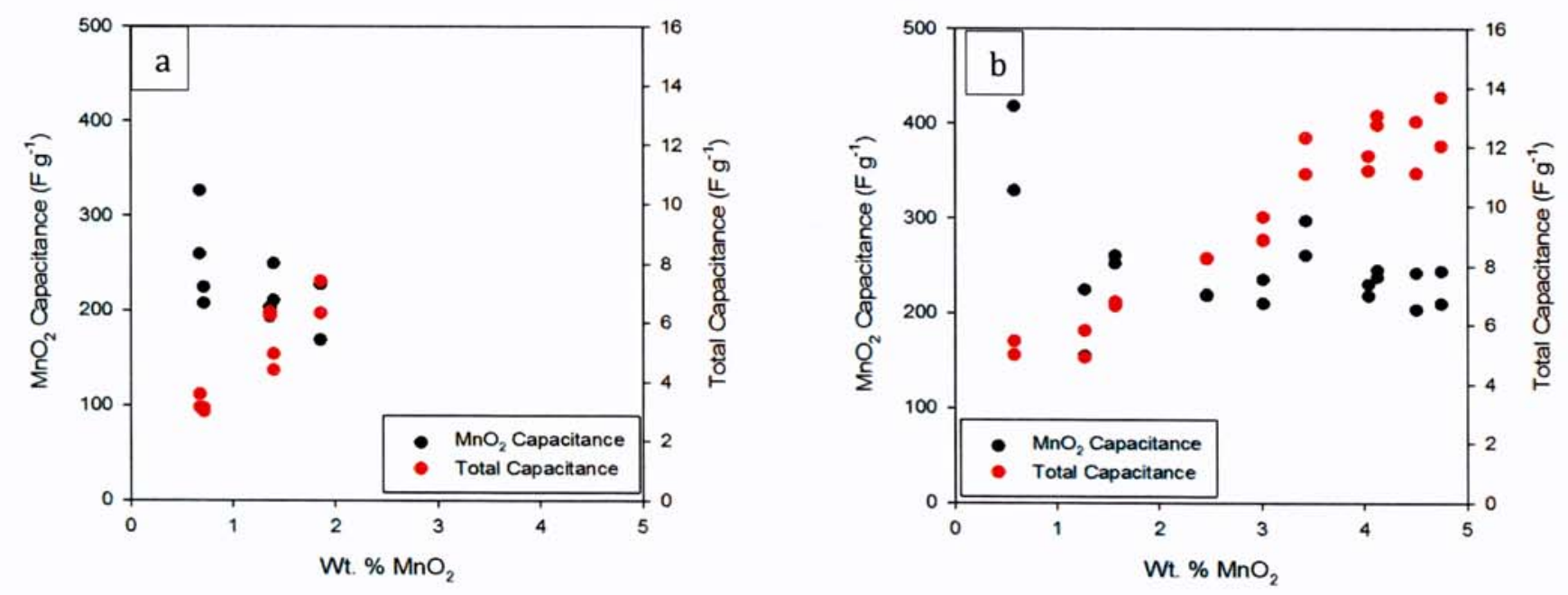

FIGURE 64: PSEUDOCAPACITANCE OF MNO2 AND TOTAL CAPACITANCE OF ELECTRODES FOR CNT/MNO2 ON 100GSM PET 4DG(A) AND 200GSM 4DG PET(B).

VIII. OTHER APPROACHES 


\section{A. CARBON FIBER}

A number of base materials other than CNT-coated polymer nonwovens have been considered for this work. Of particular interest are carbon fibers, as these materials are intrinsically highly conductive, removing the requirement of having a CNT coating step. The lack of CNT will also likely give more reproducible results, as little or no material should be lost during the coating or testing process. A varied group of nonwoven carbon fibers was collected (Table 3).

TABLE 3: SELECTION OF VARIOUS NONWOVEN CARBON FIBER FABRICS.

\begin{tabular}{|c|l|c|c|}
\hline \multicolumn{1}{|c|}{ Structure } & \multicolumn{1}{c|}{ Basis Wt. } & Thickness \\
$\begin{array}{c}\text { Fibre Glast - } \\
\text { CF Veil }\end{array}$ & $\begin{array}{l}\text { Wet laid ex-PAN fibers (1") with } \\
10 \% \text { polyester binder }\end{array}$ & $7 \mathrm{gsm}$ & $0.05 \mathrm{~mm}$ \\
$\begin{array}{c}\text { Hollingsworth } \\
\text { \& Vose - HV } \\
\mathbf{8 0 0 0 8 3 8}\end{array}$ & $\begin{array}{l}\text { Ex-PAN carbon fibers joined with } \\
\text { polyester binder, with nickel } \\
\text { coating }\end{array}$ & $47 \mathrm{gsm}$ & $0.27 \mathrm{~mm}$ \\
\cline { 2 - 4 } Ex-Kevlar & $\begin{array}{l}\text { Pre-needled Kevlar fibers } \\
\text { converted to 100\% carbon fiber } \\
\text { (40\% yield) }\end{array}$ & $200 \mathrm{gsm}$ & $2.00 \mathrm{~mm}$ \\
\hline $\begin{array}{c}\text { Hollingsworth } \\
\mathbf{8} \text { Vose - HV } \\
\mathbf{8 0 0 0 1 5 4}\end{array}$ & $\begin{array}{l}\text { Activated carbon fibers joined with } \\
\text { binder particles }\end{array}$ & $35 \mathrm{gsm}$ & $0.36 \mathrm{~mm}$ \\
\hline Fr 1410 & $\begin{array}{l}\text { Dry laid fibers, hydroentangled, } \\
\text { converted to 100\% carbon fiber }\end{array}$ & $65 \mathrm{gsm}$ & $0.15 \mathrm{~mm}$ \\
\hline
\end{tabular}

One material selected for testing was a carbon fiber veil, obtained from Fibre Glast, onto which $\mathrm{MnO}_{2}$ was deposited. SEM micrographs (Figure 65) show the fabric prior to and following $\mathrm{MnO}_{2}$ deposition. The $\mathrm{MnO}_{2}$ readily deposits onto the carbon, but does so in a platelet form rather than the flower form observed in previous work. Furthermore, despite the ease with which $\mathrm{MnO}_{2}$ is deposited, the low SSA of the carbon veil means that electrodes fabricated from this material have poor performance relative to previously studied nonwovens. 

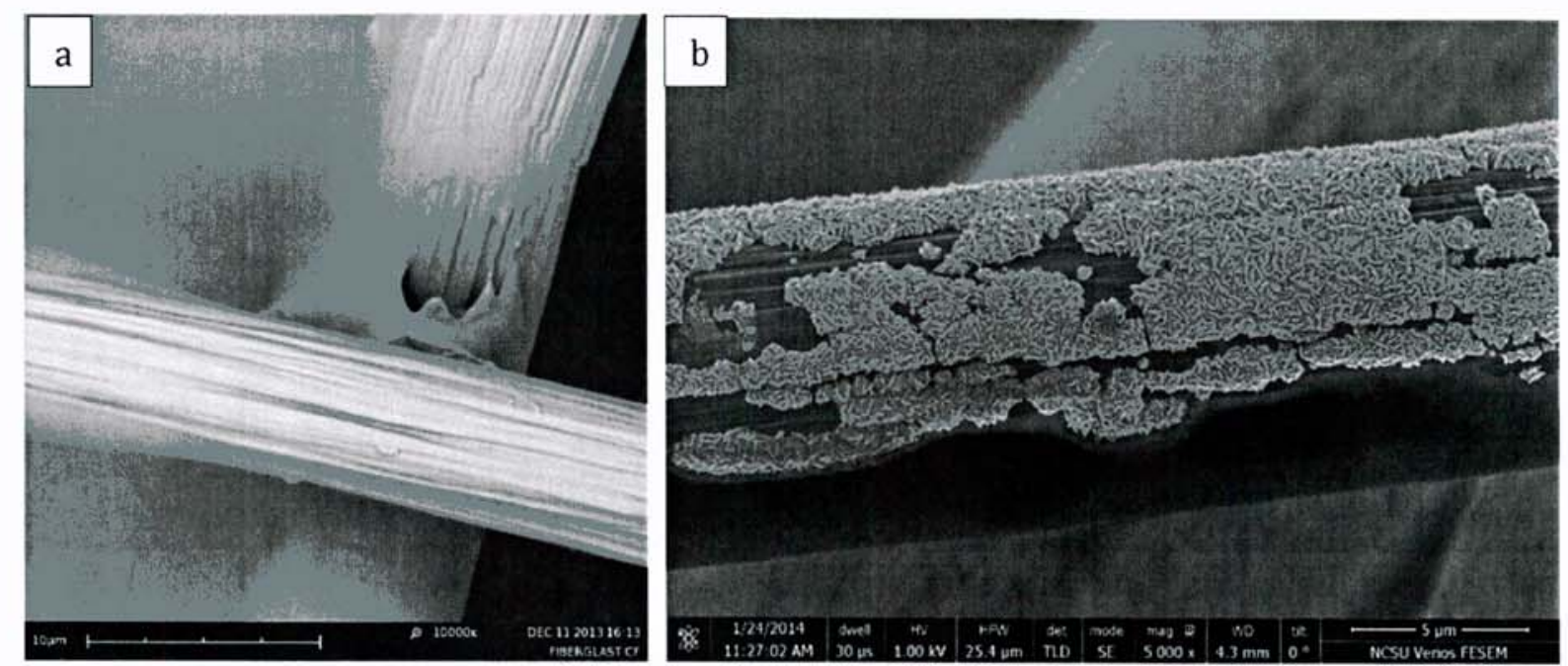

FIGURE 65: CARBON FIBER WETLAID AND HELD TOGETHER WITH BINDER. AS RECEIVED (A) AND FOLLOWING MNO2 DEPOSITION (B).

Carbon fiber was also produced in-house. A mat of needlepunched Kevlar staple fibers was converted to carbon fiber in a quartz tube furnace. After purging at $95^{\circ} \mathrm{C}$, the temperature was raised to $850^{\circ} \mathrm{C}$ and held for two hours under $\mathrm{N}_{2}$ flow. The resulting mat was highly conductive, but showed low double layer capacitance values $\left(\sim 0.30 \mathrm{~F} \mathrm{~g}^{-1}\right)$. Examination of the carbon fiber surface shows little textural change from the original Kevlar fiber (Figure 66). Without activation, the specific surface area remains low.
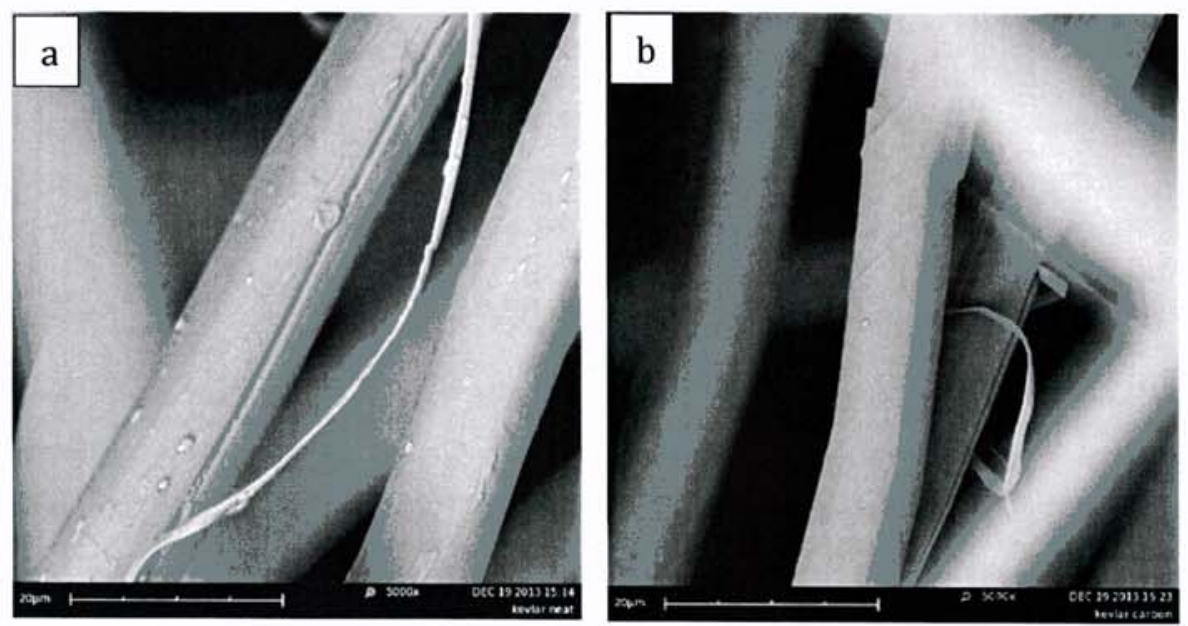

FIGURE 66: KEVLAR FIBER (5000 X) BEFORE CARBONIZATION (A) AND AFTER CARBONIZATION (B).

Investigation of HV 800154, an activated carbon fiber fabric produced by Hollingsworth \& Vose, confirmed the high specific capacitance ability of activated carbon (Figure 67). Among commercially available carbon fiber fabrics that were tested, the double-layer capacitance of HV 
800154 exceeded others by two orders of magnitude. Values range from $52-59 \mathrm{~F} \mathrm{~g}{ }^{-1}$, suggesting that activated carbon fiber is worth further study.

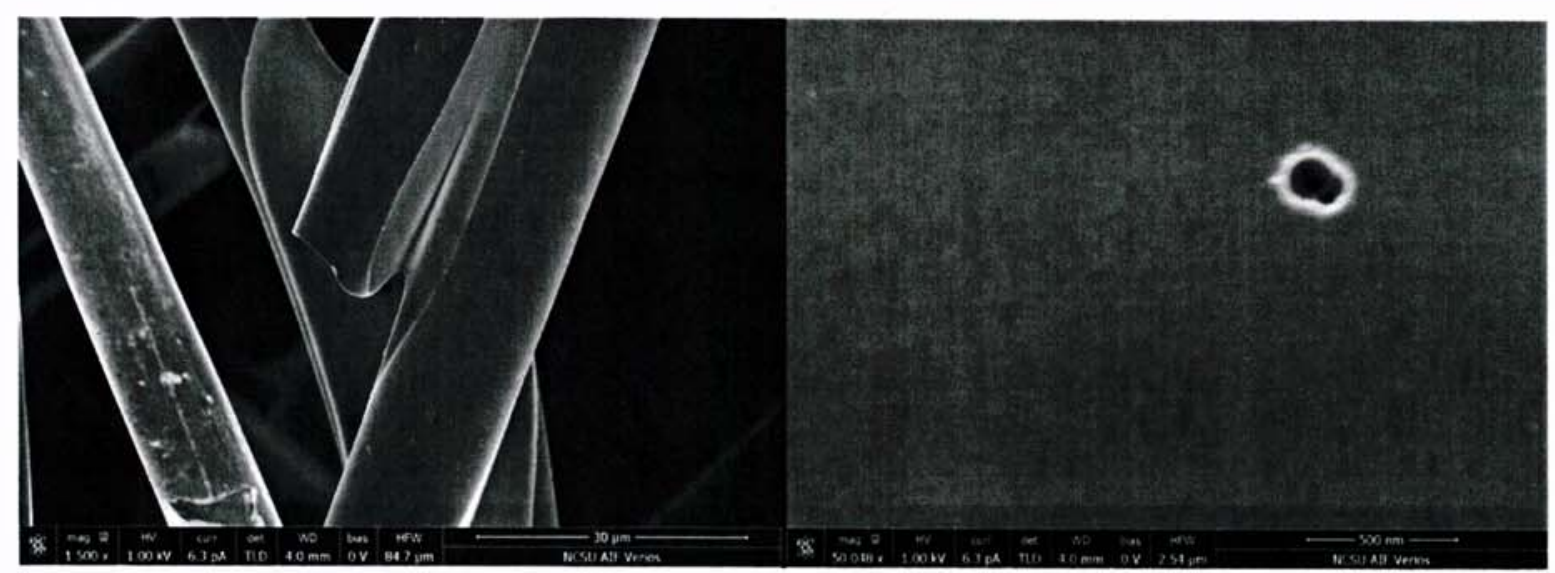

FIGURE 67: SEM OF HOLLINGSWORTH \& VOSE HV800154, ACTIVATED CARBON FIBER NONWOVEN, SHOWING SMOOTH FIBER SURFACE WITH SCATTERED ISOLATED PORE OPENINGS.

\section{B. GRAPHENE EXPERIMENTS}

As an alternative to using CNT as a conductive layer on electrodes substrates, graphene (from commercial inks produced by Vor-Ink) was used to coat PBT $37 \mathrm{I} / \mathrm{S}$. While the resistivity of graphene-coated nonwovens was higher than material loaded with an equivalent mass of CNT, potentiostatic deposition of $\mathrm{MnO}_{2}$ was still successful. SEM images of representative $\mathrm{MnO}_{2}$ /graphene/PBT samples are shown in Figure 68 (no $\mathrm{MnO}_{2}$ deposition), Figure 69 (5 min $\mathrm{MnO}_{2}$ deposition), and Figure 70 (10 $\mathrm{min} \mathrm{MnO}_{2}$ deposition).

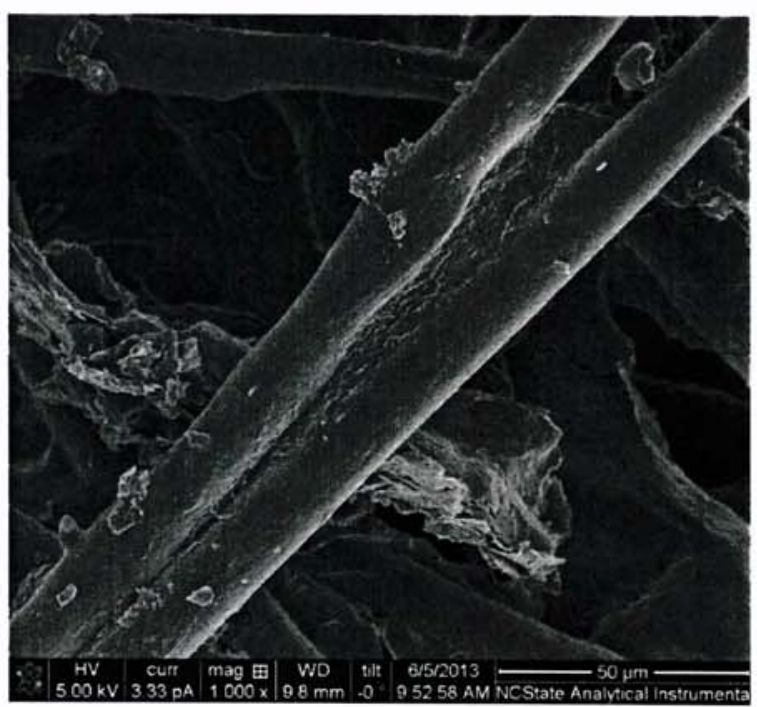

FIGURE 68: GRAPHENE-COATED PBT 37 I/S 


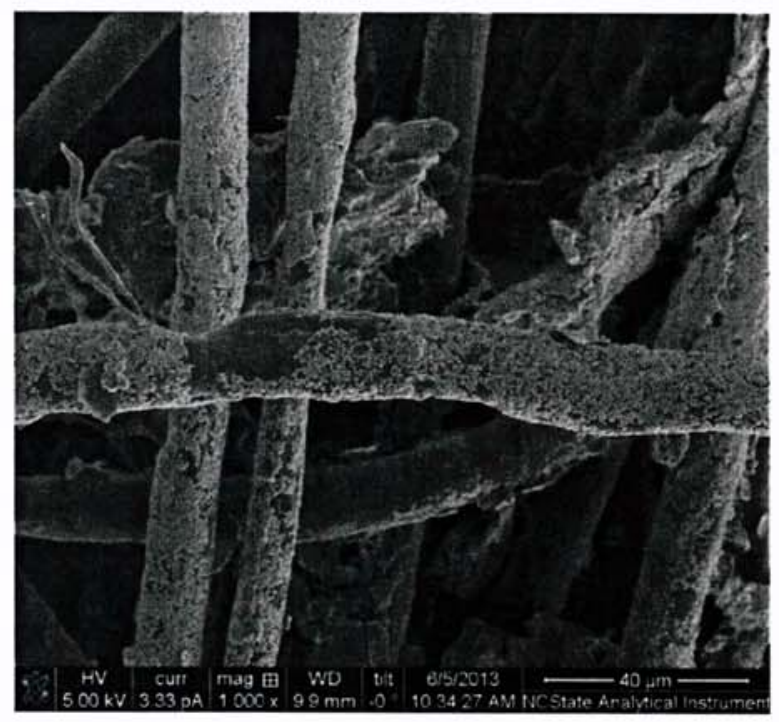

FIGURE 69: GRAPHENE-COATED PBT 37 I/S AFTER 5 MIN OF MNO2 DEPOSITION AT 1.2 V VS. AG/AGCL.

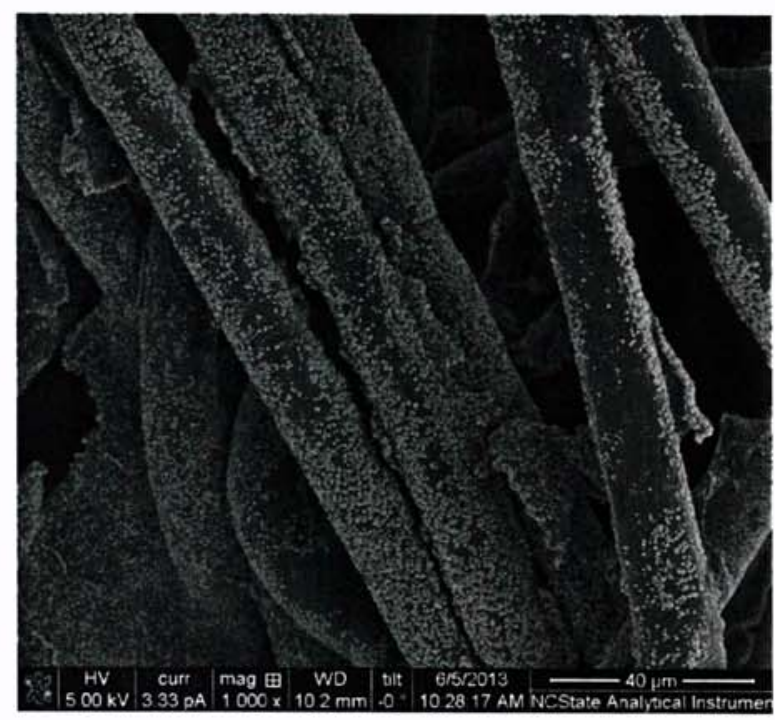

FIGURE 70: GRAPHENE-COATED PBT 37 I/S AFTER 10 MINUTES OF MNO2 DEPOSITION AT 1.2 V VS. AG/AGCL.

The graphene layer has a tendency to form sheets, as shown above. In addition, $\mathrm{MnO}_{2}$ deposition was quite uneven, which is likely due to the poor wetting behavior of the aqueous deposition solution with the hydrophobic graphene. This poor wetting behavior also resulted in poor performance (no capacitive behavior) when supercapacitors using these materials as electrodes and an aqueous electrolyte were assembled. Graphene-coated substrates may be an option with non-aqueous electrolytes, but the use of non-aqueous electrolyte may introduce compatibility issues with the polymer substrate. 
IX. CONCLUSIONS + RECOMMENDATIONS

\section{A. MODIFICATIONS TO REPORTED PROCEDURE}

Several key modifications to the procedure reported by Chen et al. were identified during this study. Suspending CNT in ethanol rather than water / SDBS led to a one-step coating cycle which eliminated the issues associated with the surfactant particles. Furthermore, the ethanol-based solution caused electrical resistance to drop at a faster rate over the course of five cycles as compared to the water-based solution. Applying the solution with the aid of a heated shake plate was also found to be more efficient than the simple dipping procedure. Per cycle, uptake of CNT mass more than doubled with the use of the shaker.

Improvements to the deposition process were also introduced. $\mathrm{MnO}_{2}$ deposition was carried out potentiostatically at a $1.0 \mathrm{~V}$ potential, rather than galvanostatically at $500 \mu \mathrm{A} \mathrm{cm}{ }^{2}$. This gave superior control over the potential and ensured that the appropriate energy was provided to activate the redox reaction and surface adsorption of $\mathrm{MnO}_{2}$. Poor current distribution produced an additional set of challenges for the electrodeposition process. The deposited species appeared to be distributed in a gradient, and was primarily concentrated near the water line. Also, the alligator clip connecting to the electrode exhibited corrosion, which was presumably causing side reactions. The use of a Teflon-enclosed steel backing electrode was able to resolve the issues of a strong current gradient from the top to the bottom of the specimen and the corrosion of the lead.

Chen et al. reported high specific $\mathrm{MnO}_{2}$ pseudocapacitance, but during this study, project metrics were reconsidered. Optimizing the specific capacitance of the electrode was determined to be of more practical impact than the $\mathrm{MnO}_{2}$ specific capacitance. Device design considers the entire electrode mass, so while $\mathrm{MnO}_{2}$ performance alone can be maximized by low deposition times, a different approach was taken to improve overall electrode performance. Total specific electrode capacitance was found to be in the range of $5-25 \mathrm{~F} \mathrm{~g}^{-1}$ for CNT / $\mathrm{MnO}_{2}$ coated nonwovens.

\section{B. EFFECTS OF FABRIC VARIABLES}

The aim of this research was to optimize a nonwoven for CNT coating and electrodepostition. Polymer type, fiber geometry, web formation and web consolidation were investigated. Most of the studied polymers have one of two attributes which enable them to bond with CNT: either aromatic ring(s) functional groups in the molecular backbone. Polypropylene lacks both of these features, 
thus explaining the poor adhesion of CNT onto PP fibers. In terms of polymers with good adhesion, cotton showed the highest uptake on a $\mathrm{g} \mathrm{g}^{-1}$ basis. However, $\mathrm{MnO}_{2}$ deposition was impeded by the swelling of the fiber. Therefore, PA6 and PET are the preferred polymer types.

Several consolidation methods were employed and their effects were explored. Structures which were carded, cross-lapped and pre-needled, then consolidated by hydroentangling, provided uniform webs with minimal SVF. Solid volume fraction (SVF) was found to be a significant parameter in depositing the active materials uniformly throughout the fabric thickness. The initial selection of high SSA nonwovens resisted uniform coating. The active materials were found to cake at the fabric surface. By producing a range of samples with various SVF values, it was found that low-SVF nonwovens did not cause CNT caking. Below a threshold SVF of 0.10 , uniform coating was attained.

Fiber geometry was found to impact the reliability of results. Among the fibers used in carded, cross-lapped samples - round, pentalobal and 4DG - 4DG produced the least amount of scatter in the capacitance values obtained. The high surface area of this deep-grooved fiber may help to compensate for any inhomogeneities in the nonwoven structure. Finally, the effect of basis weight was studied. Following the observation that $\mathrm{MnO}_{2}$ coating occurred first on the face of the fabric, it was hypothesized that reducing the thickness would limit the amount of fabric which escaped deposition. The lowest practical basis weight was found to be $\sim 100 \mathrm{gsm}$. Thinner samples were associated with poor web uniformity, leading to increased variability in the performance results.

\section{RECOMMENDATIONS AND FUTURE WORK}

The highest total specific capacitance for $\mathrm{CNT} / \mathrm{MnO}_{2}$ electrodes, measured on the basis of total mass, was found to be $25 \mathrm{~F} \mathrm{~g}^{-1}$. Various alternative approaches were explored, such as graphenecoated and carbon fiber nonwovens. Graphene has been reported to provide low electrical resistivity, but the hydrophobic nature of graphene coatings is incompatible with aqueous electrolytes. The majority of carbon fiber nonwovens used in this study had low SSA and were not promising as supercapacitor electrodes. Activated carbon fiber was found to exceed the performance of $\mathrm{CNT} / \mathrm{MnO}_{2}$ coated electrodes, solely as a result of EDLC effects.

Activated carbon is formed through either physical (thermal) or chemical treatment of char. When char is formed through carbonization, the bulk is composed of crystallite structures compiled with amorphous tar or inorganic remnants. Activation forces the impurities out, opening up crevices 
between the crystallites and resulting in micropores $(<2 \mathrm{~nm})$ throughout the carbon. Activated carbon granules are commonly utilized in supercapacitor electrodes, where they are held in place with a binder. The impressive performance of the activated carbon fiber observed in this study suggests a promising alternative to using granules / binder. Specific double layer capacitance was measured to be in excess of $50 \mathrm{~F} \mathrm{~g}^{-1}$ - more than double that of any obtained with the coating methods, and could provide the starting point for a new project. 


\begin{tabular}{|c|c|c|c|c|c|c|}
\hline Polymer type & $\begin{array}{l}\text { Fiber cross- } \\
\text { section }\end{array}$ & $\begin{array}{c}\text { Fiber } \\
\text { diameter } \\
(\mu \mathrm{m})\end{array}$ & Consolidation & $\begin{array}{c}\text { Basis } \\
\text { weight } \\
\text { (gsm) }\end{array}$ & $\begin{array}{l}\text { Thickness } \\
\text { (mm) }\end{array}$ & $\begin{array}{l}\text { SVF } \\
(\%)\end{array}$ \\
\hline \multicolumn{7}{|c|}{ Initial selection: high SSA nonwovens } \\
\hline PA6 & Winged & 30 & Hydroentangled & 100 & 0.43 & 20.4 \\
\hline PA6 & 37 Island & 2 & Hydroentangled & 48 & 0.15 & 25.4 \\
\hline PA6 & 108 Island & 1 & Hydroentangled & 100 & 0.21 & 45.9 \\
\hline PET & 64 Segment & 5 & Hydroentangled & 150 & 0.64 & 15.9 \\
\hline PBT & Round & 20 & Hydroentangled & 115 & 0.53 & 15.6 \\
\hline PP & Winged & 30 & Hydroentangled & 75 & 0.41 & 21.0 \\
\hline \multicolumn{7}{|c|}{ Low SVF: needlepunched nonwovens } \\
\hline PET/co-PET & Round & 3 den & Pre-Needled & 200 & 4.11 & 3.5 \\
\hline PET/co-PET & Round & 6 den & Pre-Needled & 200 & 4.56 & 3.2 \\
\hline PET/co-PET & Round & 15 den & Pre-Needled & 200 & 5.00 & 2.9 \\
\hline PET & Pentalobal & 6 den & Pre-Needled & 200 & 4.35 & 3.3 \\
\hline PET & 4DG & 6 den & Pre-Needled & 200 & 4.25 & 3.4 \\
\hline
\end{tabular}

Intermediate SVF: hydroentangled high SSA nonwovens with wide jet spacing

\begin{tabular}{|c|c|c|c|c|c|c|}
\hline PA6 & 108 Island & 1 & Hydro $(600 \mu \mathrm{m})$ & 85 & 0.47 & 1.6 \\
\hline PA6 & 108 Island & 1 & $\begin{array}{c}\text { Hydro }(4800 \\
\mu \mathrm{m})\end{array}$ & 88 & 0.72 & 1.1 \\
\hline
\end{tabular}

Intermediate SVF: needlepunched nonwovens compressed at different ratios

\begin{tabular}{|c|c|c|c|c|c|c|}
\hline PET/co-PET & Round & 3 den & Compressed (1) & 200 & 2.37 & 6.1 \\
\hline PET/co-PET & Round & 3 den & Compressed (2) & 200 & 1.86 & 6.6 \\
\hline PET/co-PET & Round & 3 den & Compressed (3) & 200 & 1.52 & 9.5 \\
\hline PET/co-PET & Round & 3 den & Compressed (4) & 200 & 1.05 & 13.6 \\
\hline
\end{tabular}




\begin{tabular}{|c|c|c|c|c|c|c|}
\hline PET/co-PET & Round & 6 den & Compressed (1) & 200 & 3.62 & 4.0 \\
\hline PET/co-PET & Round & 6 den & Compressed (2) & 200 & 3.13 & 4.6 \\
\hline PET/co-PET & Round & 6 den & Compressed (3) & 200 & 2.66 & 5.4 \\
\hline PET/co-PET & Round & 6 den & Compressed (4) & 200 & 2.40 & 6.0 \\
\hline PET/co-PET & Round & 15 den & Compressed (1) & 200 & 3.37 & 4.3 \\
\hline PET/co-PET & Round & 15 den & Compressed (2) & 200 & 3.05 & 4.8 \\
\hline PET/co-PET & Round & 15 den & Compressed (3) & 200 & 2.63 & 5.5 \\
\hline PET/co-PET & Round & 15 den & Compressed (4) & 200 & 2.19 & 6.6 \\
\hline
\end{tabular}

Low basis weight: low SVF nonwovens with $\sim 50$ gsm basis weight

\begin{tabular}{|c|c|c|c|c|c|c|}
\hline Cotton & Kidney & $\mathrm{x}$ & Pre-Needled & 51 & 1.44 & 2.3 \\
\hline PA6/co-PET & Round & 3 den & Pre-Needled & 80 & 2.05 & 3.3 \\
\hline PA6/co-PET & Round & 6 den & Pre-Needled & 64 & 0.79 & 3.0 \\
\hline PET/co-PET & Round & 1.5 den & Pre-Needled & 53 & 1.87 & 2.1 \\
\hline PET/co-PET & Round & 3 den & Pre-Needled & 33 & 1.81 & 1.3 \\
\hline PET/co-PET & Round & 6 den & Pre-Needled & 51 & 2.31 & 1.6 \\
\hline PET/co-PET & Pentalobal & 6 den & Pre-Needled & 64 & 2.63 & 1.8 \\
\hline
\end{tabular}

Good reproducibility: low SVF, moderate basis weight nonwovens

\begin{tabular}{|c|c|c|c|c|c|c|}
\hline PET & 4DG & 6 den & $\begin{array}{c}\text { Pre-Needled / } \\
\text { Hydroentangled }\end{array}$ & 100 & $\mathrm{x}$ & $\mathrm{x}$ \\
\hline PET & $4 \mathrm{DG}$ & 6 den & $\begin{array}{c}\text { Pre-Needled / } \\
\text { Hydroentangled }\end{array}$ & 50 & $\mathrm{x}$ & $\mathrm{x}$ \\
\hline
\end{tabular}


Figure 1: Capacitors, supercapacitors, batteries, fuel cells and fossil fuel energy sources shown on a Ragone plot (Winter, 2004). 5

Figure 2: Illustration of original Supercapacitor using lampblack, and PLacement of an electrochemical capacitor in as a backup power source (Becker, 1957; Kotz, 2000)..... 6

Figure 3: The capacitance performance for both carbon-based EDLC electrodes and pseudocapacitor electrodes. (Naoi, 2008).

Figure 4: Specific capacitance normalized by the mass of $\mathrm{MnO}_{2}$ for various deposition times (Chen, 2011)

Figure 5: Porous sponge electrode coated with $\mathrm{MnO}_{2}$ nanoparticles (Chen, 2011).................................. 8

Figure 6: Sponge following several dip-dry cycles (Chen, 2011).

Figure 7: (a) Surface area for round, 4DG, and winged fibers as a function of diameter, and (b)

Typical winged fiber shown in SEM..

Figure 8: Twin extruders aligned to spin a bicomponent fiber composed of two polymers.

Figure 9: Cross-sectional SEM of various microfibers: (a) Isalnds-in-the-Sea as-extruded, (b) washed winged fiber, (c) split segmented pie.

Figure 10: Schematic of an open spunbond process with a belt collector. .12

Figure 11: Carding machine for nonwoven web with two chute feeds.

Figure 12: The Cross-lapping unit folds a single web to increase thickness.

Figure 13: Illustration of a carded web being consolidated by water jets on a hydroentangling unit.

Figure 14: Schematic of the Hydroentangling unit at the Nonwovens Institute.

Figure 15: Two method of mechanical web consolidation: (a) Hydroentangling uses high-pressure water jets and (b) needlepunching uses barbed needles.

Figure 16: Cross-section of a needlepunched web showing the fibers pulled into the z-direction and interlocking (Krcma, 1971).

Figure 17: model of three main CNT forms: armchair (A), zigzag (B) and chiral (C)( Baughman, 2002).

Figure 18: Schematic representation of CNT "skin" wrapped around cotton yarns. $(\mathrm{Hu}, 2010)$..........17

Figure 19: Anionic acid red dye molecule used to disperse CNTs for use in illustrated coating process. (Zhang, 2012) 
Figure 20: Photographic images of dipping procedure and cloth surface taken through multiple cycles (Wang, 2011).

Figure 21: Diagram showing exhaustion dyeing conditions used for cotton fabric (a) and polyester fabric (b) (Goncalves, 2012).

Figure 22: (a) In graphite layers, the p-electron of each atom is delocalized over the entire network (Dresselhaus, 1988), (B) graphene sheet captured with TEM (Dato, 2010).

Figure 23: Schematic of process stages for coating polyester textile with graphene and $\mathrm{MnO} 2(\mathrm{Yu}$, 2011).

Figure 24: Cotton textile coated with (a) graphene oxide and (b) graphene, following reduction. (Liu, 2012)

Figure 25: Repeat unit of Novoloid fiber, which has a chemical formula of $\mathrm{C}_{63} \mathrm{H}_{55} \mathrm{O}_{11}$ (Lo, 2002).......23

Figure 26: Example of PAN carbonization, showing the main steps of stabilization and carbonization (Hearle, 2001).

Figure 27: Side-by-side comparison of the pore structures of granular activated carbon and activated carbon fiber (Kuraray).

Figure 28: (a) Schematic of an electrochemical cell with a carbon felt working electrode and (b) carbon felt electrode with (c) deposited reduced hexavalent chromium (Golub, 1989; Roberts, 2002)

Figure 29: Birnessite-type $\mathrm{MnO}_{2}$ in two variations: (A) So-called "Black" and (b) "Brown". (Cheney, 2008)

Figure 30: Schematic illustration of the charge-storage mechanism between two $\mathrm{MnO}_{2}$ electrodes (Pang, 2000).

Figure 31: (a) Guide to interpreting CV curve with various characteristic effects, and (b) Model of the rectangular $\mathrm{MnO}_{2} \mathrm{CV}$ Curve showing a sequence of reactions. (Frakowiack, 2004; Simon, 2008).

Figure 32: P3-SWNT with functional carboxylic acid groups (Carbon Solutions, Inc.). .30

Figure 33: Networked bundles of nanotubes pinning surfactant to the substrate. .30

Figure 34: Water-based CNT coating compared to ethanol-based coating, showing mass gain $(a+b)$ and resistance drop $(c+d)$ following the dip and wash parts of the cycle. .31

Figure 35: Method for applying CNT coating onto fiber surfaces. .32

Figure 36: Example of $\mathrm{MnO}_{2}$ gradient after electrodeposition onto a PU sponge. .33

Figure 37: Linear sweep voltammograms for CNT electrode (red) and gold electrode (blue) in MnSO4 solution. 
Figure 38: Electrodeposition setups for dip technique (a) and masked technique (b). 35

Figure 39: XPS results of $\mathrm{MnO}_{2}$ coated nonwovens.

Figure 40: $\mathrm{MnO}_{2}$ nanoparticles grown on CNT-coated fiber, shown at 10,000x, 50,000x, and 200,000x (left to right).

Figure 41: A typical $6.5 \mathrm{~cm}$ diameter sample tested along the edge cut to $3.5 \mathrm{~cm}$. 37

Figure 42: Resistance measured after each CNT coating cycle for four types of fabric 37

Figure 43: Specific capacitance based on mass loading of CNT for three low-SVF fabrics. 39

Figure 44: Specific double-layer capacitance for PA6 I/S fabric with 600 micron hydrojet spacing (closed) and 4800 micron spacing (open), with various levels of CNT mass loading..

Figure 45: From left to right - SEM of reported sponge (Chen, et al.), SEM of cellulose sponge, SEM of polyurethane sponge.

Figure 46: FT-IR spectra of sponge (blue line) and composite spectra of polyurethane foam (red line).

Figure 47: Repeat unit of polyethylene trephthalate (polyester) with an aromatic ring (left) and repeat unit of polypropylene polymer (right).

Figure 48: Specific Total capacitance of nonwovens from various polymers as a function of CNT loading. All have 7.5 minutes $\mathrm{MnO}_{2}$ deposition.

Figure 49: SEM images at $2000 \mathrm{x}$ showing $37 \mathrm{I} / \mathrm{S}$ fabric (a) before and (b) after PLA is washed away with $\mathrm{NaOH}$ solution.

Figure 50: Cross-section of Pentalobal (a) and 4DG (b) fibers.

Figure 51: Double-layer capacitance for needlepunched PET fibers of various geometries.

Figure 52: Specific pseudocapacitance for $\mathrm{MnO2} / \mathrm{CNT} 4 \mathrm{DG}$ electrodes with various $\mathrm{MnO}_{2}$ loadings.

Figure 53: Specific capacitance based on electrode mass (a) and $\mathrm{MnO}_{2}$ mass (b) for PA6 wingedfiber nonwoven electrodes.

Figure 54: Cross-sectional SEM of PA6 Winged Fiber with CNT and $\mathrm{MnO}_{2}$.

Figure 55: Depth Profile of $\mathrm{MnO}_{2}$ Deposited on CNT-coated PA6 I/S Fibers, at surface (a), 100 micron (b) and 200 micron (c)

Figure 56: SVF for a range of substrates, including the Polyurethane sponge.

Figure 57: SVF values for PET round fibers after hot pressing and for PA6 $108 \mathrm{I} / \mathrm{S}$ with variable hydrojet spacing. 
Figure 58: SEm of the surface layer of CNT/PET needlepunched nonwovens with various SVF values.

Figure 59: PA6 Winged Fiber fabrics coated with the standard CNT dispersion (a) and a dilute solution (b).

Figure 60: Total capacitance values for 50 gsm fabrics with $\mathrm{CNT} / \mathrm{MnO}_{2}$ deposited for various durations.

Figure 61: Specific double-layer capacitance for 100gsm 4DG CNT-coated electrodes, shown against results for $200 \mathrm{gsm}$.

Figure 62: Specific pseudocapacitance of 100 gsm electrodes tested at $0.5 \mathrm{~mA}$ (a) and $0.1 \mathrm{~mA}(\mathrm{~b})$, compared to $200 \mathrm{gsm}$ electrodes (both at $0.5 \mathrm{~mA}$ ).

Figure 63: From Chen, et al. (2011). Specific $\mathrm{MnO}_{2}$ capacitance as a function of scan rate for (a) $\mathrm{MnO}_{2}$ on planar electrode vs. sponge electrode, and (b) $\mathrm{MnO} 2$ on sponge electrode for a range of deposition times.

Figure 64: Pseudocapacitance of $\mathrm{MnO}_{2}$ and Total capacitance of electrodes for $\mathrm{CNT} / \mathrm{MnO}_{2}$ on 100gsm PET 4DG(a) and 200gsm 4DG PET(b).

Figure 65: Carbon fiber wetlaid and held together with binder. AS received (a) and following $\mathrm{MnO}_{2}$ deposition (b).

Figure 66: Kevlar fiber (5000 x) before carbonization (a) and after carbonization (b).

Figure 67: SEM of Hollingsworth \& Vose HV800154, activated carbon fiber nonwoven, showing smooth fiber surface with scattered isolated pore openings.

Figure 68: Graphene-coated PBT 37 I/S 60

Figure 69: Graphene-coated PBT $37 \mathrm{I} / \mathrm{S}$ after 5 min of MnO2 deposition at $1.2 \mathrm{~V}$ vs. $\mathrm{Ag} / \mathrm{AgCl}$.

Figure 70: Graphene-coated PBT $37 \mathrm{I} / \mathrm{S}$ after 10 minutes of MnO2 deposition at $1.2 \mathrm{~V}$ vs. Ag/AgCl.61 
[1] M. Winter and R. J. Brodd, "What Are Batteries, Fuel Cells, and Supercapacitors?," Chem. Rev., vol. 104, no. 10, pp. 4245-4270, Oct. 2004.

[2] J. O. Bockris, Modern electrochemistry, 2nd ed. New York: Plenum Press, 1998.

[3] “supercapacitor 'energy density' - Google Scholar.’[Online]. Available: http://scholar.google.com.prox.lib.ncsu.edu/scholar?as_q=supercapacitor\&as_epq=energy+ density\&as_oq $=\&$ as_eq $=\&$ as_occt $=$ any\&as_sauthors $=\&$ as_publication $=\&$ as_ylo $=2003 \&$ as 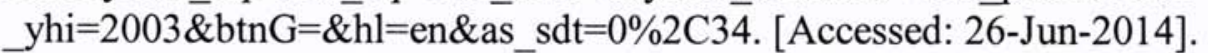

[4] B. E. Conway, "Transition from 'Supercapacitor' to 'Battery' Behavior in Electrochemical Energy Storage,” J. Electrochem. Soc., vol. 138, no. 6, p. 1539, 1991.

[5] A. M. Chockla, J. T. Harris, V. A. Akhavan, T. D. Bogart, V. C. Holmberg, C. Steinhagen, C. B. Mullins, K. J. Stevenson, and B. A. Korgel, "Silicon Nanowire Fabric as a Lithium Ion Battery Electrode Material,” J. Am. Chem. Soc., vol. 133, no. 51, pp. 20914-20921, Dec. 2011.

[6] W. Liu, X. Yan, J. Lang, C. Peng, and Q. Xue, "Flexible and conductive nanocomposite electrode based on graphene sheets and cotton cloth for supercapacitor," J. Mater. Chem., vol. 22, no. 33, p. 17245, 2012.

[7] W. Chen, R. B. Rakhi, L. Hu, X. Xie, Y. Cui, and H. N. Alshareef, "High-Performance Nanostructured Supercapacitors on a Sponge," Nano Lett., vol. 11, no. 12, pp. 5165-5172, Dec. 2011.

[8] A. J. Bard, Electrochemical methods: fundamentals and applications, 2nd ed. New York: Wiley, 2001.

[9] R. Kötz and M. Carlen, "Principles and applications of electrochemical capacitors," Electrochimica Acta, vol. 45, no. 15-16, pp. 2483-2498, May 2000.

[10] H. L. Becker, "Low Voltage Electrolytic Capacitor,” 2800616, 13-Jul-1957.

[11] P. Simon and Y. Gogotsi, "Materials for electrochemical capacitors," Nat. Mater., vol. 7, no. 11, pp. 845-854, Nov. 2008.

[12] US Department of Energy, "Basic Research Needs for Electrical Energy Storage," US Department of Energy, Jul. 2007.

[13] S. Sarangapani, "Materials for Electrochemical Capacitors," J. Electrochem. Soc., vol. 143, no. 11, p. 3791, 1996.

[14] B. Yue, C. Wang, X. Ding, and G. G. Wallace, "Polypyrrole coated nylon lycra fabric as stretchable electrode for supercapacitor applications," Electrochimica Acta, vol. 68, pp. 1824, Apr. 2012.

[15] H. Y. Lee and J. B. Goodenough, "Supercapacitor Behavior with KCl Electrolyte," J. Solid State Chem., vol. 144, no. 1, pp. 220-223, Apr. 1999.

[16] W. Wei, X. Cui, W. Chen, and D. G. Ivey, "Manganese oxide-based materials as electrochemical supercapacitor electrodes," Chem. Soc. Rev., vol. 40, no. 3, p. 1697, 2011.

[17] M. Toupin, T. Brousse, and D. Bélanger, "Charge Storage Mechanism of $\mathrm{MnO}_{2}$ Electrode Used in Aqueous Electrochemical Capacitor,” Chem. Mater., vol. 16, no. 16, pp. 3184 3190, Aug. 2004.

[18] L. Hu, M. Pasta, F. L. Mantia, L. Cui, S. Jeong, H. D. Deshazer, J. W. Choi, S. M. Han, and Y. Cui, "Stretchable, Porous, and Conductive Energy Textiles," Nano Lett., vol. 10, no. 2, pp. 708-714, Feb. 2010. 
[19] R. H. Baughman, A. A. Zakhidov, and W. A. de Heer, "Carbon Nanotubes--the Route Toward Applications," Science, vol. 297, no. 5582, pp. 787-792, Aug. 2002.

[20] K. Evanoff, J. Benson, M. Schauer, I. Kovalenko, D. Lashmore, W. J. Ready, and G. Yushin, "Ultra Strong Silicon-Coated Carbon Nanotube Nonwoven Fabric as a Multifunctional Lithium-Ion Battery Anode," ACS Nano, vol. 6, no. 11, pp. 9837-9845, Nov. 2012.

[21] X. Cai, M. Peng, X. Yu, Y. Fu, and D. Zou, "Flexible planar/fiber-architectured supercapacitors for wearable energy storage,” J. Mater. Chem. C, 2014.

[22] D. S. Hecht, L. Hu, and G. Grüner, "Electronic properties of carbon nanotube/fabric composites," Curr. Appl. Phys., vol. 7, no. 1, pp. 60-63, Jan. 2007.

[23] G. Yu, L. Hu, N. Liu, H. Wang, M. Vosgueritchian, Y. Yang, Y. Cui, and Z. Bao, "Enhancing the Supercapacitor Performance of Graphene/ $\mathrm{MnO}_{2}$ Nanostructured Electrodes by Conductive Wrapping," Nano Lett., vol. 11, no. 10, pp. 4438-4442, Oct. 2011.

[24] M. Kaempgen, C. K. Chan, J. Ma, Y. Cui, and G. Gruner, "Printable Thin Film Supercapacitors Using Single-Walled Carbon Nanotubes,” Nano Lett., vol. 9, no. 5, pp. 1872-1876, May 2009.

[25] K. Jost, D. Stenger, C. R. Perez, J. K. McDonough, K. Lian, Y. Gogotsi, and G. Dion, "Knitted and screen printed carbon-fiber supercapacitors for applications in wearable electronics," Energy Environ. Sci., vol. 6, no. 9, p. 2698, 2013.

[26] "Cloud 9 Dream Fleece, 45 in x 10 yds," McCall's Patterns. [Online]. Available: http://mccallpattern.mccall.com/cloud-9-dream-fleece--45-in-x-10-yds-products-14213.php. [Accessed: 05-Dec-2013].

[27] L. Hu, W. Chen, X. Xie, N. Liu, Y. Yang, H. Wu, Y. Yao, M. Pasta, H. N. Alshareef, and Y. Cui, "Symmetrical $\mathrm{MnO}_{2}$-Carbon Nanotube-Textile Nanostructures for Wearable Pseudocapacitors with High Mass Loading," ACS Nano, vol. 5, no. 11, pp. 8904-8913, Nov. 2011.

[28] W. Zhang, Y. Y. Tan, C. Wu, and S. R. P. Silva, "Self-assembly of single walled carbon nanotubes onto cotton to make conductive yarn," Particuology, vol. 10, no. 4, pp. 517-521, Aug. 2012.

[29] K. Wang, P. Zhao, X. Zhou, H. Wu, and Z. Wei, "Flexible supercapacitors based on clothsupported electrodes of conducting polymer nanowire array/SWCNT composites," $J$. Mater. Chem., vol. 21, no. 41, p. 16373, 2011.

[30] M. in het Panhuis, J. Wu, S. A. Ashraf, and G. G. Wallace, "Conducting textiles from single-walled carbon nanotubes," Synth. Met., vol. 157, no. 8-9, pp. 358-362, May 2007.

[31] A. G. Gonçalves, B. Jarrais, C. Pereira, J. Morgado, C. Freire, and M. F. R. Pereira, "Functionalization of textiles with multi-walled carbon nanotubes by a novel dyeing-like process,” J. Mater. Sci., vol. 47, no. 13, pp. 5263-5275, Mar. 2012.

[32] M. Pasta, L. Hu, F. La Mantia, and Y. Cui, "Electrodeposited gold nanoparticles on carbon nanotube-textile: Anode material for glucose alkaline fuel cells," Electrochem. Commun., vol. 19, pp. 81-84, Jun. 2012.

[33] C. Lam, J. T. James, R. McCluskey, S. Arepalli, and R. L. Hunter, “A Review of Carbon Nanotube Toxicity and Assessment of Potential Occupational and Environmental Health Risks," Crit. Rev. Toxicol., vol. 36, no. 3, pp. 189-217, Jan. 2006.

[34] B. Karaguzel, "Printing Conductive Inks on Nonwovens: Challenges and Opportunities," PhD Dissertation, North Carolina State University, Raleigh, 2006. 
[35] E. Frackowiak and F. Béguin, "Carbon materials for the electrochemical storage of energy in capacitors," Carbon, vol. 39, no. 6, pp. 937-950, May 2001.

[36] H. Wang, Z. Li, J. K. Tak, C. M. B. Holt, X. Tan, Z. Xu, B. S. Amirkhiz, D. Harfield, A. Anyia, T. Stephenson, and D. Mitlin, "Supercapacitors based on carbons with tuned porosity derived from paper pulp mill sludge biowaste," Carbon, vol. 57, pp. 317-328, Jun. 2013.

[37] A. G. Pandolfo and A. F. Hollenkamp, "Carbon properties and their role in supercapacitors,” J. Power Sources, vol. 157, no. 1, pp. 11-27, Jun. 2006.

[38] J. M. Laval, C. Bourdillon, and J. Moiroux, "Enzymic electrocatalysis: electrochemical regeneration of NAD+ with immobilized lactate dehydrogenase modified electrodes," $J$. Am. Chem. Soc., vol. 106, no. 17, pp. 4701-4706, Aug. 1984.

[39] M. D. Stoller and R. S. Ruoff, "Best practice methods for determining an electrode material's performance for ultracapacitors," Energy Environ. Sci., vol. 3, no. 9, p. 1294, 2010.

[40] K. S. Novoselov, "Electric Field Effect in Atomically Thin Carbon Films," Science, vol. 306, no. 5696, pp. 666-669, Oct. 2004.

[41] M. D. Stoller, S. Park, Y. Zhu, J. An, and R. S. Ruoff, "Graphene-Based Ultracapacitors," Nano Lett., vol. 8, no. 10, pp. 3498-3502, Oct. 2008.

[42] K. R. Paton, E. Varrla, C. Backes, R. J. Smith, U. Khan, A. O’Neill, C. Boland, M. Lotya, O. M. Istrate, P. King, T. Higgins, S. Barwich, P. May, P. Puczkarski, I. Ahmed, M. Moebius, H. Pettersson, E. Long, J. Coelho, S. E. O’Brien, E. K. McGuire, B. M. Sanchez, G. S. Duesberg, N. McEvoy, T. J. Pennycook, C. Downing, A. Crossley, V. Nicolosi, and J. N. Coleman, "Scalable production of large quantities of defect-free few-layer graphene by shear exfoliation in liquids," Nat. Mater., vol. 13, no. 6, pp. 624-630, Apr. 2014.

[43] Textile Institute (Manchester, England), High-performance fibres. Boca Raton : Cambridge, England: CRC Press; Woodhead Pub, 2001.

[44] M. E. Ramos, J. D. González, P. R. Bonelli, and A. L. Cukierman, "Effect of Process Conditions on Physicochemical and Electrical Characteristics of Denim-Based Activated Carbon Cloths," Ind. Eng. Chem. Res., vol. 46, no. 4, pp. 1167-1173, Feb. 2007.

[45] M. S. Dresselhaus, Graphite fibers and filaments. Berlin; New York: Springer-Verlag, 1988.

[46] SUK-YI LO, “CHARACTERIZATION OF THE CHEMICAL, PHYSICAL, THERMAL AND ELECTRICAL PROPERTIES OF A SERIES OF ACTIVATED CARBON FIBER CLOTHS," Masters, University of Illinois at Urbana-Champaign, 2002.

[47] Emma L. Wong, James F. Snyder, and Clifford W. Hubbard, "Electrochemical Capacities of Commercially Available Structural Carbon Fibers, Fabrics, and Papers," U.S. Army Research Laboratory, Final ARL-TR-4574, Sep. 2008.

[48] A. Afkhami and B. E. Conway, "Investigation of Removal of Cr(VI), Mo(VI), W(VI), V(IV), and V(V) Oxy-ions from Industrial Waste-Waters by Adsorption and Electrosorption at High-Area Carbon Cloth," J. Colloid Interface Sci., vol. 251, no. 2, pp. 248-255, Jul. 2002.

[49] B. Logan, S. Cheng, V. Watson, and G. Estadt, "Graphite Fiber Brush Anodes for Increased Power Production in Air-Cathode Microbial Fuel Cells," Environ. Sci. Technol., vol. 41, no. 9, pp. 3341-3346, May 2007. 
[50] D. Golub and Y. Oren, "Removal of chromium from aqueous solutions by treatment with porous carbon electrodes: Electrochemical principles," J. Appl. Electrochem., vol. 19, no. 3, pp. 311-316, May 1989.

[51] R. M. de Carvalho, L. T. Kubota, J. J. R. Rohwedder, E. Csöregi, and L. Gorton, "Effect on electrochemistry of hexacyanoferrate at carbon fibers after pretreatment with titanium chloride," J. Electroanal. Chem., vol. 457, no. 1-2, pp. 83-88, Oct. 1998.

[52] J. González-García, P. Bonete, E. Expósito, V. Montiel, A. Aldaz, and R. TorregrosaMaciá, "Characterization of a carbon felt electrode: structural and physical properties," $J$. Mater. Chem., vol. 9, no. 2, pp. 419-426, 1999.

[53] Q. Deng, X. Li, J. Zuo, A. Ling, and B. E. Logan, "Power generation using an activated carbon fiber felt cathode in an upflow microbial fuel cell," J. Power Sources, vol. 195, no. 4, pp. 1130-1135, Feb. 2010.

[54] M. Toupin, T. Brousse, and D. Bélanger, "Influence of Microstucture on the Charge Storage Properties of Chemically Synthesized Manganese Dioxide," Chem. Mater., vol. 14, no. 9, pp. 3946-3952, Sep. 2002.

[55] M. A. Cheney, P. K. Bhowmik, S. Qian, S. W. Joo, W. Hou, and J. M. Okoh, "A New Method of Synthesizing Black Birnessite Nanoparticles: From Brown to Black Birnessite with Nanostructures," J. Nanomater., vol. 2008, pp. 1-8, 2008.

[56] P. Lv, Y. Y. Feng, Y. Li, and W. Feng, "Carbon fabric-aligned carbon nanotube/ $\mathrm{MnO} 2 /$ conducting polymers ternary composite electrodes with high utilization and mass loading of $\mathrm{MnO} 2$ for super-capacitors," J. Power Sources, vol. 220, pp. 160-168, Dec. 2012.

[57] K.-W. Nam, C.-W. Lee, X.-Q. Yang, B. W. Cho, W.-S. Yoon, and K.-B. Kim, "Electrodeposited manganese oxides on three-dimensional carbon nanotube substrate: Supercapacitive behaviour in aqueous and organic electrolytes," J. Power Sources, vol. 188, no. 1, pp. 323-331, Mar. 2009.

[58] Y. J. Kang, B. Kim, H. Chung, and W. Kim, "Fabrication and characterization of flexible and high capacitance supercapacitors based on MnO2/CNT/papers," Synth. Met., vol. 160, no. 23-24, pp. 2510-2514, Dec. 2010.

[59] J. Yan, Z. Fan, T. Wei, W. Qian, M. Zhang, and F. Wei, "Fast and reversible surface redox reaction of graphene-MnO2 composites as supercapacitor electrodes," Carbon, vol. 48, no. 13, pp. 3825-3833, Nov. 2010.

[60] Carbon Solutions, Inc., "Specification Sheet for P3-SWNT." 2013.

[61] W. Chen, R. B. Rakhi, and H. N. Alshareef, "High energy density supercapacitors using macroporous kitchen sponges," J. Mater. Chem., vol. 22, no. 29, p. 14394, 2012.

[62] "Haz-Map Category Details." [Online]. Available: http://hazmap.nlm.nih.gov/categorydetails?id=16757\&table=copytblagents. [Accessed: 26-Jun-2014].

[63] W. Zhang, L. Johnson, S. R. P. Silva, and M. K. Lei, "The effect of plasma modification on the sheet resistance of nylon fabrics coated with carbon nanotubes," Appl. Surf. Sci., vol. 258, no. 20, pp. 8209-8213, Aug. 2012.

[64] S.-C. Pang, M. A. Anderson, and T. W. Chapman, "Novel Electrode Materials for ThinFilm Ultracapacitors: Comparison of Electrochemical Properties of Sol-Gel-Derived and Electrodeposited Manganese Dioxide," J. Electrochem. Soc., vol. 147, no. 2, p. 444, 2000.

[65] K. Naoi and P. Simon, "New Materials and New Configurations for Advanced Electrochemical Capacitors," J. Electrochem. Soc., vol. 17, no. 1, pp. 34 - 37, 2008. 
[66] A. Dato and M. Frenklach, "Substrate-free microwave synthesis of graphene: experimental conditions and hydrocarbon precursors," New J. Phys., vol. 12, no. 12, p. 125013, Dec. 2010 . 